\title{
Identification of indicator parameters for the quantitative assessment of vulnerability in karst aquifers
}

\author{
Dissertation \\ zur Erlangung des Doktorgrades \\ der Mathematisch-Naturwissenschaftlichen Fakultäten \\ der Georg-August-Universität zu Göttingen
}

vorgelegt von

Joanna Jean Doummar

aus Beirut-Libanon

Göttingen 2012 
Referent:

Korreferent:
Martin Sauter

Thomas Himmelsbach

Tag der mündlichen Prüfung: 02. Juli 2012 




\section{TABLE OF CONTENTS}

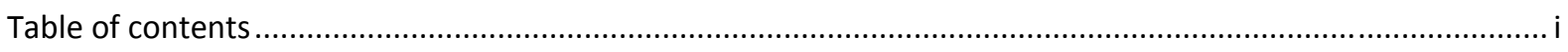

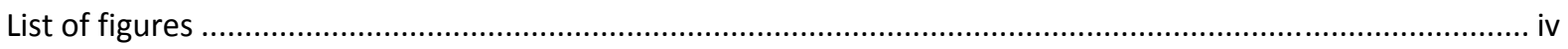

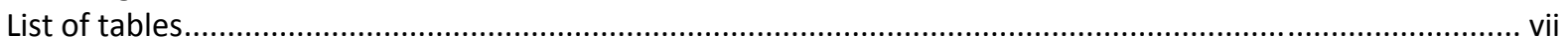

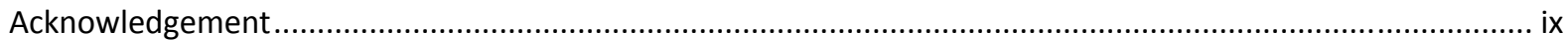

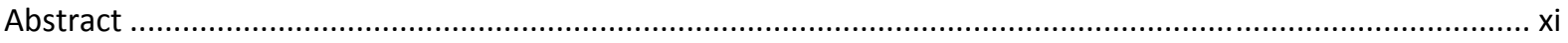

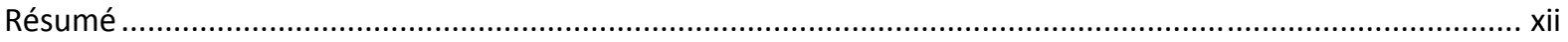

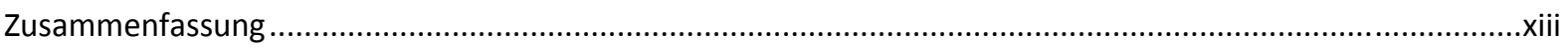

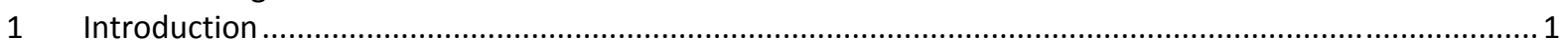

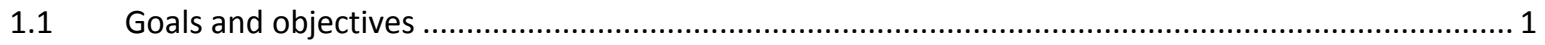

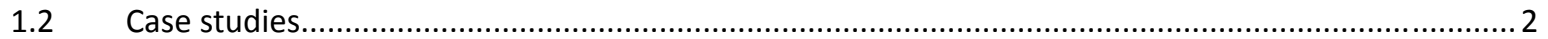

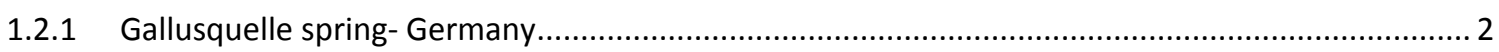

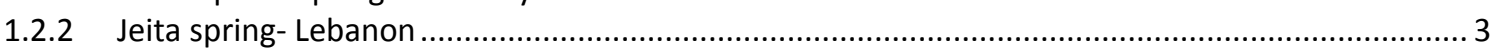

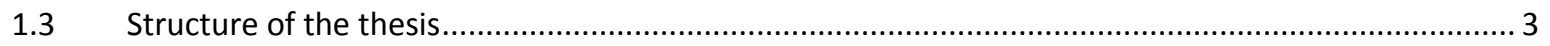

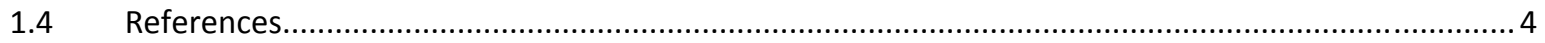

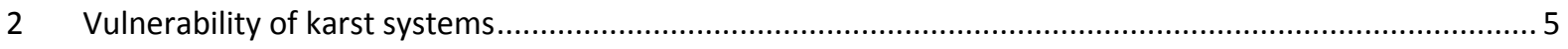

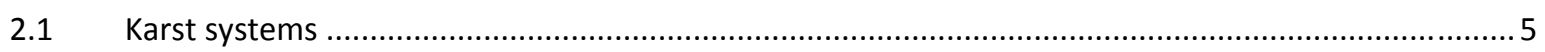

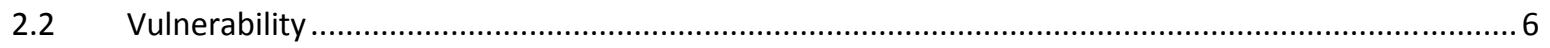

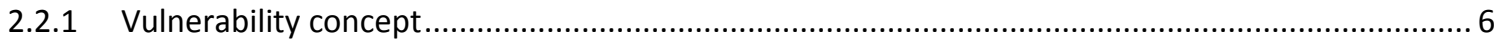

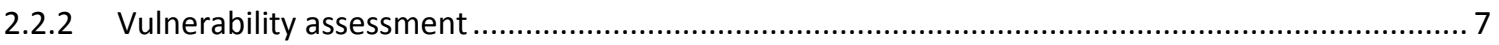

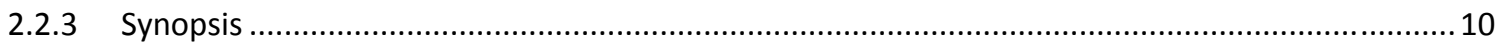

2.3 Investigation of karst aquifers for vulnerability assessment.............................................. 12

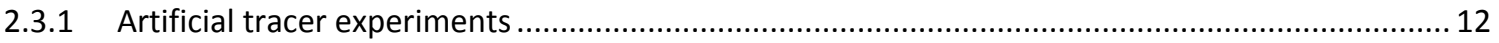

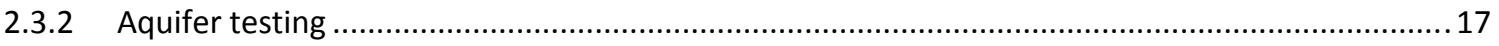

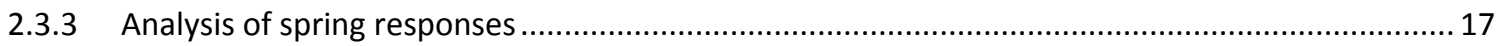

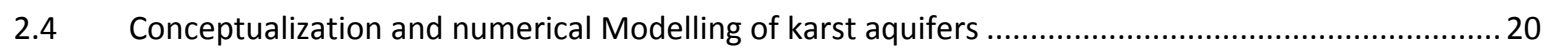

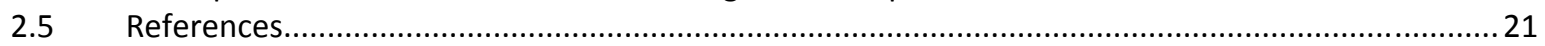

3 Simulation of flow processes in a large scale karst system with an integrated catchment model (Mike She) - Identification of relevant parameters influencing spring discharge ..........................................................25

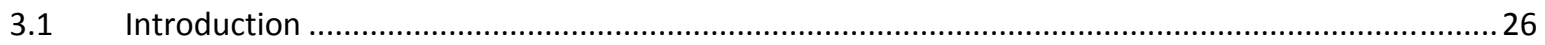

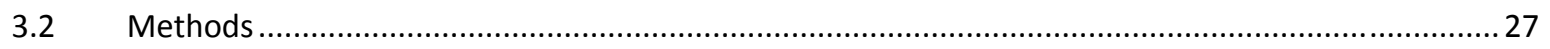

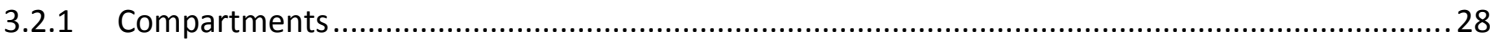

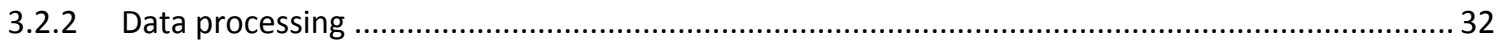

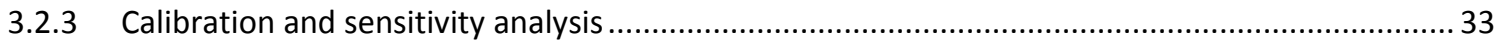

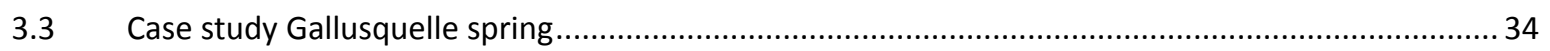

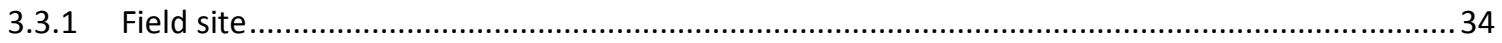

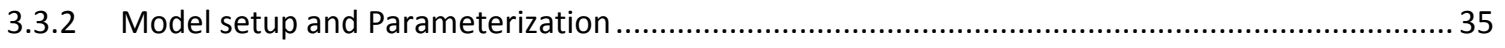

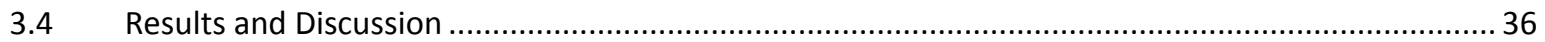




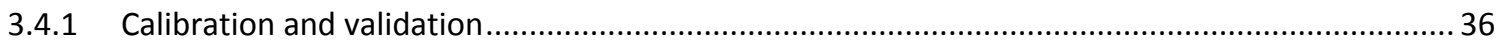

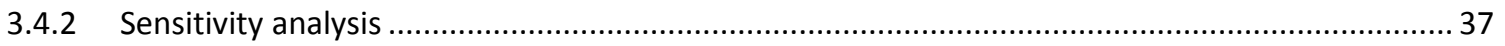

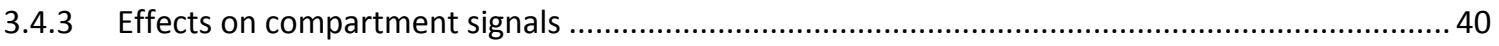

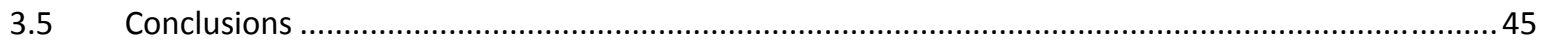

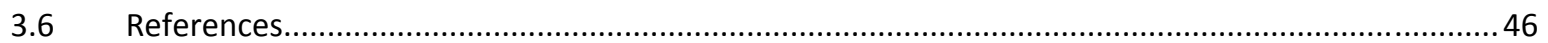

4 Assessment of effective transport parameters in a karst system under dynamic flow conditions by

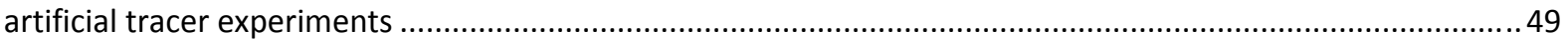

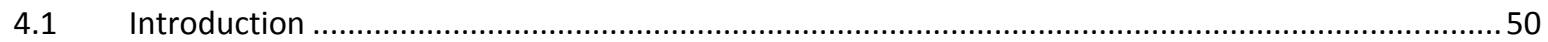

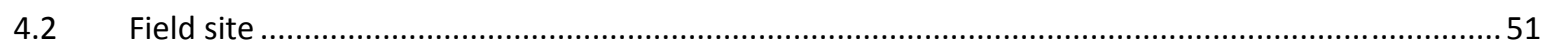

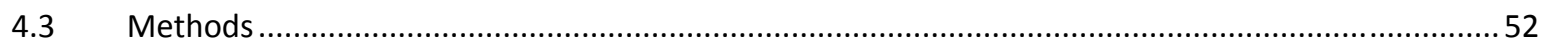

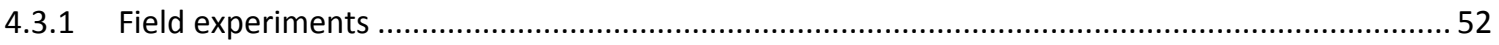

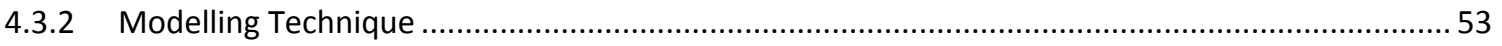

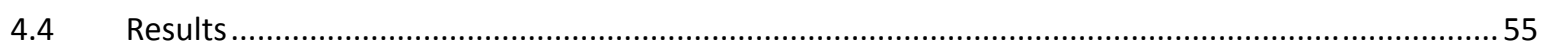

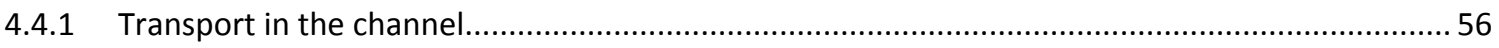

4.4.2 Transport outside the channel (compartments of the karst systems) .....................................58

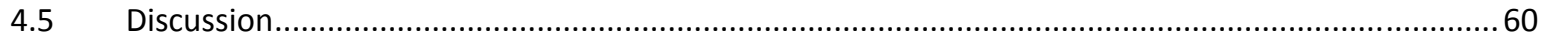

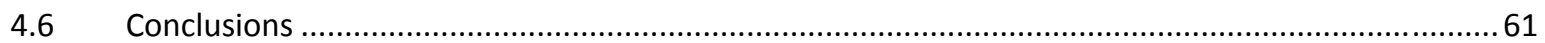

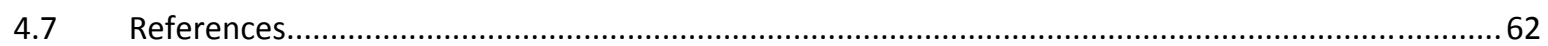

5 Spatial and temporal distribution of carbamazepine, caffeine and benzoylecgonine as waste water

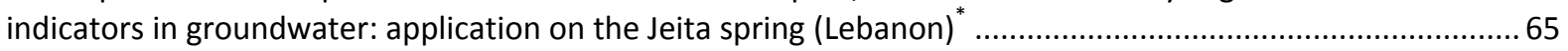

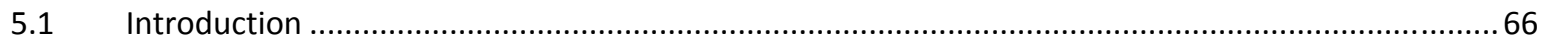

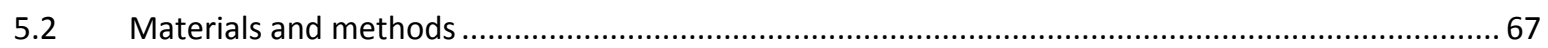

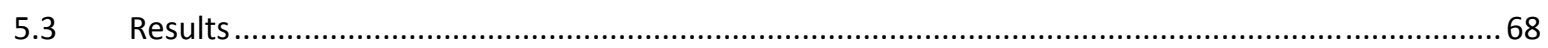

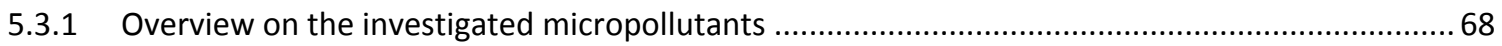

5.3.2 Spatial and temporal distribution of caffeine, carbamazepine, and benzoylecgonine under

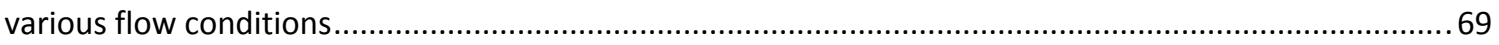

F.4 Fate of micropollutants within the subsurface channel ............................................................ 70

5.4.1 September 2011 (low flow periods; Figure 5-4) …........................................................ 71

5.4.2 December 2012 (intermediate flow periods; Figure $5-5$ ) ..................................................... 71

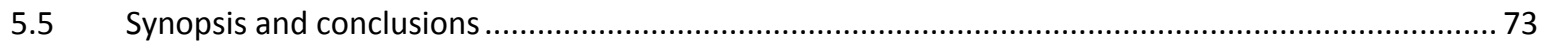

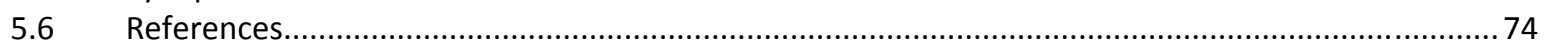

6 Carbamazepine breakthrough as indicator for specific vulnerability of karst springs: application on the

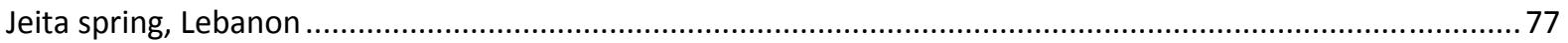

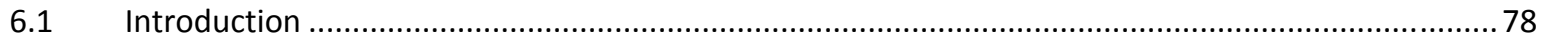

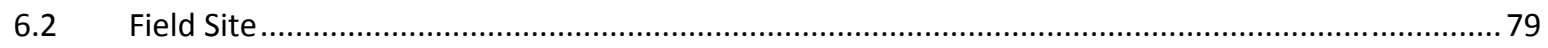

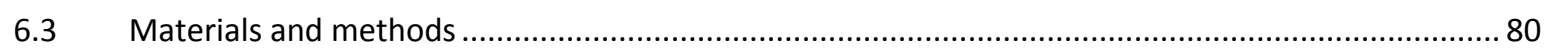

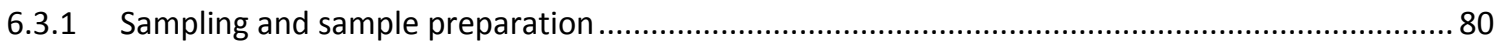

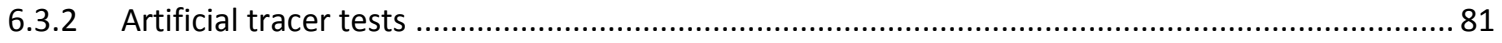

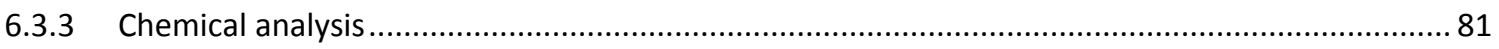

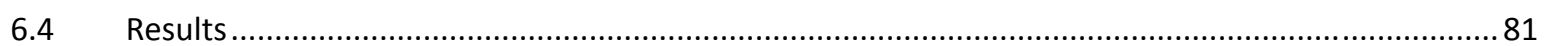




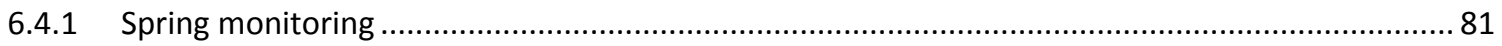

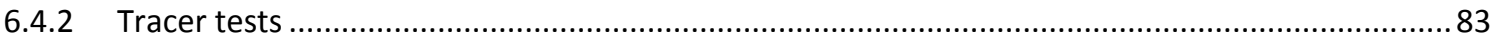

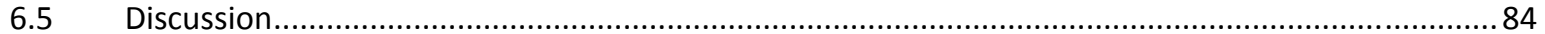

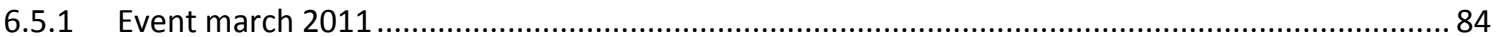

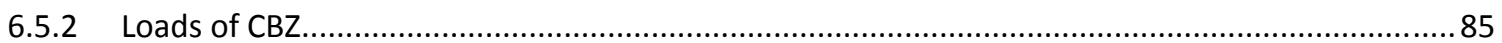

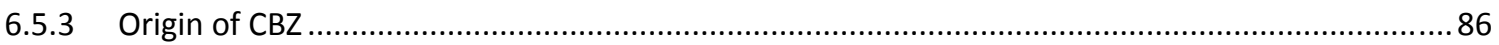

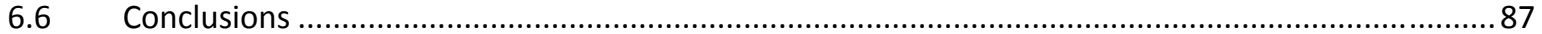

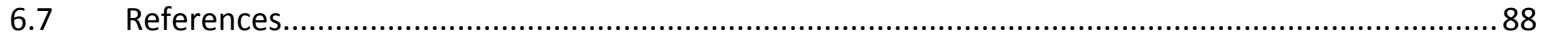

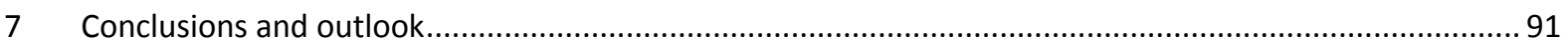

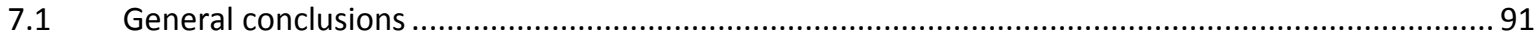

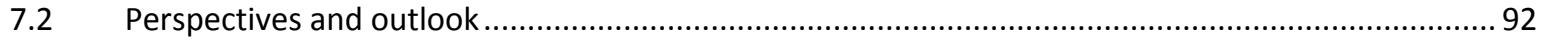

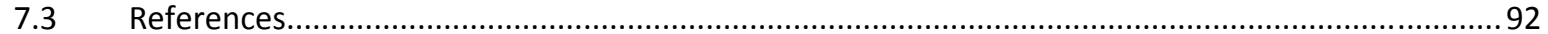

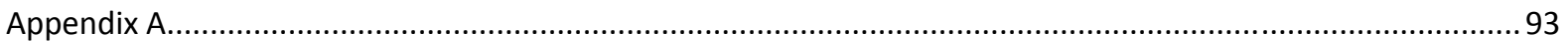




\section{LIST OF FIGURES}

Figure 1-1 a) Example of delineation of protection zones in porous media in Germany (not to scale; Mull, 1981): Zone 1 is the discharge area (well head), Zone 2 (50-day line) represents the time needed for indicator pathogens to degrade significantly, the rest of the recharge area is zone 3 . b) Survival of selected microorganisms in groundwater over a period of 100 days showing that most of the pathogens indicator of bacteriological contamination ( $Y$. enterococci and E.coli) can survive in groundwater for a period exceeding 100 days (Ford and Williams 2007)

Figure 1-2 Climatic characteristics of the investigated catchment showing the fluctuation in temperature, precipitation and spring discharge

Figure 2-1 Schematic representation of a karst aquifer portraying the duality of flow and recharge in karst aquifer (diffuse versus local)

Figure 2-2 A Dirac input concentration results in various responses (breakthrough curves) at a target depending on the nature of the injected tracer, the geometry, flow and transport parameters of a system, (modified from COST Action 620, 2003)

Figure 2-3 Origin-pathway- target concept applied for vulnerability assessment (after Goldscheider 2002)...7

Figure 2-4 Typical tracer breakthrough curves simulated with VULK for the following parameter combinations for soil cover and epikarst, $\{0011\}$ : $b_{\text {soil }}=0.1 \mathrm{~m}, \mathrm{~K}_{\text {soil }}=1 \mathrm{E} 10^{-5} \mathrm{~m} / \mathrm{s}, \mathrm{b}_{\text {epi }}=50 \mathrm{~m}, \mathrm{~K}_{\text {epi }}=3 \mathrm{E}$ $10^{-4} \mathrm{~m} / \mathrm{s}$, and $\{0002\}: b_{\text {soil }}=0.1 \mathrm{~m}, K_{\text {soil }}=1 E 10^{-5} \mathrm{~m}, b_{\text {epi }}=50 \mathrm{~m}, K_{\text {epi }}=1 E 10^{-4} \mathrm{~m} / \mathrm{s},\left(C_{0}\right.$ and $C_{p}$ being the input and maximum concentrations respectively; modified from Malík and Vojtková, 2007)......... 9

Figure 2-5 Example of vulnerability mapping for a catchment area using the COP and EPIK methods showing discrepancies in the vulnerability classification (Doummar et al., 2012a).....

Figure 2-6 Duality of recharge, storage and flow in a karst system (modified from Smart and Hobbs, 1986, in Geyer, 2008).......

Figure 2-7 Information about different pathways, transport parameters and mass fluxes retrieved from the analysis of a tracer breakthrough curve.

Figure 2-8 Extent of lateral mixing of the tracer and longitudinal dispersion over a distance following a Dirac injection pulse (slug injection). Effect of dispersion on the variation of the peak concentration (Kilpatrick, 1993 in Jobson 1997)

Figure 2-9 Example of recession coefficients showing a predominant conduit flow regime in a karst system (Jeita Spring, Lebanon; high flow periods for the hydrological year 2010-2011, BEl refers to a meteorological station located $18 \mathrm{~km}$ south to the Jeita spring at $14 \mathrm{~m}$ above sea level). Red and black lines refer to electrical conductivity and discharge respectively. 18

Figure 2-10 Relationship between discharge and transit time, dilution and solute concentration in a system and their relevance to vulnerability

Figure 2-11 Combination of hydrographs and chemographs to understand the conceptual behavior of a karst system (modified after Williams, 1983)

Figure 2-12 Example of a conceptual model of a karst aquifer (modified from White, 2003). 20 
Figure 2-13 Signal transmission within the compartments of a karst system

Figure 3-1 Schematic Representation of MIKE-SHE Modelling Principles (adapted from Mike-She User Manual, 2007)

Figure 3-2 Moisture Retention Curves based on Van Genuchten for Soil and Campbell for unsaturated rock matrix showing effect of parameter variation on the curve shape. (a: Soil- Van Genuchten; $n=2$, $\theta s=0.395, \theta r=0.171 ; b$ : unsaturated rock matrix- Campbell; $\lambda=0.5, \theta s=0.015, c$ : unsaturated rock matrix- Campbell; $\left.\psi_{\mathrm{b}}=0.2, \theta \mathrm{s}=0.015\right)$

Figure 3-3 Catchment Area of Gallusquelle spring in the Swabian Albs (delineation according to Sauter (1992); location of the highly conductive zone is modified from Mohrlok and Sauter (1997) ....... 34

Figure 3-4 Comparison of simulated and observed discharge rates at the Gallusquelle spring for the years 1989-2000 and 1989-1992, daily precipitation and evapotranspiration curves are also displayed...

Figure 3-5 Results of the sensitivity analysis (RMSE) of the fitting and calibration parameters.....................38

Figure 3-6 Results of the sensitivity analysis (\% error volume) of the fitting and calibration parameters .......38

Figure 3-7 Results of the spatial evaluation of recharge per unit area in different types of crops..................42

Figure 3-8 Effect of the variation of the type of soil on the recharge and discharge curves ........................43

Figure 3-9 Effect of the variation of the the particle index $(\lambda ; b)$ and saturated moisture content $(a)$ in the unsaturated rock matrix on the recharge and discharge curves

Figure 3-10 Effect of the variation of the hydraulic conductivity of the highly conductive zone on the discharge curve

Figure 4-1 Location of the artificial tracer experiments undertaken on the catchment of Jeita Spring, northern Lebanon

Figure 4-2 Artificial tracer experiments at the Jeita spring (U: uranine, AG: amidorhodamine, Na: sodium naphtionate).

Figure 4-3 Measured normalized TBCs $\left(C / C_{p}\right)$ in the subsurface channel (over $5300 \mathrm{~m}$ ) as a function of time after injection.

Figure 4-4 Measured TBCs from surface injections as observed in the main spring ( $\mathrm{J}$ at the end of the subsurface channel) and at the beginning of the channel (D); J refers to TBCs at the spring outlet, and $D$ is the beginning of the subsurface channel 55

Figure 4-5 Relationships between velocities $\left(v_{m}\right)$, transit time $\left(t_{m}\right)$, discharge $(Q)$, and phreatic diameter $(\phi)$..

Figure 4-6 Relationships between longitudinal dispersion (D) and longitudinal dispersivity ( $\alpha$ ) and discharge (Q)

Figure 4-7 Correlation between longitudinal dispersion and longitudinal dispersivity and attenuation of the artificial tracer peak concentration $\left(\mathrm{C}_{\mathrm{p}} / \mathrm{M}_{\text {recovered }}\right)$

Figure 4-8 Correlation between partition coefficient $(\beta)$ and discharge $(Q)$ as well as with the mass transfer coefficient $(\omega)$ 
Figure 4-9 Relationships between various transport parameters (mean velocity to partition coefficient; a, longitudinal dispersivity; b, and phreatic diameter; c) from the tracer tests performed in the subsurface channel as well as from surface injections (different compartments in the karst aquifer). Control of advection (Pe number) over partition coefficient (d)

Figure 4-10 Importance of dispersion in the attenuation of the maximum observed peak in all the compartments of the investigated karst system under various flow dynamics

Figure 5-1 Sampling locations within the Jeita cave (September 2011) ............................................67

Figure 5-2 Sampling locations within the Jeita cave (December 2011) .......................................................68

Figure 5-3 Mass flux (g/d) of various compounds in Jeita Spring during different sampling periods (Low flow, high flow and Intermediate flow, when discharge measurements are available). 70

Figure 5-4 Behavior of benzoylecgonine and carbamazepine (mass flux and concentrations) in samples collected along the subsurface channel showing in some locations the input of additional compounds and/or effect of dilution (September 2011)

Figure 5-5 Behavior of benzoylecgonine and carbamazepine (mass flux and concentrations) in samples collected along the subsurface channel showing in some locations the input of additional compounds and/or effect of dilution (December 2011).....

Figure 6-1 Overview map of the field site showing the location of the Jeita Spring within the Dog River surface water catchment

Figure 6-2 Chemograph showing the variation of physico-chemical parameters and CBZ concentrations as a response of the precipitation event. $t_{0}$ to $t_{3}$ refer to the division of the spring response into 4 different periods mainly according to the variation of EC

Figure 6-3 Negative correlation between carbamazepine, calcium and electrical conductivity, and positive correlation with nitrates

Figure 6-4 Results of the tracer tests performed in March 2011 in the subsurface channel showing mean velocities.

Figure 6-5 Conceptual models of the aquifer behavior before and following the precipitation event ....... 85 


\section{LIST OF TABLES}

Table 2-1 Qualitative intrinsic vulnerability methods based on different controlling factors..... 8

Table 2-2 Parameters affecting vulnerability in the case of six vulnerability methods applied in karst systems

Table 2-3 Categories of parameters incorporated in static and temporally variable vulnerability methods developed to date 10

Table 2-4 Key parameters identified from the analysis of tracer breakthrough curves 15

Table 2-5 Main methods used to characterize karst aquifers for vulnerability purposes 20

Table 3-1 Parameters obtained for the best fit simulation and ranges for sensitivity analysis. Type of parameters are separated into measured/literature values and fitted values.

Table 3-2 Summary of the water balance results 36

Table 3-3 Identification of indicator parameters from sensitivity analysis results 39

Table 3-4 Parameters playing a major role in the model results (highly indicator in bold) ..........................40

Table 3-5 Influence of the indicator parameters on the output curve of the three compartments .............41

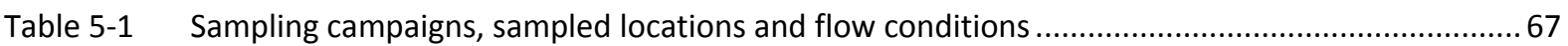

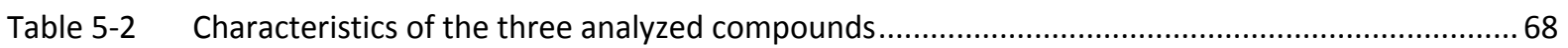




\section{ACKNOWLEDGEMENT}

First, I am highly indebted to my supervisors Martin Sauter and Tobias Geyer for their continuous guidance and stimulating suggestions. Without their constructive comments, insightful discussions and support, this research wouldn't have been possible. I would like to extend my appreciation further to Tobias Geyer who was not only an advisor but also a friend of the research group. I would like to extend my gratitude to the members of the committee for their kind attendance in the defense and perceptive feedback; Martin Sauter and Thomas Himmelsbach, in addition to Andrea Carminati, Gerard Gerold, Tobias Geyer and Hans Ruppert.

I would like to thank the Deutscher Akademischer Austausch Dienst (DAAD) for giving me the opportunity to pursue my doctorate studies and financing my staying in Germany. Frau Cornelia Hanzlik is deeply thanked for her administrative support.

The Bundesanstalt für Geowissenschaften and Rohstoffe (BGR; Germany) is highly thanked for the fruitful cooperation project "Protection of the Jeita Spring" though which I was able to conduct various experiments and tests and analyze collected data necessary for this work, as well as for accommodation during field sampling. Armin Margane is acknowledged for the initiation of this cooperation and for the successful tracer experiments conducted jointly in Lebanon.

I would like to extend my appreciation to DHI (Danish Hydraulic Institute) for kindly providing the Mike She software for the purpose of this research. Peter Knaus and the water supply company of Hermentingen are also thanked for their kind cooperation.

I would like to express my great appreciation for all the staff of the Jeita Grotto in Lebanon namely Najib Najib and Ayman Ibrahim for being always ready for any short notice task and for helping me collect data within the cave even under very difficult conditions.

I am grateful to the Dbayeh Water Treatment Station (Beirut Water Authority) in Lebanon, especially Paul Souaid, Rajaa Mhanna, Roger Haddad and Jihane Badran for providing laboratory facilities for solid phase extraction and chemical products. The hydrochemistry group in the Georg August Universität is highly acknowledged, namely Tobias Licha for his suggestions, Karsten Nödler for his interesting feedback and for the micro-pollutant analysis, and Mechtild Rittmeier and Anke Von Gaza for performing the chemical analysis.

I have to thank Riad Al Solh Al Khodari from the International Airport of Beirut for providing detailed climatic data for the purpose of this work.

Ramez Kayal is also thanked for being always supportive through his company ELARD (Lebanon) and Pierre Andre Schnegg from the University of Neuchâtel (Switzerland) for kindly attending to technical problems in measuring devices and instruments as well as shipment.

I extend my appreciation to my colleagues and friends at the Georg-August Universität for the nice atmosphere within the working groups especially William, Michael, Steffen, Aziz, and Torsten.

I would also like to thank the best roommates ever for the great time and understanding during the end phase of the thesis writing: the Goldgräber, Lili, Lukas, Karo, Nils, Anne, Antje, Moritz, Ruben, Christian, Juan, Hannes, and Bianka, as well as Jaime, Tine, Cornelia and all my friends in Göttingen which made my stay in Germany extremely smooth and interesting, without forgetting to thank all my friends in Lebanon and elsewhere as well.

I am particularly grateful to Sebastian and Jannes, for being great mates and friends, for their support at all times. Exploring in science wouldn't have been that pleasant if it weren't for our endless discussions and very special time spent within the karst group.

Finally, words cannot express what I owe you for your encouragement, patience and unconditional love: my big fat family, my sister Nay, Naim for being always there, and my parents Jean and Nohad. 



\section{ABSTRACT}

Prediction of contaminant transport in karst aquifers is therefore challenging and requires the knowledge of flow characteristics and transport processes in these systems. Based in this information, quantitative vulnerability concepts can be established, which are a prerequisite for management of karst water resources and conservation of their quality.

The present thesis investigates indicator parameters of intrinsic and specific vulnerability in karst aquifers through the characterization of karst systems based on spring responses and integrated numerical Modelling at a catchment scale.

Spring responses include discharge and chemographs and reflect the integrated response of all the flow and transport processes occurring in a system. For this purpose flow in a well investigated karst system was first numerically simulated using the Mike She software (DHI). The spatially distributed model accounts for all the physical processes taking place in the hydrological cycle, and therefore considers all the compartments of a karst system (atmosphere, unsaturated zone, and saturated zone). The physical or empirical parameters involved in the model, which play a role in the shape of the flow response and its transmission, were delineated through an extensive sensitivity analysis. This work shows that all the compartments within a karst system strongly influence the discharge; consequently they have to be accounted for in intrinsic vulnerability assessment. The significance of the physical processes and parameters in the numerical flow model were quantified using two objective functions: the Root Mean Square Error (RMSE) and the percentage error in the annual volume over the modeled period.

In the second part of this work, an extensive campaign of about 30 artificial tracer experiments were evaluated for different compartments of a mature karst system. The tracer breakthrough curves (TBCS) were modeled using the Two Region Non Equilibrium Model (2RNEM) to account for irregularities and tailing in the observed TBCs. The conservative transport parameters including tracer transit times, longitudinal dispersivity as well as the portion of the mobile region ( $\beta$ ) correlate with one another following statistical relationships and depend highly on flow conditions and prevailing processes

The third and fourth parts of this work give insights to specific vulnerability. The specific transport of a specific organic micropollutant is investigated in a karst catchment area. The analysis performed in the subsurface in a phreatic karst cave show that carbamazepine, an anticonvulsant indicator for waste water contamination, is persistently present in groundwater. The variation of the estimated mass fluxes within the subsurface channel under various flow conditions implies that carbamazepine is introduced to the system in various point sources. This same compound is also introduced under high flow conditions through fast flow pathways following a precipitation event. A quantification of the added loads (e.g., $2.6 \mathrm{~g}$ ) and an estimation of the distance to contamination could be performed. The infiltration and transport behavior of the event based input is however highly dependent on the distribution of precipitation in the area.

Further investigations include testing the applicability of the integrated numerical flow model in other more challenging karst catchment areas. The model can be further validated by supplementing it with the conservative or reactive transport components. Spring signals such as electrical conductivity or turbidity should be further compared to specific contaminants and applied as easily monitored indicators for vulnerability. 


\section{RESUME}

La prédiction du transport des contaminants dans les aquifères karstiques est difficile et nécessite une caractérisation des écoulements et des processus de transport dans ces systèmes. En caractérisant ces aquifères, il est possible d'établir des concepts quantitatifs de vulnérabilité, qui aident à une gestion durable des ressources en eau karstiques et à la préservation de leur qualité.

Les paramètres indicateurs de la vulnérabilité intrinsèque et spécifique dans les aquifères karstiques sont investigués dans ce travail à travers une caractérisation des systèmes karstiques basée sur les réponses enregistrées à la source et sur la modélisation numérique à l'échelle du bassin versant.

Les réponses à la source comprennent les hydrographes et les chémographes et reflètent la réponse intégrée de tous les processus d'écoulement et de transport qui se produisent dans un système. Dans la première partie, un système karstique bien investigué a été en premier simulé numériquement en utilisant le logiciel de Mike She (DHI). Le modèle tient compte des paramètres influant les processus physiques qui sont impliqués dans le cycle hydrologique, et considère par conséquent tous les compartiments d'un système karstique (atmosphère, zone non saturée, et la zone saturée). Les paramètres physiques ou empiriques impliqués dans le modèle, qui jouent un rôle dans la réponse de débit et de sa transmission, ont été délimité suite à une analyse de sensibilité approfondie. Ce travail montre que tous les compartiments au sein d'un système karstique influent fortement le débit, et par conséquent, doivent être pris en compte dans l'évaluation de la vulnérabilité intrinsèque d'un système karstique. L'importance des processus physiques et des paramètres dans le modèle numérique d'écoulement ont été quantifiés à l'aide de deux fonctions objectives: l'erreur quadratique moyenne (RMSE) et le pourcentage d'erreur dans le volume annuel sur la période modélisée.

Dans la deuxième partie de ce travail, environ 30 essais de traçage ont été évalués pour les différents compartiments d'un système karstique. Les courbes de restitution du traceur ont été modélisées à l'aide du modèle Two-Region Non Equilibrium Model (2RNEM ; Cxtfit) qui tient compte des irrégularités observées dans les courbes de restitution. Les paramètres (conservatifs) de transport, y compris temps de transit, dispersivité longitudinale ainsi que la partition de la région mobile $(\beta)$ corrèlent l'un avec l'autre suivant des relations statistiques et dépendent des conditions d'écoulement et des processus physiques dominants dans le système étudié.

Les troisième et quatrième parties de ce travail donnent un aperçu de la vulnérabilité spécifique. Le transport spécifique d'un micropolluant organique spécifique est investigué dans un bassin versant karstique. L'analyse des échantillons d'eau prélevés dans une grotte karstique phréatique montrent que la carbamazépine, un anticonvulsivant indicateur de contamination des eaux usées, est constamment présente dans les eaux souterraines. La variation des flux massiques estimée dans les échantillons prélevés sous différents régimes de débits implique que la carbamazépine est introduite dans le système à travers des sources ponctuelles diverses. Ce même composé est également introduit durant les hauts débits à travers les voies d'écoulement rapide juste après un événement de précipitation. Une quantification des masses ajoutées (par exemple, 2,6 g) et une estimation de la distance entre la source et le point de contamination ont pu être déduites. La réponse obtenue à la source et le transport du contaminant suite à l'événement de précipitation est cependant hautement dépendant de la répartition des précipitations dans le bassin versant. II reste à tester et valider l'applicabilité du modèle numérique d'écoulement intégré dans d'autres bassins versants karstiques plus complexes. Le modèle peut être validé en y ajoutant la composante de transport conservatif ou réactif. Les réponses enregistrées à la source telles que la conductivité électrique ou de la turbidité peuvent être davantage analysées et appliquées comme des indicateurs de vulnérabilité. 


\section{ZUSAMMENFASSUNG}

Die Entwicklung von Methoden zur Charakterisierung der heterogenen Karstsysteme ist Grundlage für die Vorhersage der Strömung und des Schadstofftransports, sowie für die Entwicklung quantitativer Vulnerabilitätskonzepte zum Schutz der Grundwasserressourcen.

Diese Arbeit beschäftigt sich mit der Analyse und Modellierung von Quellsignalen zur Identifikation von Indikatorparametern zur quantitativen Beschreibung der Vulnerabilität eines Karstsystems auf der Einzugsgebietsskala. Quellsignale beinhalten hierbei die Kombination aus Hydrographen und Chemographen.

Im ersten Teil dieser Arbeit wurde die Strömungsdynamik eines Karstsystems mit dem numerischen Modell Mike She (DHI) simuliert. Das Modell berücksichtigt verschiedene Parameter, welche die physikalischen Prozesse eines Wasserkreislaufes beschreiben. Es wurde gezeigt, dass die Abflussreaktion eines Karstsystems durch verschiedene Kompartimente (Klima, Vegetation, Boden, Festgestein) beeinflusst wird. Sensitive Parameter wurden durch eine umfangreiche Sensitivitätsanalyse identifiziert. Die Sensitivitätsanalyse basiert auf den Zielfunktionen: (1) mittlerer quadratischer Fehler (RMSE) und (2) prozentualer Fehler des jährlichen Abflussvolumens im Untersuchungszeitraum.

Im zweiten Teil der Arbeit wurden künstliche Markierungsversuche zur Charakterisierung des Stofftransports in hochdurchlässigen Karströhrensystemen ausgewertet. Die Durchbruchskurven der Markierungsstoffe wurden mit dem Modell Cxtfit simuliert. Aufgrund der systematischen Auswertung von über dreißig Markierungsversuchen konnten Korrelationen zwischen verschiedenen konservativen Transportparametern (Verweilzeit, Dispersivität etc.) aufgestellt werden. Die Korrelationen verschiedener konservativer Transportparameter liefern die Grundlage für die Bestimmung der intrinsischen Vulnerabilität eines Karstsystems.

Der dritte und vierte Teil der vorliegenden Arbeit beschäftigt sich mit der spezifischen Vulnerabilität eines Karstsystems mit Hinblick auf den Eintrag organischer Spurenstoffe. Die Auswertung von Quellwasserproben zeigt das kontinuierliche Auftreten des organischen Spurenstoffs Carbamazepin im Grundwasser. Der Stoff ist Indikator für Abwasserkontaminationen im Grundwasser. Die Variation von Carbamazepin im Quellwasser unter verschiedenen Abflussregimes zeigt, dass Carbamazepin ereignisabhängig durch verschiedene Punktquellen in das Grundwasserfließsystem gelangt. Eine Quantifizierung der eingetragenen Menge und eine Abschätzung der Entfernung zwischen Karst- und Eintragsquelle wurden abgeleitet. 



\section{INTRODUCTION}

\subsection{GOALS AND OBJECTIVES}

Many approaches have aimed to date at protecting water resources and/or reducing contamination at a catchment scale or in water resources used for domestic water. Technological advancements have been developed to treat the water at the discharge zone depending on the type of contamination before providing it for domestic consumption. Another preventive approach focuses on protecting the recharge zone. The latter consists of the assessment and protection of the mechanisms involved in recharge from precipitation, through infiltration to resurgence at an outlet. The terms vulnerability and risk assessment are used since 1968 (Margat, 1968) to define the sensitivity of a system to potential contamination. The establishment of the vulnerability is a prerequisite for the management of water resources and the conservation of their quality. Vulnerability can be easily defined in porous aquifers, where protection zones are delineated based on specific hydraulic laws (Figure 1-1; Darcy's law, velocity distance relationships, etc.; Mull, 1981) that apply in homogeneous systems. Vulnerability concepts are however difficult to establish in karst aquifers, because they are known to be challenging due to their high heterogeneity with respect to other homogeneous porous media (Butscher and Huggenberger, 2009). Karst aquifers are formed in carbonate rocks mainly by groundwater flowing in existing fractures and faults where subsequent rock dissolution leads to the formation of wide conduits as in cave genesis (Bauer et al., 2003). Recharge of groundwater in karst aquifers occurs by direct and diffuse infiltration. Processes of infiltration depend on surface geomorphologic features and are not always homogeneous over the entire recharge area. Additionally, flow direction and pathways are often unpredictable, even though they follow major fracturing or bedding plane patterns in most of the cases. Finally, flow velocities are considered to be relatively significant, violating hydraulic basic laws (e.g., Darcy's law or laminar flow).

About $25 \%$ of the world population relies on ground water from karst aquifers (Ford and Williams, 2007). Given the importance of karst aquifers worldwide, it is primordial to ensure the proper management of their water resources and their protection against contamination.

As karst aquifers are characterized by high flow velocities, contaminants can easily be conveyed in the aquifer and consequently be very difficult to manage and remediate. Thus, protection of karst springs at the source and adequate treatment can be in instances challenging. Therefore, it is important to understand and assess karst springs vulnerability by adopting a preventive approach, rather than remediating at the source. 


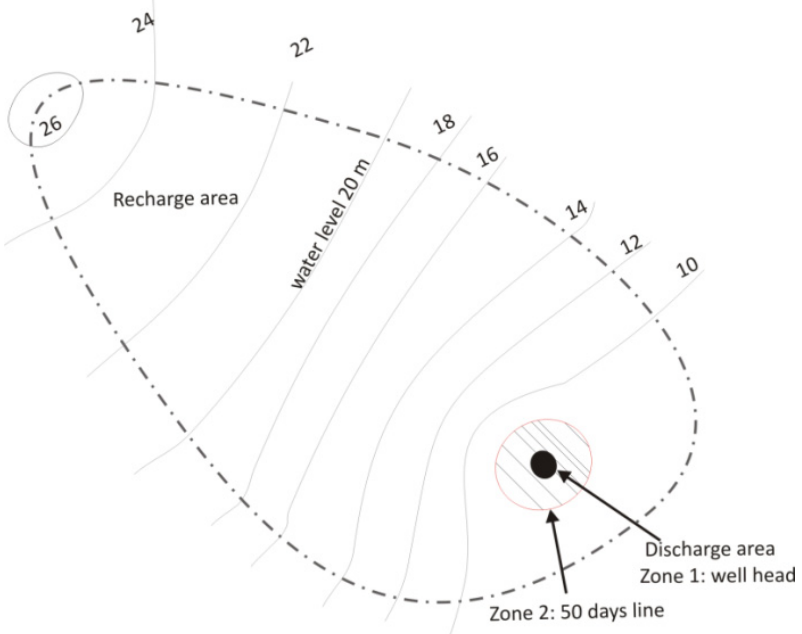

a

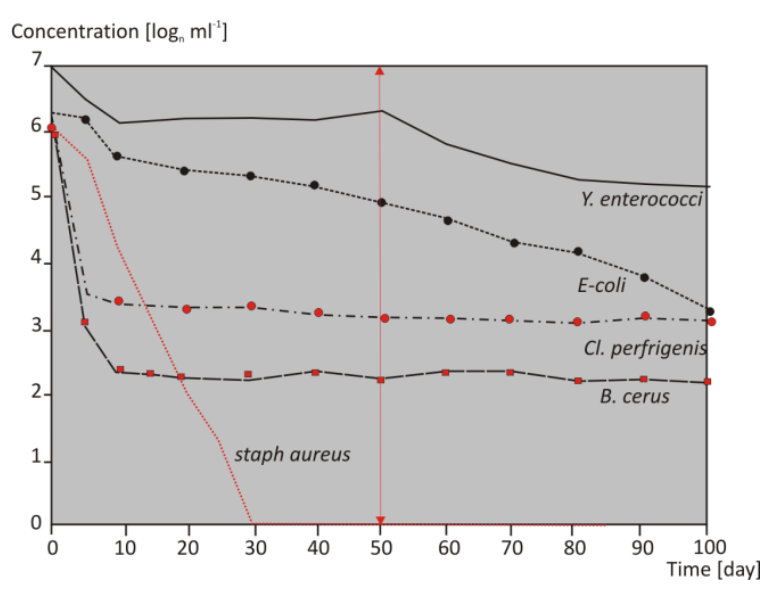

Figure 1-1 $\quad$ a) Example of delineation of protection zones in porous media in Germany (not to scale; Mull, 1981): Zone 1 is the discharge area (well head), Zone 2 (50-day line) represents the time needed for indicator pathogens to degrade significantly, the rest of the recharge area is zone 3. b) Survival of selected microorganisms in groundwater over a period of $\mathbf{1 0 0}$ days showing that most of the pathogens indicator of bacteriological contamination ( $Y$. enterococci and $E$.coli) can survive in groundwater for a period exceeding 100 days (Ford and Williams 2007)

The present thesis aims at defining practical quantitative methods for the assessment of vulnerability through a better understanding of flow and transport processes in karst systems. The ultimate goal is to transform karst systems into "Gray Boxes", to enable the establishment of practical vulnerability concepts, aiming at a better preservation of water quality at the source, the source being the recharge area. The present work takes the two aspects of vulnerability into consideration, the intrinsic which is related to the inherent properties of a karst media and the specific which is dependent on the type of contaminant and its specific transport parameters.

\subsection{CASe Studies}

The two catchment areas selected for the purpose of this work are located in different climatic areas. The Gallusquelle spring in Germany is located in a humid area, where precipitation (rain and snow) input occurs throughout the year (Figure 1-2; a), whereas the Jeita spring is situated in a Mediterranean zone in Lebanon, where precipitation (rain and snow) is absent for about 4 months a year (summer periods; Figure 1-2; b). The difference in climatic conditions results in different recession patterns and spring responses (Figure 1-2).

\subsubsection{Gallusquelle spring- Germany}

The Gallusquelle spring, located in the Swabian Alb in southern Germany provides about 40,000 inhabitants with domestic water. This aquifer has been thoroughly investigated whereby climatic records and spring physico-chemical parameters and discharge are available over a time span of 50 years (Sauter, 1992, Geyer, 2008; Chapter 3) 


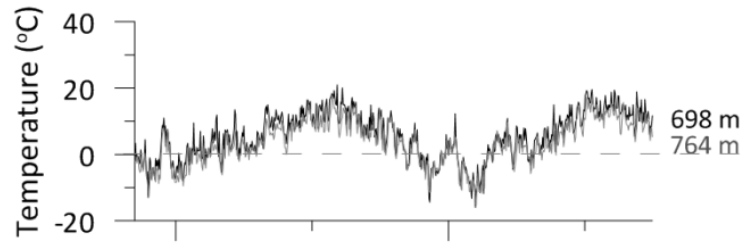

01-01-90

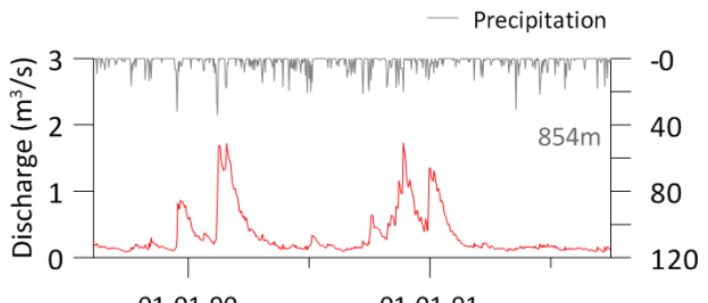

01-01-90
01-01-91

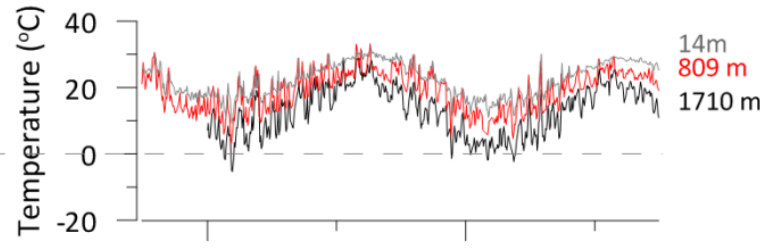

01-01-10

01-01-11

- Observed discharge

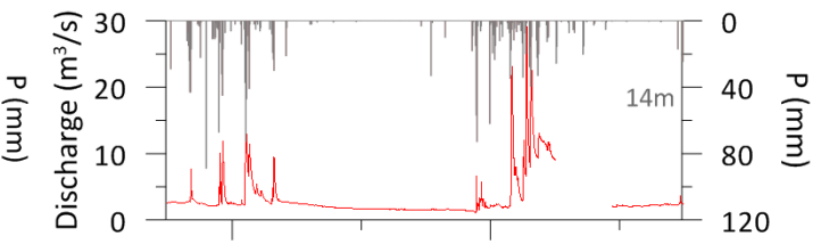

01-01-10

01-01-11

b

Figure 1-2 Climatic characteristics of the investigated catchment showing the fluctuation in temperature, precipitation and spring discharge

\subsubsection{Jeita spring- Lebanon}

The Jeita Spring is located north to Beirut in northern Lebanon. It constitutes the main water source for Beirut Area for domestic use (about 1.5 million inhabitants) and its northern suburbs for domestic use. The total yearly precipitation on the Jeita catchment is estimated at about $407 \mathrm{Mm}^{3}$, out of which only about $52 \%$ are infiltrated, whereas about $15 \%$ and $33 \%$ are lost in surface runoff and evapotranspiration respectively (Bakic, 1970). This spring is poorly studied and lacks adequate long term discharge monitoring; therefore a multi parameter probe was installed as part of this work in the Jeita spring (since May 2009) for the continuous monitoring of water level, temperature, $\mathrm{pH}$, electrical conductivity, and turbidity (Chapter 4, Chapter 5, and Chapter 6).

\subsection{STRUCTURE OF THE THESIS}

This thesis presents different quantitative approaches to assessing intrinsic and specific vulnerability of karst systems. The assessment of vulnerability is done at catchment scale, and mainly based on spring responses. The chapters of this thesis have a manuscript format, as they were prepared for submission to peer reviewed journals. Following the Introduction, Chapter 2 presents an overview on the vulnerability of karst aquifers, where vulnerability is discussed with respect to peculiarities of the karst media. The quality of the water retrieved at a spring or at a well is reflective of the rain/snow melt water infiltrated at the surface in the recharge area along with the associated contaminants. Therefore the most suitable assessment of vulnerability lies in a numerical model, thus a quantitative approach. In this perspective, Chapter 3 presents the evaluation of intrinsic vulnerability through numerical flow Modelling of the entire hydrological cycle. The significance of the parameters involved in the hydrological cycle is depicted through an extensive sensitivity analysis. Chapter 4 presents the temporal variation of the transport parameters of conservative tracers, which are indicators of intrinsic vulnerability, namely transit times, dispersion and their implication in reshaping a conservative tracer 
breakthrough curve at a spring under various flow conditions. Chapter 5 is an overview on spatial and temporal occurrence of three organic micropollutants (carbamazepine, caffeine and benzoyglecgonine) in groundwater as indicators of short and long term wastewater contamination, followed by Chapter 6, where the behavior of one specific micropollutant (carbamazepine) is thoroughly investigated following a precipitation event. Chapter 5 and 6 show the importance of the input function (precipitation) and provide insights into specific vulnerability.

\subsection{References}

Bakic, M., 1972. Jeita the Famous Spring of Lebanon, United Nation Development Report. UN. Beirut: 1-149pp

Bauer, S., Liedl, R., and Sauter, M., 2003. Modelling of karst aquifer genesis: Influence of exchange flow, Water Resources Research, 39, no. 10: 1285-1297

Butscher, C., and Huggenberger, P., 2009. Enhanced vulnerability assessment in karst areas by combining mapping with Modelling approaches. Science of the Total Environment, 407, no. 3: 1153-1163

Ford, D., and Williams, P., 2007. Karst hydrogeology and Geomorphology. John Wiley \& Sons Ltd., West Sussex, $562 p p$

Geyer, T., 2008. Process based characterization of flow and transport in karst aquifers at catchment scale. Ph.D. Dissertation, Mathematisch-naturwissenschaftliche Fakultäten. Georg-August-Universität Göttingen. $103 p p$

Margat, J., 1968. Contamination vulnerability mapping of groundwater, Bureau de Recherches Geologiques et Minieres, Orleans

Mull, R., 1981. Ground-Water Protection Zones. GeoJournal, 5, no. 5: 473-481

Sauter, M., 1992. Quantification and forecasting of regional groundwater flow and transport in a karst aquifer (Gallusquelle, Malm, SW. Germany). Tübinger Geowissenschaftliche Arbeiten, C13, 150pp 


\section{VULNERABILITY OF KARST SYSTEMS}

\subsection{KARST SYSTEMS}

Karst systems are characterized by a duality of recharge and flow (Kiraly, 2002). Diffuse and concentrated recharge mechanisms can be identified in such systems (Figure 2-1). Concentrated recharge can be significant in mature karst and occurs through point sources (e.g., dolines, sinking streams etc.). On the contrary, diffuse or non point source recharge is homogeneous over the entire area. Recharge in karst systems can be assessed using soil-water balance approaches (Sauter, 1992), which however do not take into account flow through the unsaturated rock matrix. Karst systems portray a duality of flow as well, where high permeability conduit systems or solution enlarged voids (Baedke and Krothe, 2001) drain a low permeability fissured matrix which holds most of the aquifer storage (Ashton, 1966).

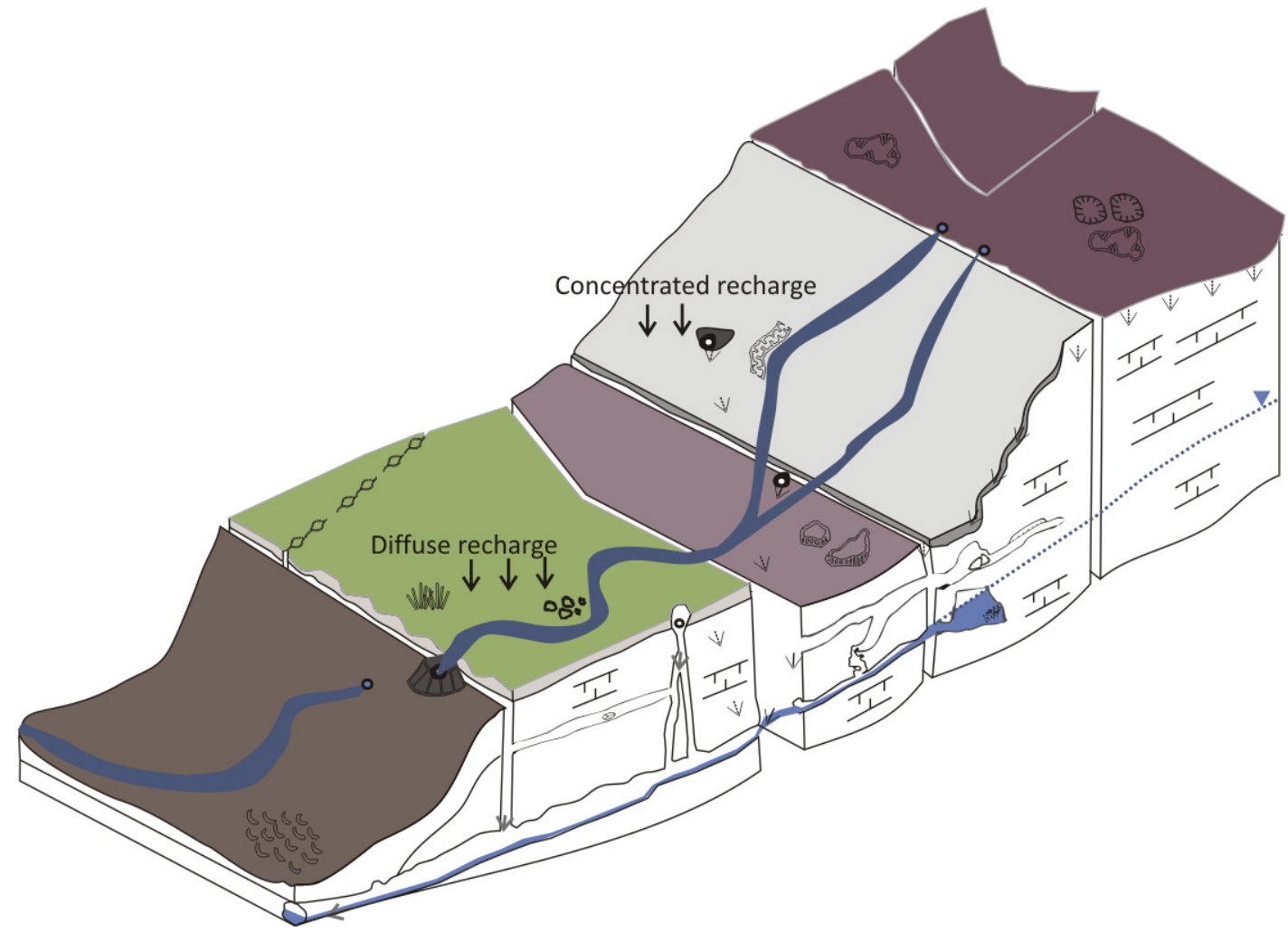

Figure 2-1 Schematic representation of a karst aquifer portraying the duality of flow and recharge in karst aquifer (diffuse versus local)

Given that karst systems are highly heterogeneous in terms of hydraulic parameters and recharge and flow processes (Goldscheider, 2002, Butscher and Huggenberger, 2009), it is often difficult to foreseen the groundwater flow in such media (Baedke and Krothe, 2001), especially that conventional methods for the assessment of groundwater resources often fail to apply (Smart, 1988). Furthermore, they are mostly characterized by low transit times in rapid flow pathways; therefore the likelihood for fast contaminant migration is very high (Field, 1990) and natural attenuation is less likely to occur (Vías et al., 2006). 
The assessment of the sensitivity of water bodies to contamination and the delineation of protection zones are to be done and validated in order to secure a sustainable management of water resources in karst aquifers (Bakalowicz, 2005). The latter means, in applied terms that, areas having a high sensibility to convey potential pollution to the subsurface should be identified. Additionally, the assessment should enable to predict the arrival and the maximum concentration of a contaminant at a target (spring, well etc.), as well as the duration of the contamination, and to allocate sufficient time for remediation. This exercise will take into account the hydraulic characteristics of the karst system as well as the properties of the contaminant (reactive versus conservative; Figure 2-2).

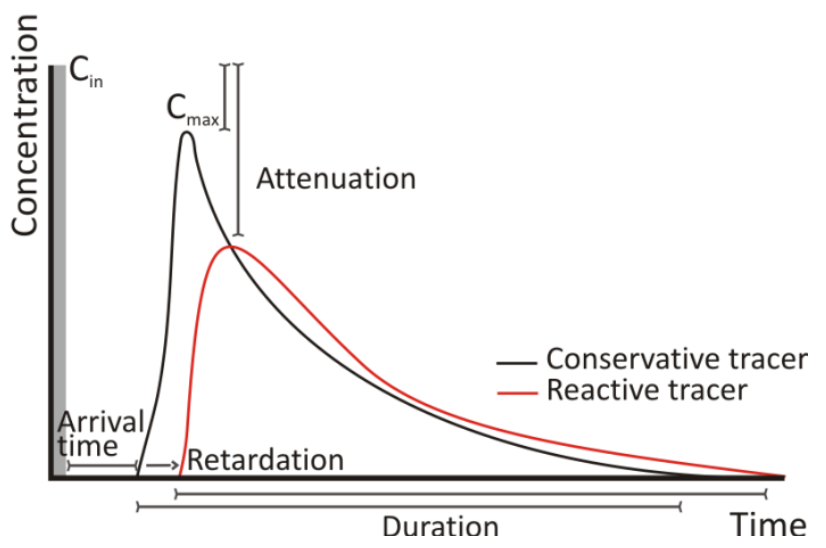

Figure 2-2 A Dirac input concentration results in various responses (breakthrough curves) at a target depending on the nature of the injected tracer, the geometry, flow and transport parameters of a system, (modified from COST Action 620, 2003)

\subsection{VULNERABILITY}

\subsubsection{Vulnerability concept}

Vulnerability defines the sensitivity of an environment for contamination. The term was first introduced by Margat (1968) to refer to the extent to which aquifers can be exposed to contamination (Foster, 1987, Vías et al., 2006). The vulnerability concept is often represented by the simplified origin-pathway-target scheme (Goldscheider, 2002, Neukum et al., 2008, Figure 2-3). The origin defines the source of contaminant, the pathway represents the media through which the contaminant is transported (i.e., from the moment it infiltrates at the surface, throughout the unsaturated zone and saturated zone) to reach the groundwater target, which can be a well or a spring.

Two types of vulnerability can be distinguished: the intrinsic vulnerability represents the sensitivity of a media or target to contamination independent of the type of contaminant to which it is being subject (Vías et al., 2006, Civita, 2010). On the other hand, the specific vulnerability is an intrinsic vulnerability that takes into account the characteristics of the contaminant that is of threat to the target. Therefore, the intrinsic vulnerability accounts for the inherent properties of a system/media, e.g., geological, and hydrogeological properties, in other terms conservative flow and transport parameters. The specific vulnerability considers the 
reactive transport characteristics of a specific contaminant, including transit time, dispersion and diffusion, sorption, decay and biodegradation, in addition to duration or attenuation of the contaminant upon passage in the subsurface.

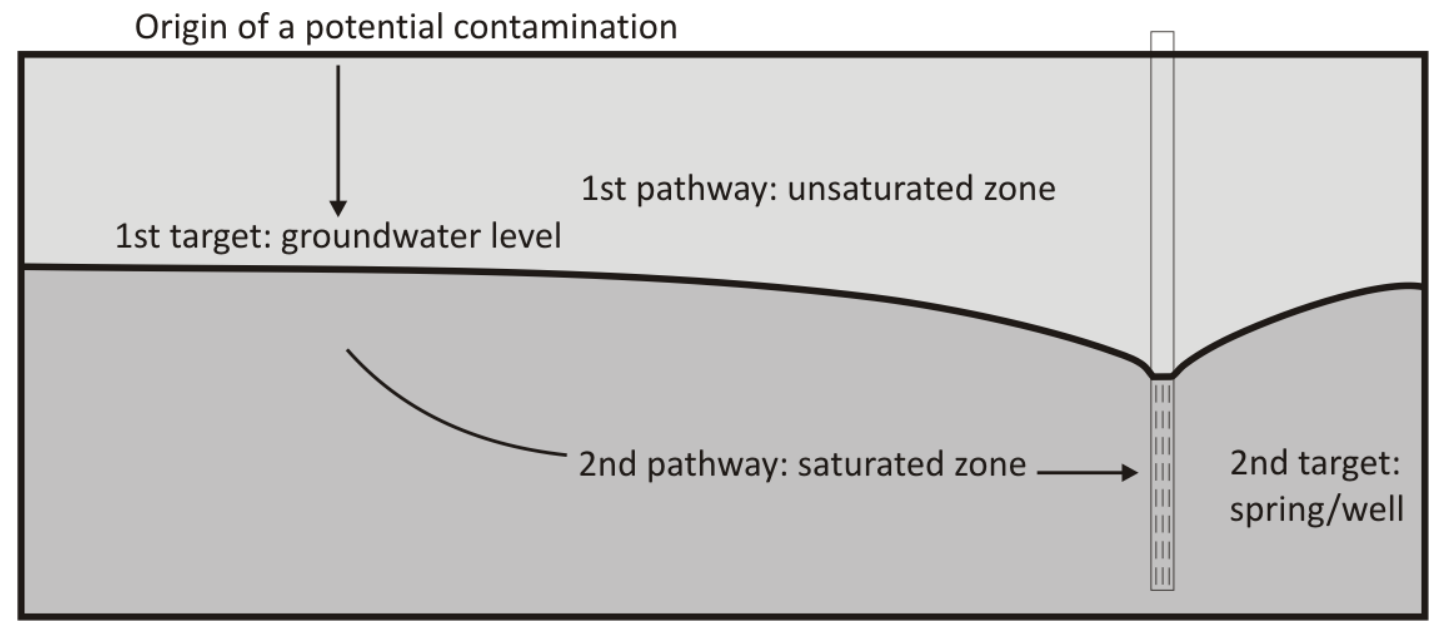

Figure 2-3

Origin-pathway- target concept applied for vulnerability assessment (after Goldscheider 2002)

However, the combination of all the parameters cannot provide a straight forward assessment of vulnerability. For instance, a high transit time will enable attenuation processes to be active for a longer time and allow for time to react to pollution at the target (Perrin et al., 2003). However processes like dispersion and diffusion will enhance contaminant attenuation, but will controversially increase the duration of restitution at the target.

\subsubsection{Vulnerability assessment}

Methods were proposed since 1968 to assess groundwater vulnerability in all types of aquifers. Vulnerability mapping is the most common tool to define vulnerability. Additionally, semi-quantitative methods, relying on processes and qualitative assessment of vulnerability, were also later proposed to validate the qualitative vulnerability approaches. Unlike in porous aquifers, vulnerability assessment in karst aquifers has to account for both the concentrated and diffuse recharge as well as for the significant heterogeneity of hydraulic properties and geometries prevailing in the subsurface.

\subsubsection{Vulnerability mapping}

The qualitative methods aim at simplifying hydraulic processes and subsurface geometry to varying degrees and represent them by static spatially distributed parameters that can be assessed in the field or based on literature values. All the vulnerability methods are not applicable in karst aquifers because they do not account for the duality of infiltration and recharge in such systems. Therefore further methods were later developed for or adapted especially to karst media and applied around the world in various climatic regions (DRASTIC, SINTACS, PI, EPIK, COP, GOD etc.; Table 2-1). The parameters shown in Table 2-2 belong to the domains where water flows from origin, through pathway until target scheme, i.e., surface features, the unsaturated zone and 
the saturated zone. For each method, controlling parameters play a different role in the final vulnerability score according on the weighting coefficient assigned to them.

Table 2-1 Qualitative intrinsic vulnerability methods based on different controlling factors

\begin{tabular}{|c|c|c|}
\hline $\begin{array}{l}\text { Vulnerability } \\
\text { method }\end{array}$ & Origin & Parameters affecting vulnerability \\
\hline DRASTIC & Aller et al., 1987 & $\begin{array}{l}\text { Depth to water }(D) \text {, net recharge }(R) \text {, aquifer media }(A) \text {, soil media }(S) \text {, } \\
\text { topography (slope), impact of the vadose zone media (I), hydraulic } \\
\text { conductivity (K) }\end{array}$ \\
\hline SINTACS & Civita and De Maio, 1997 & $\begin{array}{l}\text { Depth to groundwater }(S) \text {, effective infiltration Rate }(I) \text {, unsaturated } \\
\text { zone }(N) \text {, soil attenuation capacity }(T) \text {, aquifer characteristics }(A) \text {, } \\
\text { hydraulic conductivity }(C) \text {, topography }(S)\end{array}$ \\
\hline EPIK & Doerfliger et al., 1999 & Epikarst $(E)$, protective cover $(P)$, infiltration $(I)$, karst $(K)$ \\
\hline GOD & Foster, 1987 & $\begin{array}{l}\text { Groundwater type }(G) \text {, overlying lithology }(O) \text {, depth to groundwater } \\
\text { (D), soil type }\end{array}$ \\
\hline COP & Vías et al., 2006 & $\begin{array}{l}\text { Overlying layer (soil thickness and type, lithology, depth to unsaturated } \\
\text { zone, aquifer confinement), concentrated recharge (sinkholes and } \\
\text { distance to sinking streams, slope and vegetation), precipitation } \\
\text { (amount and intensity) }\end{array}$ \\
\hline $\mathrm{PI}$ & Goldscheider et al., 2000 & $\begin{array}{l}\text { Topography, vegetation recharge, karst features, soil thickness, } \\
\text { permeability and texture, unsaturated zone thickness and permeability, } \\
\text { lithology, aquifer confinement conditions. }\end{array}$ \\
\hline
\end{tabular}

Table 2-2 Parameters affecting vulnerability in the case of six vulnerability methods applied in karst systems

\begin{tabular}{|llccccc|}
\hline Domain & Parameter & DRASTIC & SINTACS & COP & PI & EPIK \\
& & GOD \\
\hline Surface & Recharge rate & $\checkmark$ & $\checkmark$ & $\checkmark$ & $\checkmark$ & $\checkmark$ \\
features & Topography/ Slope & $\checkmark$ & $\checkmark$ & $\checkmark$ & $\checkmark$ & $\checkmark$ \\
& Karst features- rapid infiltration & & & $\checkmark$ & $\checkmark$ & $\checkmark$ \\
Unsaturated & Soil type & $\checkmark$ & $\checkmark$ & $\checkmark$ & $\checkmark$ & $\checkmark$ \\
& Soil thickness & & & $\checkmark$ & $\checkmark$ & $\checkmark$ \\
Saturated & Depth to aquifer & Characteristics of unsaturated zone & & $\checkmark$ & $\checkmark$ & $\checkmark$ \\
zone & Aquifer lithology & $\checkmark$ & $\checkmark$ & $\checkmark$ & $\checkmark$ \\
& Hydraulic properties of saturated zone & $\checkmark$ & $\checkmark$ & & $\checkmark$ & $\checkmark$ \\
\hline
\end{tabular}

\subsubsection{Semi-quantitative to quantitative vulnerability methods}

The travel time approach was used to characterize groundwater protection zones based on the time needed for a contaminant to reach a target (e.g., well). In many countries, the middle protection zone (Zone 2 ) is 
defined based on a transit time day line (e.g., 50-day line in Germany; Mull, 1981), which represents the time needed for contaminants like pathogens to be attenuated (Cf. Introduction).

However, in this case, given the duality of recharge and the relatively low transit times, the travel time method cannot be usually applied in karst systems. Brosig et al. (2008) introduced a transit time method to define vulnerability of a karst catchment area, where Darcy's law is applied to calculate transit times based on velocities within a surface catchment. This method considers lateral flow along slopes from high to low gradients as well as vertical flow in point sources (sinkholes).

The VULK method (Jeannin et al., 2001) is based on a one dimensional analytical transport model (velocity, dispersion, decay and retardation), where each grid on the map is assigned different transport parameters of the unsaturated and saturated zone. Vulnerability is therefore defined by the significance of the transit time and attenuation of the contaminant. This method applies for a conservative or specific contaminant. Malík and Vojtková (2007) applied this method to highlight the importance of the intrinsic properties of a karst aquifer in controlling conservative transport. For instance, they showed the importance of the epikarst using a simple Advection Dispersion Model (ADM) where the variation of thickness $\left(b_{\text {soil }}\right)$ and hydraulic conductivity $\left(K_{\text {soil }}\right)$ of the soil cover or thickness $\left(\mathrm{b}_{\mathrm{epi}}\right)$ or hydraulic conductivity $\left(\mathrm{K}_{\mathrm{epi}}\right)$ of the epikarst highly affects the shape of the breakthrough curves at the target (Figure 2-4).

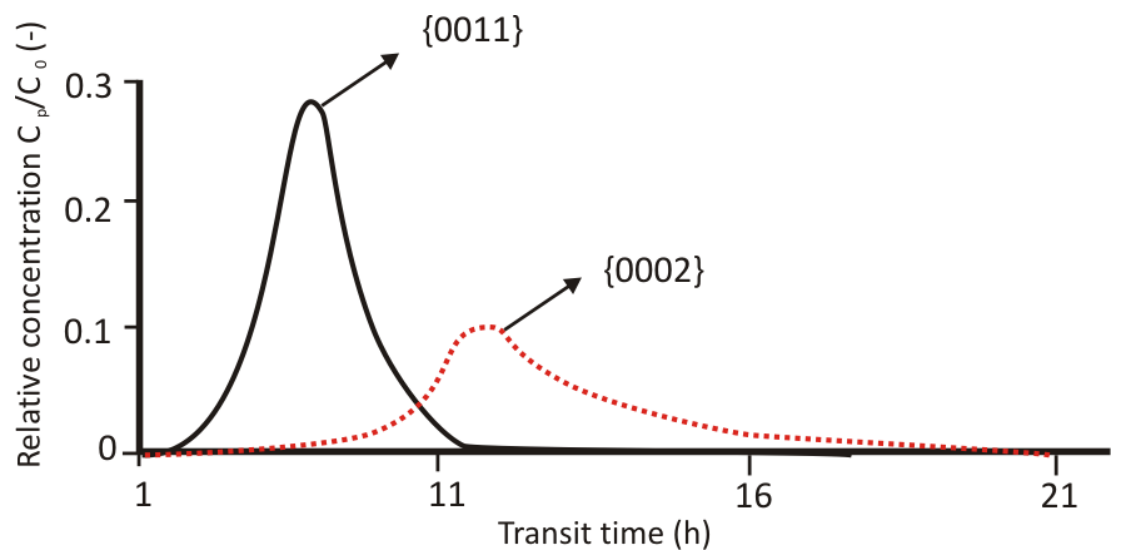

Figure 2-4 Typical tracer breakthrough curves simulated with VULK for the following parameter combinations for soil cover and epikarst, $\{0011\}: b_{\text {soil }}=0.1 \mathrm{~m}, K_{\text {soil }}=1 E 10^{-5} \mathrm{~m} / \mathrm{s}, b_{\text {epi }}=50 \mathrm{~m}, K_{\text {epi }}=3 E 10^{-4} \mathrm{~m} / \mathrm{s}$, and $\{0002\}$ : $b_{\text {soil }}=0.1 \mathrm{~m}, K_{\text {soil }}=1 E 10^{-5} \mathrm{~m}, b_{\text {epi }}=50 \mathrm{~m}, K_{\text {epi }}=1 E 10^{-4} \mathrm{~m} / \mathrm{s},\left(C_{0}\right.$ and $C_{p}$ being the input and maximum concentrations respectively; modified from Malík and Vojtková, 2007)

Butscher and Huggenberger (2009) proposed a quantitative method to assess vulnerability based on a reservoir Modelling approach calibrated on the basis of karst spring discharges. A vulnerability index (VI) is developed based on a vulnerability concentration $\left(C_{v}\right) . C_{v}$ represents different breakthrough curves resulting either from a continuous or semi-Dirac (single time step) input of a conservative contaminant to the system under different flow conditions. In this case, flow conditions play a role in the dilution, advection or dispersion of the contaminant, as reactive transport is disregarded. In this method, vulnerability is assessed on the basis of the spring response rather than at a catchment scale. 


\subsubsection{Synopsis}

Most of the vulnerability models/methods developed to date have failed incorporating the heterogeneity and dynamics of the karst system (Butscher and Huggenberger, 2009). They account for either one or a combination of the following parameters displayed in Table 2-3.

Qualitative methods accounts for the spatial variability of vulnerability, however they rely of surface features to define the sensibility of a subsurface to contamination. Therefore the evaluation of the parameters playing a role in vulnerability and the weighting factor are highly subjective according to each method. Moreover, vulnerability maps based on different methods portray discrepancies between the delineated vulnerability classes (Polemio et al., 2009, Doummar et al., 2012a; Figure 2-5)

Table 2-3 Categories of parameters incorporated in static and temporally variable vulnerability methods developed to date

\begin{tabular}{|c|c|c|}
\hline \multicolumn{3}{|l|}{ Vulnerability assessment } \\
\hline Type of parameter & Example & Influence on \\
\hline Input & Precipitation & Recharge amounts \\
\hline Geometry/spatial distribution & $\begin{array}{l}\text { Thickness of soil/ depth to water } \\
\text { table/location of concentrated recharge }\end{array}$ & $\begin{array}{l}\text { Extent and type of } \\
\text { infiltration/drainage }\end{array}$ \\
\hline Hydraulic parameters & hydraulic conductivity & Flow \\
\hline Transport parameters & Transit times, attenuation & Ability for attenuation \\
\hline \multicolumn{3}{|l|}{ Vulnerability quantification } \\
\hline Methods & Output & Calibration \\
\hline \multirow[t]{2}{*}{ Flow equations/models } & Static: Darcy's law (transit times) & Gradient/ water level \\
\hline & Temporally variable: (reservoir Modelling) & Discharge \\
\hline \multicolumn{3}{|l|}{ Vulnerability validation } \\
\hline $\begin{array}{l}\text { Tracer tests } \\
\text { Transport models }\end{array}$ & Connection to point source, transit times & $\begin{array}{l}\text { Type of infiltration/ ability } \\
\text { for attenuation }\end{array}$ \\
\hline
\end{tabular}



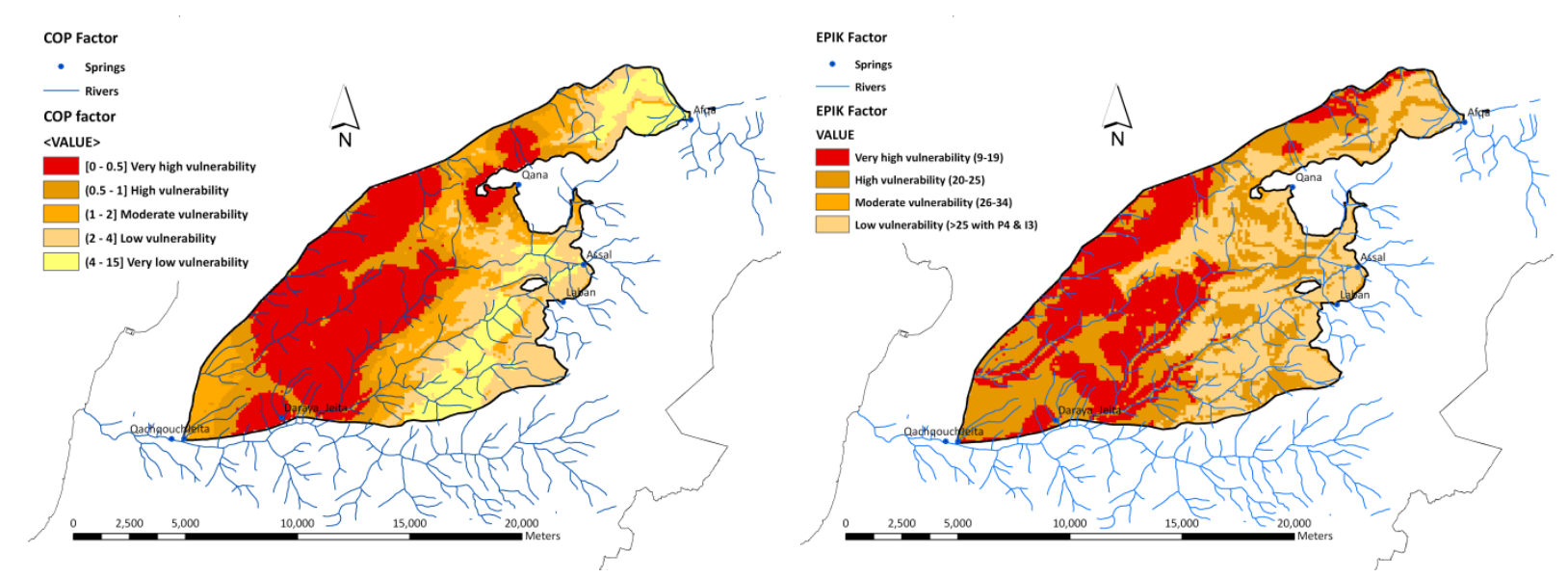

Figure 2-5 Example of vulnerability mapping for a catchment area using the COP and EPIK methods showing discrepancies in the vulnerability classification (Doummar et al., 2012a)

Spring responses are the output signal of a karst system and are highly variable with time according to the input signal and prevailing transport and flow conditions. Therefore spring responses and their temporal variability cannot be neglected in vulnerability assessments. The existing quantitative intrinsic vulnerability (e.g., reservoir models; Table 2-3) model fails to account for the spatial variability of vulnerability.

The assessment of vulnerability is closely related to physical processes taking place in a karst system. Processes such as type of recharge and flow, along with the importance of storage, play a major role in shaping the output signal (discharge) at an outlet (Figure 2-6). The assessment of parameters and processes influencing vulnerability requires first a thorough characterization of a karst system at a catchment scale.

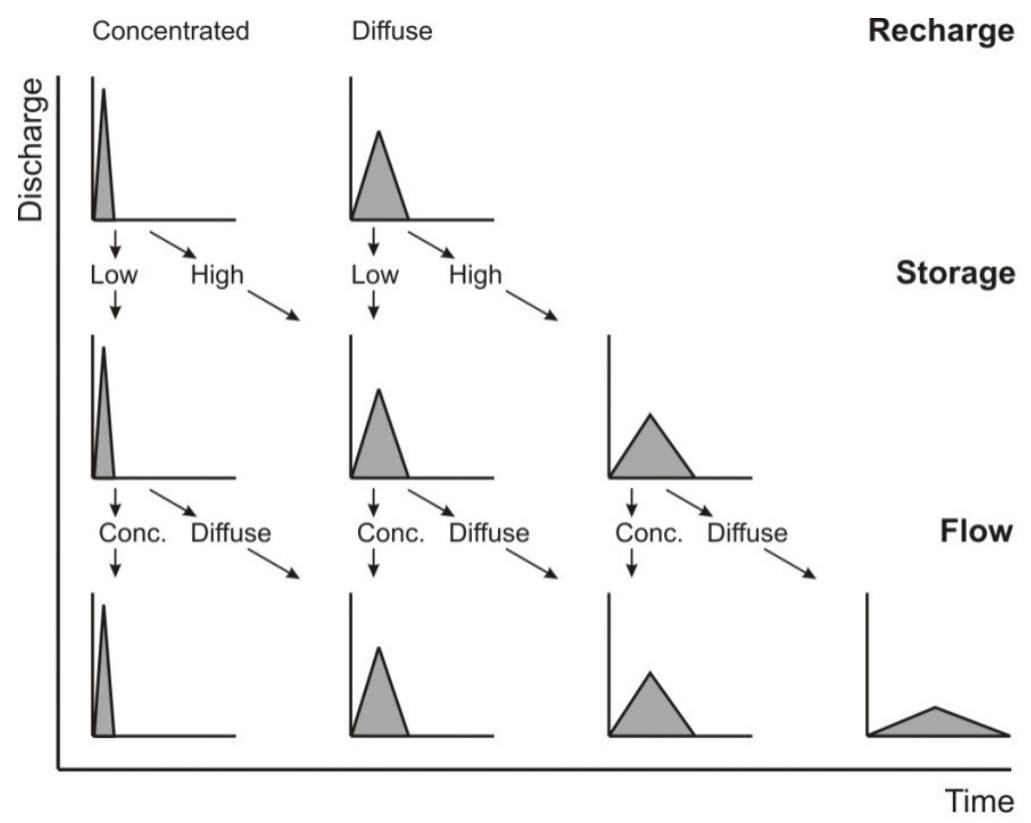

Figure 2-6 Duality of recharge, storage and flow in a karst system (modified from Smart and Hobbs, 1986, in Geyer, 2008) 


\subsection{INVESTIGATION OF KARST AQUIFERS FOR VULNERABILITY ASSESSMENT}

Characterization of karst aquifers for vulnerability purposes, involve assessing flow and transport at a catchment scale using different field investigations and data analysis. They include field investigations such as artificial tracer experiments and aquifer testing. The identification of indicator parameters is performed through an extensive analysis of spring responses (discharge, electrical conductivity, temperature, turbidity etc.; Atkinson, 1977).

\subsubsection{Artificial tracer experiments}

Artificial tracer tests are applied extensively to identify a potential hydrogeological connection between a point source and a target (well or spring), to define the boundaries of a karst catchment and to characterize hydrodynamic flow and transport parameters (mean and maximum flow velocities, transit times, longitudinal dispersivities, mass restitution, etc...), as well as flow divergence and convergence (Smart, 1988, Morales et al., 2007, Figure 2-7) in different compartments of a karst system. Geometry of conduits network can be inferred from the shape of a tracer breakthrough curve (TBC; Figure 2-7; mono versus multi peak). This information is essential to develop a conceptual model of a karst aquifer that can be used in flow and transport numerical models and prediction of contamination migration patterns. The numerical or statistical analysis of a tracer breakthrough curve (TBC) allows the estimation (numerically or analytically) of tracer recovery, restitution "key" times, flow velocities, longitudinal dispersion/dispersivity, and Peclet numbers (Equations and details in Table 2-4) discussed as follows:

- $\quad$ Tracer recovery

Recovery $M$ is calculated based on the TBC, upon integration of the concentration multiplied by flow data over the tracer restitution period, from its first detection until end of tailing. Tracer recovery provides information about the attenuation of the tracer mass, tracer divergence from injection point to different pathways etc.

- $\quad$ Flow velocities and transit times

Mean $\left(v_{m}\right)$, maximum $\left(v_{\max }\right)$, and peak $\left(v_{p}\right)$ flow velocities are calculated respectively based on the mean residence time, the time of first detection, and time of peak detection. The mean residence time represents statistically the time where half of the recovered tracer mass has elapsed the observation point. Flow velocities are transformed into transit times knowing the linear or sinuous distance from injection point to target (Goldscheider et al., 2008). 


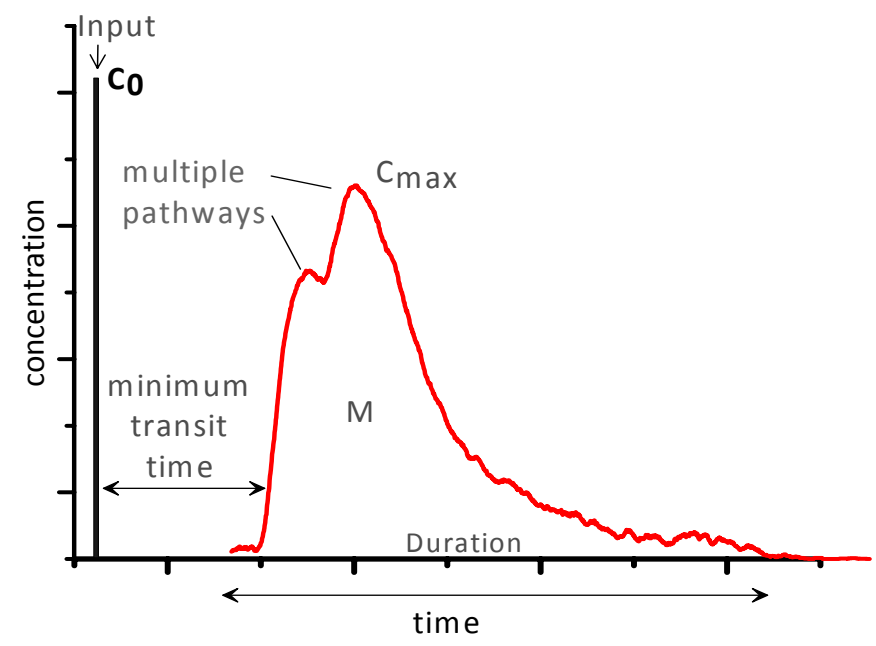

Figure 2-7 Information about different pathways, transport parameters and mass fluxes retrieved from the analysis of a tracer breakthrough curve

- Longitudinal dispersivity and dispersion

The shape of the TBC provides an indication of the longitudinal dispersion of the tracer (Kilpatrick, 1993), for a one-dimensional TBC. The variance of the TBC $\left(\sigma^{2}\right)$ allows the estimation of longitudinal dispersion $\left(D_{L}\right)$ and consequently dispersivity $\left(\alpha_{L}\right)$. Dispersion portrayed by the variance of the TBC is due to the variation in velocities during transport. It usually reflects the degree of heterogeneity of the flow path, and plays a role in reshaping the TBC, where different $T B C$ can be recovered depending on the monitored distance and the location of the observation point (Figure 2-8).

- Channel or conduit geometry

Assuming that the conduit is cylindrical in shape, characteristics and geometry (area, volume and diameter) of a single conduit can be inferred from the TBC and the discharge measurement curve (Geyer et al., 2007, Göppert and Goldscheider, 2008 etc.). 


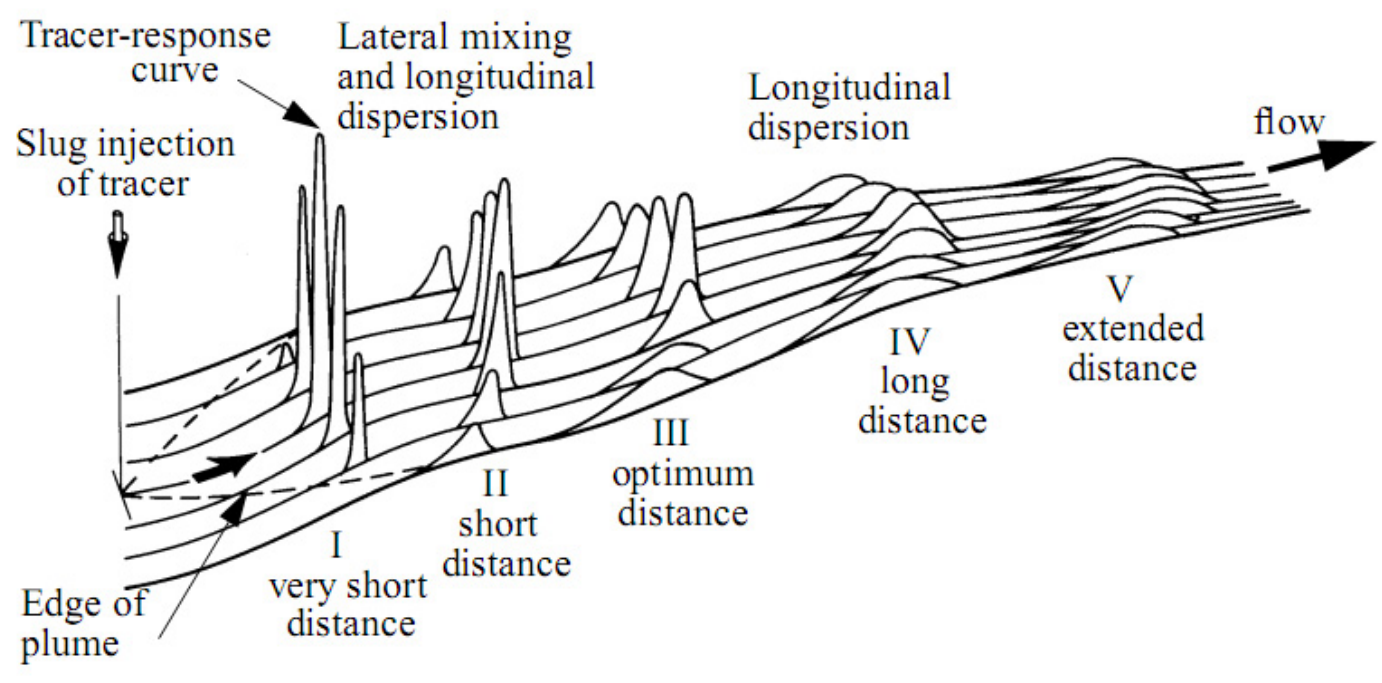

Figure 2-8 Extent of lateral mixing of the tracer and longitudinal dispersion over a distance following a Dirac injection pulse (slug injection). Effect of dispersion on the variation of the peak concentration (Kilpatrick, 1993 in Jobson 1997) 
Table 2-4 Key parameters identified from the analysis of tracer breakthrough curves

\begin{tabular}{|c|c|c|c|c|}
\hline Parameter & Description & Symbol & $\begin{array}{c}\text { Related statistical } \\
\text { formula }\end{array}$ & Limitations and conditions \\
\hline Tracer recovery & Mass recovered & $M$ & $M=\int_{t=0}^{\infty} C(t) Q(t) d t$ & $\begin{array}{l}\text { Discharge rate to be recorded } \\
\text { continuously or averaged during the } \\
\text { tracer recovery time }\end{array}$ \\
\hline $\begin{array}{l}\text { Presence of immobile phase: } \\
\text { Mass transfer and partition } \\
\text { coefficient (Method discussed in } \\
\text { details in Chapter 4) }\end{array}$ & $\begin{array}{l}\text { Requires to define the behavior of } \\
\text { the mobile fluid phase and the } \\
\text { exchange between mobile and } \\
\text { immobile phases }\end{array}$ & $\beta$ and $\omega$ & - & $\begin{array}{l}\text { Parameters that allow accounting for } \\
\text { tailing in the TBC. The model is highly } \\
\text { influenced by the fitting parameters: } \\
\text { partition coefficient } \beta \text { and } 1^{\text {st }} \text { order mass } \\
\text { transfer coefficient }(\omega) \\
0<\beta<1 ; 0<\omega\end{array}$ \\
\hline Mean tracer velocity & $\begin{array}{l}\text { Dominant flow velocity, ratio of } \\
\text { the linear distance and the mean } \\
\text { transit time }\end{array}$ & $v_{m}$ & $v_{m}=\frac{d_{\text {linear }}}{t_{d}}$ & $\begin{array}{l}\text { The linear distance }\left(d_{\text {linear }}\right) \text { which is a } \\
\text { straight line distance from injection } \\
\text { point to monitoring point, is not } \\
\text { representative of the true distance. True } \\
\text { distance, which is greater, takes } \\
\text { sinuosity into account }\end{array}$ \\
\hline Mean transit time & $\begin{array}{l}\text { Length of time required for the } \\
\text { centroid of the tracer to traverse } \\
\text { the entire aquifer, i.e. time } \\
\text { required for half the total } \\
\text { restitution to be recovered }\end{array}$ & $t_{m}$ & $t_{m}=\int_{t=0}^{\infty} \frac{Q(c) t d t}{Q(c) d t}$ & \\
\hline Maximum tracer velocity & $\begin{array}{l}\text { Maximum tracer velocity, based } \\
\text { on the time of tracer first arrival } \\
\left(\mathrm{t}_{\mathrm{f}}\right)\end{array}$ & $v_{\max }$ & $v_{\max }=\frac{d_{\text {linear }}}{t_{f}}$ & $\begin{array}{l}\text { In the case of irregularly and } \\
\text { asymmetrical curves or a high tracer } \\
\text { background, first arrival is not accurately } \\
\text { defined }\end{array}$ \\
\hline
\end{tabular}




\begin{tabular}{|lllll|}
\hline Parameter & Description & Symbol & $\begin{array}{c}\text { Related statistical } \\
\text { formula }\end{array}$ & Limitations and conditions \\
\hline Longitudinal dispersion & $\begin{array}{l}\text { Rate at which the tracer mass } \\
\text { spreads out along a flow path }\end{array}$ & $D_{L}$ & $\frac{D_{L}}{\bar{v}_{m} d_{\text {linear }}}=\frac{1}{2} \frac{\sigma^{2}}{{\overline{t_{m}}}^{2}}$ & $\begin{array}{l}\text { Parameter related to the variance }\left(\sigma^{2}\right) \text { of } \\
\text { the restitution curve (Maloszewski and } \\
\text { Zuber, 1992) }\end{array}$ \\
Longitudinal dispersivity & $\begin{array}{l}\text { Spatial extent to which dispersion } \\
\text { will occur }\end{array}$ & $\alpha_{L}$ & $D_{L}=\alpha_{L} v_{m}+D_{m}$ & Molecular diffusivity is often neglected \\
Peclet number & $\begin{array}{l}\text { Reflective of the contribution of } \\
\text { each of the mechanical dispersion } \\
\text { and advection flow onto mass } \\
\text { transport }\end{array}$ & $P_{e}$ & $P_{e}=\frac{d_{l i n e a r}}{\alpha_{L}}$ & $\begin{array}{l}\text { In karst } P_{\mathrm{e}} \text { is greater than } 6, \text { which } \\
\text { reflects a control of advection over } \\
\text { diffusion in transport processes }\end{array}$ \\
Channel/conduit dimensions & $\begin{array}{l}\text { Cross sectional area/ surface area, } \\
\text { channel diameter }\end{array}$ & $A, \phi$ & $A=\frac{\int_{0}^{t m} Q(t) d t}{d_{\text {linear }}}$ & $\begin{array}{l}\text { Assuming pipe flow along fractures or } \\
\text { homogeneous section. Not always } \\
\text { applicable }\end{array}$ \\
\hline
\end{tabular}

*Some parameters can be also be determined numerically (Chapter 4) 


\subsubsection{Aquifer testing}

Hydraulic conductivity and storativity of an aquifer can be estimated through the analysis of drawdown curves from pumping tests or slug tests (Sauter, 1992). However, the obtained data are obtained for a small scale and have to be extrapolated to a catchment scale or upscaled to various extents (Teutsch and Sauter, 1991, Geyer, 2008) for the generation of a numerical flow models. Moreover, the hydraulic parameters derived from aquifer testing might only apply for the diffuse matrix and might not be suitable for the conduit system (Sauter, 1992, Padilla et al., 1994).

\subsubsection{Analysis of spring responses}

Hydraulic and chemical signals recorded at a spring reflect the characteristics and structure of a karst system (Grasso and Jeannin, 2002). Spring responses are controlled by the type of recharge (diffuse or controlled), storage (significant or low), flow (conduit or matrix) and transport. They include in addition to hydrographs and chemographs, bacteriographs etc.

\subsubsection{Spring hydrograph analysis}

Spring hydrographs portray the response of the whole karst system to recharge events (Padilla et al., 1994). They are mostly characterized by an abrupt rise in discharge followed by a decreasing limb with one or varying slopes (Kiraly, 1998). The fastest response is believed to be triggered by flow in the conduit system, whereas the slowest response represents the matrix diffuse media of the karst system. Given that flow occurs in two continuums (matrix, conduit and the interaction between both), hydrographs in karst aquifers show high temporal and spatial variations depending on flow velocities and aquifer geometry, extent of surface and aquifer karstification, percentage of fast recharge component, flow intensity and distribution etc

Maillet (1905) introduced a simple method to analyze spring hydrographs using the recession coefficient $\left(\alpha_{r}\right)$. It can be evaluated in different karst spring hydrographs to acquire information about dominant flow regime in a karst system (matrix, conduit, or fissured mixed; Figure 2-9).

$$
Q_{t}=Q_{0} e^{\alpha_{r}\left(t-t_{0}\right)}
$$

where $Q_{t}$ is the discharge $\left[\mathrm{L}^{3} / T\right]$ at the time $t[T], Q_{0}\left[\mathrm{~L}^{3} / T\right]$ is the discharge at time $t_{0}[\mathrm{~T}]$ where the observation period is $t-t_{0}$.

Given a few assumptions, other hydraulic parameters can be also estimated from hydrograph analysis e.g., ratio of transmissivity $(T)$ to specific yield $\left(S_{y}\right)$; (Atkinson, 1977, Sauter, 1992).

However discharge cannot solely be regarded as an indicator for vulnerability, because it is an indicator for both transit time and dilution. As shown in Figure 2-10, depending on the conditions prevailing in the investigated system, discharge fails in being a suitable indicator for vulnerability. For instance, an increasing discharge can imply short transit times and high dilution at the same time, therefore high and low vulnerability conditions simultaneously. Moreover concentrations of "solutes" in a system can be either drastically decreased by dilution under high flow conditions, because of the inflow of a solute free tributary to the main 
outlet or increased because of the inflow of solute enriched waters. Therefore the combination of hydrographs and chemographs helps further understand the conceptual response of a karst system to precipitation events.

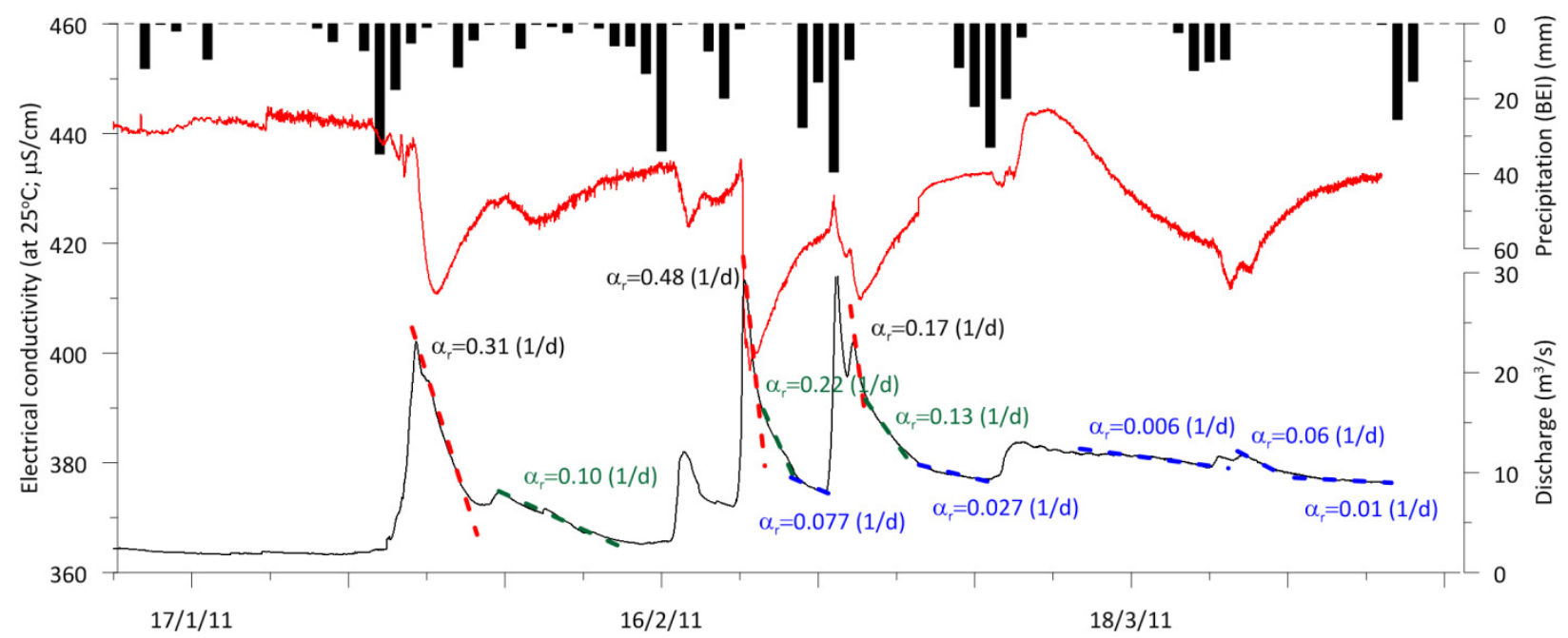

Figure 2-9 Example of recession coefficients showing a predominant conduit flow regime in a karst system (Jeita Spring, Lebanon; high flow periods for the hydrological year 2010-2011, BEl refers to a meteorological station located $18 \mathrm{~km}$ south to the Jeita spring at $14 \mathrm{~m}$ above sea level). Red and black lines refer to electrical conductivity and discharge respectively.

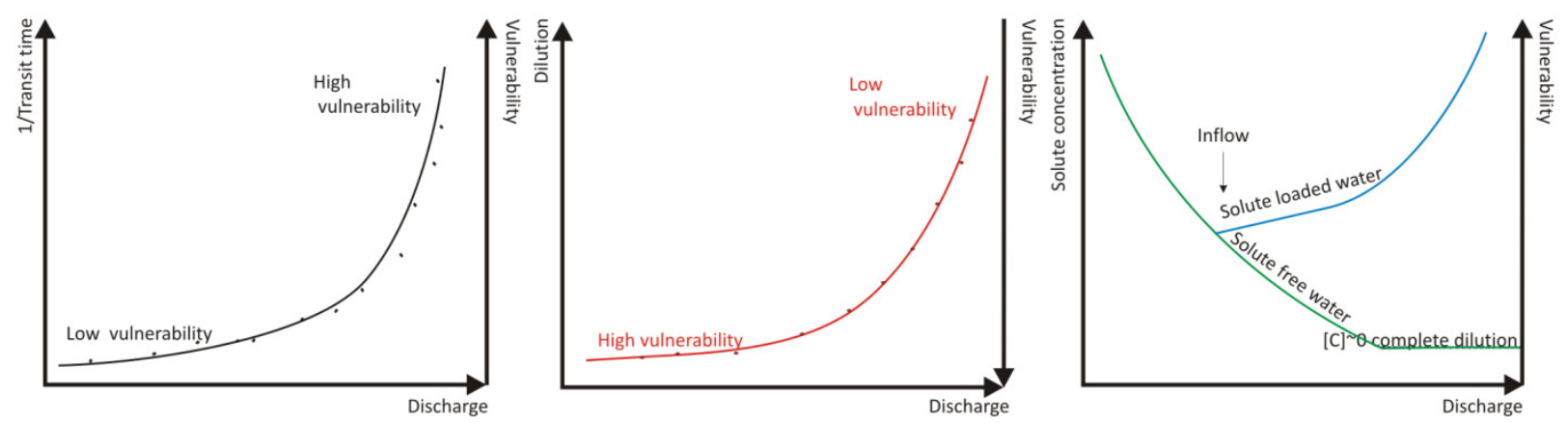

Figure 2-10 Relationship between discharge and transit time, dilution and solute concentration in a system and their relevance to vulnerability

\subsubsection{Spring chemograph analysis}

A chemograph is a series of physical or chemical measurements recorded at a spring. Spring chemographs include electrical conductivity, temperature, $\mathrm{pH}$, turbidity, as well as major ions, and stable water isotopes (Sauter, 1997) etc.

Sauter (1992) and Pronk et al. (2007) investigated turbidity signals at a spring, and identified primary and secondary turbidity peaks resulting from autochthonous and allochthonous sources. Turbidity can be an indicator for a fast pathway extending from a sinking stream located outside the catchment (Pronk et al., 2007).

Williams 1983 developed a concept to portray the behavior of a karst system following infiltration events by combining chemograph and hydrograph analysis (Figure 2-11). Additionally, the discharge at a spring allows 
the quantification of mass fluxes and dilution upon tracer breakthrough at a karst spring (Smart, 1988) if input functions are known.

Chemographs (major ions and natural isotopes) are suitable to estimate mixing proportions of new waters (from precipitation or anthropogenic origin e.g., wastewater) and stored waters. For instance, Sauter (1997) used oxygen isotopes to identify the fast flow component arriving at the spring following infiltration events using a mixing model.

Grasso and Jeannin (2002) have introduced a relationship between the discharge, ions concentration and electrical conductivity, where variation of the concentration is controlled by the ratio of dilution effect from the flow rate to the dissolved mass flux. Variation of natural tracers at a spring depends on the significance of the newly infiltrated fast water component usually poorly mineralized and the extent of mineralization of the background mixed water (Grasso and Jeannin 2002). However, this variation might also be due to the extent of mixing or to the interaction with the source rock.

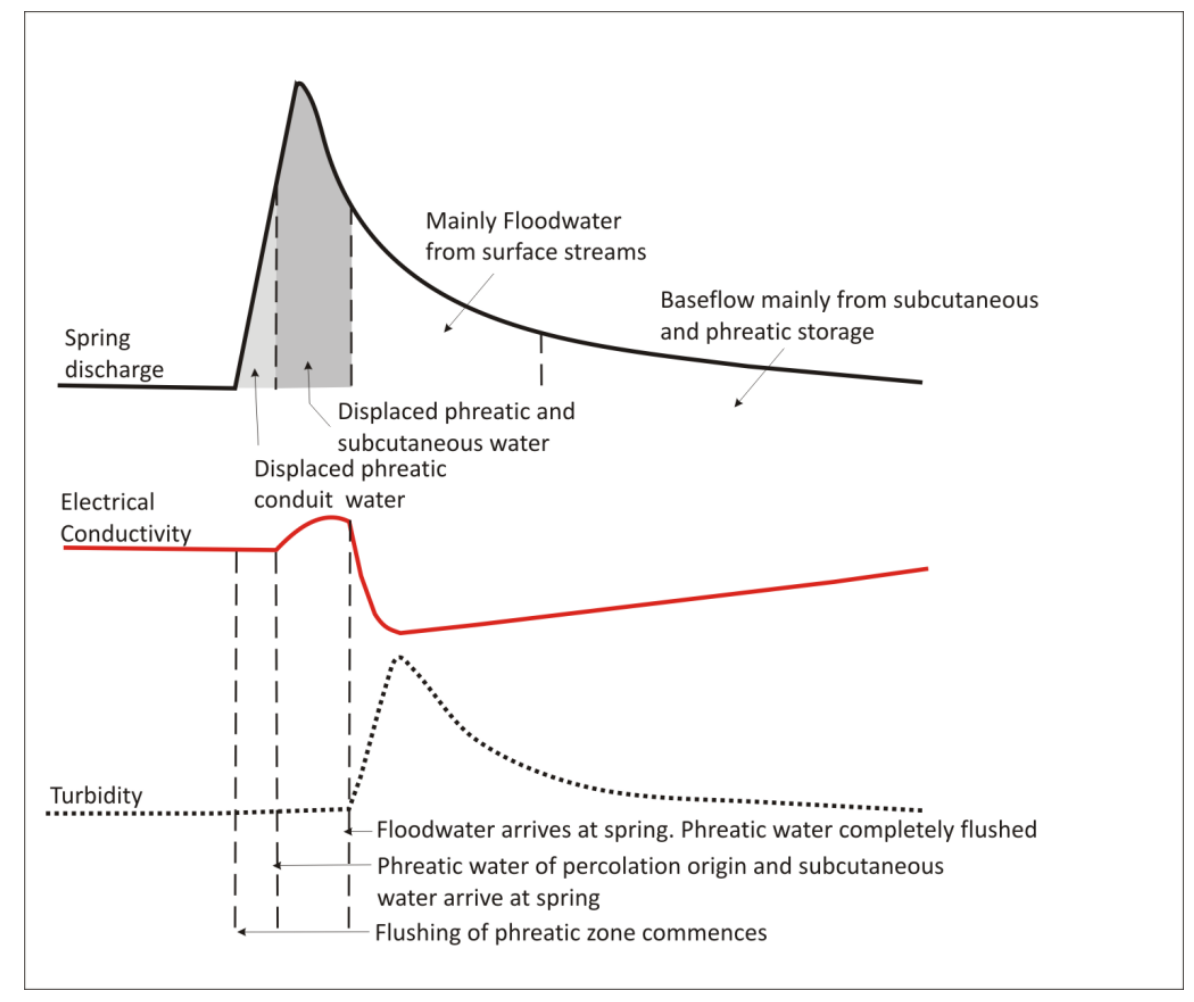

Figure 2-11 Combination of hydrographs and chemographs to understand the conceptual behavior of a karst system (modified after Williams, 1983)

The analysis of organic micropollutants (pharmaceuticals, pesticides, or industrial compounds) is commonly used since the past decade to trace back sources of pollution, especially those related to wastewater, clinical wastewater or agricultural practices (Heberer, 2002). They are also applied to some extent to delineate catchment areas, relationships between surface and groundwater, or to quantify mass fluxes of a certain compound on a catchment area (e.g., Zuccato et al., 2005) and consequently volumes or masses of discharged wastewater. The analysis of specific compounds is primordial in the assessment of specific vulnerability especially if the compound is a suitable indicator for a certain type of contaminant (e.g., Gasser et al., 2010). 


\subsection{CONCEPTUALIZATION AND NUMERICAL MOdelLING OF KARST AQUIFERS}

The investigated geometry, flow and transport parameters of a karst aquifer (Section 2.3, Table 2-5) can be translated and input into conceptual models, then to numerical models for a comprehensive understanding of the karst system. A conceptual model can be defined as a discretization of a system into a sequence of compartments, where water is added, removed or exchanged (White, 2003; Figure 2-12). Conceptual models can be transferred to mathematical models that enable quantification of water budgets and hydrological prediction. Mathematical models can be divided into stochastic and process-based. Examples of stochastic models are black box models that investigate input and output in a karst system based on statistical means without providing insights to processes that take place in the hydrological cycle (Dreiss, 1982).

\section{Table 2-5 Main methods used to characterize karst aquifers for vulnerability purposes}

\begin{tabular}{|lcccc|}
\hline & $\begin{array}{c}\text { Artificial } \\
\text { tracer tests }\end{array}$ & $\begin{array}{c}\text { Field Investigations } \\
\text { (pumping tests) }\end{array}$ & $\begin{array}{c}\text { Spring response } \\
\text { analysis }\end{array}$ & $\begin{array}{c}\text { Numerical } \\
\text { Geometry }\end{array}$ \\
Flow & $\checkmark$ & $\checkmark$ & $\checkmark$ & $\checkmark$ \\
parameters & & $\checkmark$ & $\checkmark$ & $\checkmark$ \\
$\begin{array}{l}\text { Transport } \\
\text { parameters }\end{array}$ & $\checkmark$ & $\checkmark$ & $\checkmark$ \\
$\begin{array}{l}\text { Karst specific } \\
\text { mechanisms } \\
\text { (fast flow etc...) }\end{array}$ & $\checkmark$ & & & \\
\hline
\end{tabular}

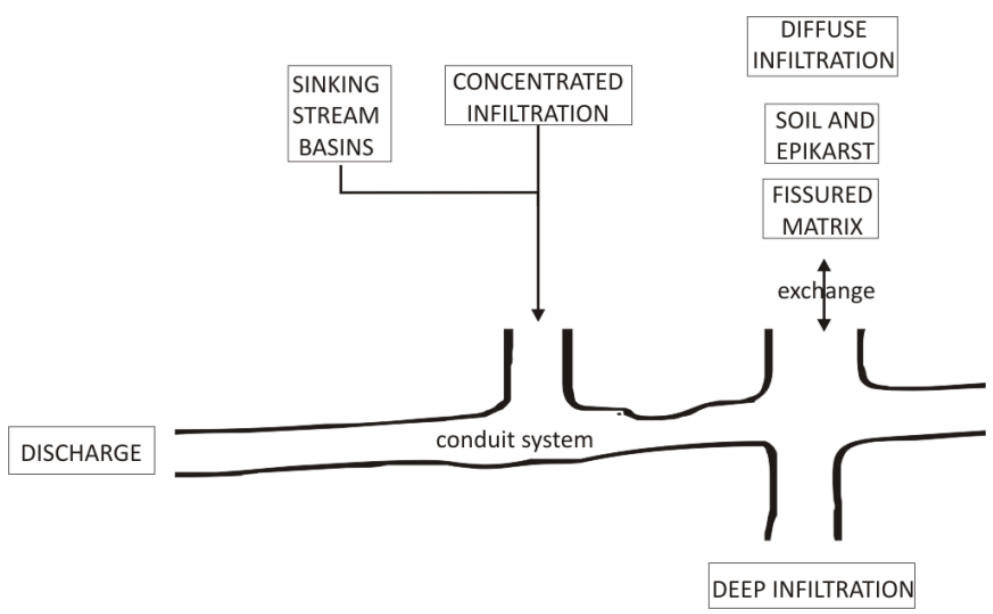

Figure 2-12 Example of a conceptual model of a karst aquifer (modified from White, 2003)

A process based numerical model incorporates all processes (evapotranspiration, recharge, etc.) to assess signal transmission (flow and transport) through all the compartments (Figure 2-13) and to define the relationship between them (Teutsch and Sauter, 1991, Kiraly, 1998). They mostly rely on empirical or physical principles. Process based models can be spatially lumped or distributed. Spatially distributed models require an extensive amount of data (geometry, parameterization, location of past flow pathways etc.), therefore it 
can only be applied in well investigated catchment areas, whereas lumped models will consider the entire catchment as being one entity. The process based approach assumes that all the hydraulic processes highly influence the hydraulic signal in the different compartments of a hydrological cycle (Figure 2-13) and are therefore of high relevance to intrinsic vulnerability. In this perspective, many authors have suggested that numerical models should be used as efficient tools for the calibration and validation of vulnerability methods (Goldscheider, 2002, Zwahlen, 2004, Neukum et al., 2008); especially the spatially distributed process based Modelling approach (Doummar et al., 2012).

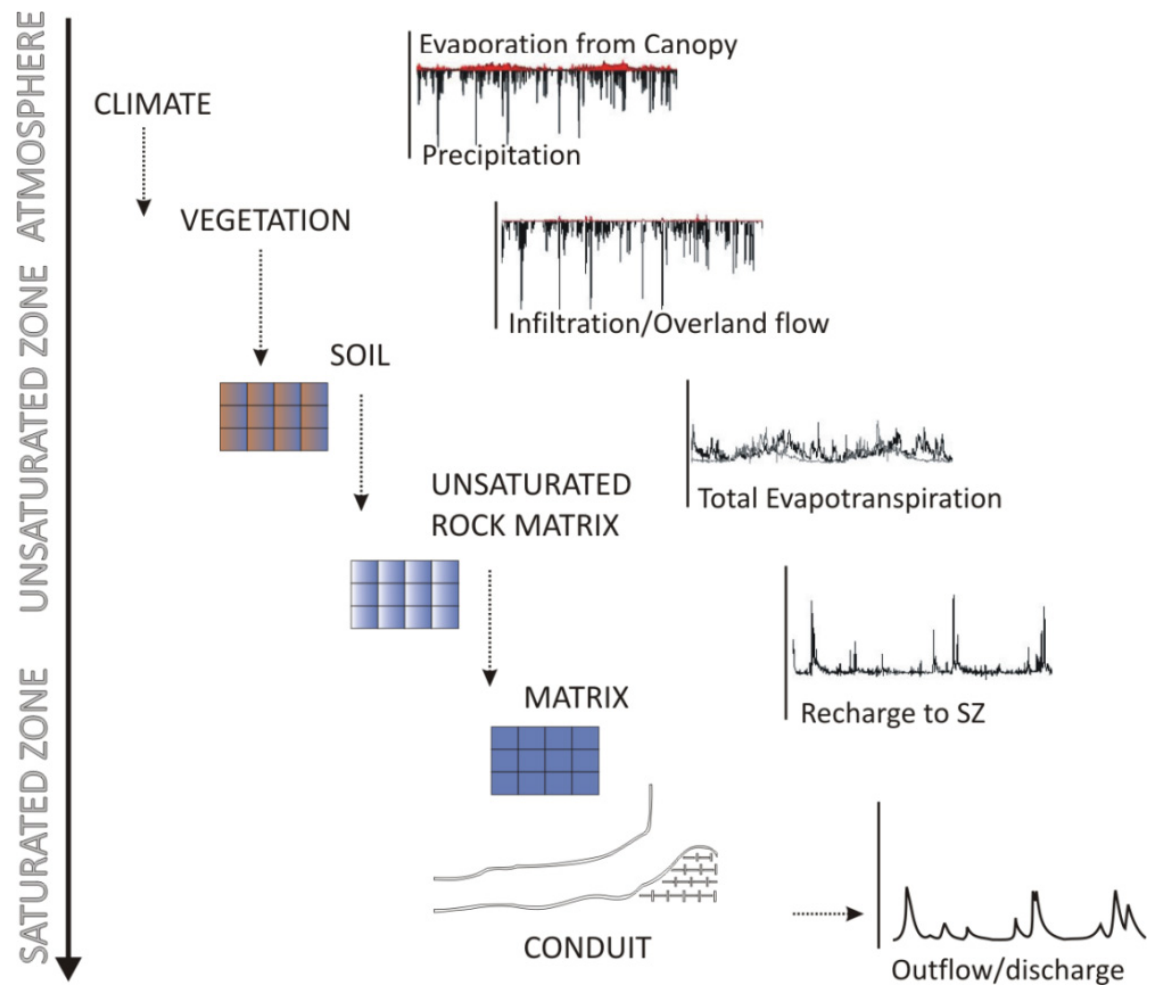

Figure 2-13 Signal transmission within the compartments of a karst system

\subsection{References}

Aller, L., Bennett, T., Lehr, J. H., Petty, R.H., and Hackett, G., 1987. DRASTIC: A standardized system for evaluating groundwater pollution potential using hydrogeologic settings. US EPA Report600/2-87/035, Robert S. Kerr Environmental Research Laboratory, Ada, Oklahoma

Ashton, K., 1966. The analysis of flow data from karst drainage systems. Transaction of the Cave Research Group of Great Britain, 7, no. 2: 161-203

Atkinson, T.C., 1977. Diffuse flow and conduit flow in limestone terrain in Mendip Hills, Somerset, England. Journal of Hydrology, 35: 93-100

Baedke, S.J., and Krothe, N.C., 2001. Derivation of effective hydraulic parameters of a karst aquifer from discharge hydrograph analysis. Water Resources Research, 37, no. 1: 13-19

Bakalowicz, M., 2005. Karst groundwater: a challenge for new resources, Hydrogeology Journal, 13: 148-160.

Brosig, K., Geyer, T., Subah, A., and Sauter, M., 2008. Travel time based approach for the assessment of vulnerability of karst groundwater: the Transit Time Method. Environmental Geology, 54, no. 5: $905-911$ 
Butscher, C., and Huggenberger, P., 2009. Enhanced vulnerability assessment in karst areas by combining mapping with Modelling approaches. Science of the Total Environment, 407, no. 3: 1153-1163

Civita, M., 2010. The combined approach when assessing and mapping groundwater vulnerability to contamination. Journal of Water Resource and Protection, 2: 14-28

Civita, M., and De Maio, M., 1997. SINTACS Un sistema parametrico per la valutazione e la cartografia per la valutazione della vulnerabilita degli acquiferi all'inquinamento, Metodologia e automazione, Pitagora Ed., Bologna: 191pp

COST: Action 620, 2003. Vulnerability and risk mapping for the protection of carbonate (karst) aquifers, European Commission, Directorate-General for Research, Report EUR 20912, Luxemburg (2003)

Doerfliger, N., Jeannin, P.Y., and Zwahlen, F., 1999. Water vulnerability assessment in karst environments: a new method of defining protection areas using a multi-attribute approach and GIS tools (EPIK method), Environmental Geology, 39, no. 2: 165-176

Doummar, J., Sauter, M., and Geyer, T., 2012. Simulation of flow processes in a large scale karst system with an integrated catchment model (Mike She) - Identification of relevant parameters influencing spring discharge. Journal of Hydrology, 426-427: 112-123

Doummar, J., Geyer, T., and Sauter, M., 2012a. Protection of the Jeita Spring: Vulnerability mapping using the COP and EPIK Methods. Special report VI. Protection of the Jeita Spring. Applied Geosciences. Georg August University, Göttingen

Dreiss, S., J., 1982. Linear kernels for karst aquifers. Water Resources Research, 18, no. 4: 865-876

Field, M.S., 1990. Transport of Chemical Contaminants in Karst Terranes: Outline and Summary. in Selected Papers on Hydrogeology, edited by E. S. Sharp and J.M. Sharp, Jr, 1: 17-27

Foster, S., S., D., 1987. Fundamental concepts in aquifer vulnerability, pollution risk and protection strategy. In: van Duijvenbooden W, van Waegeningh HG (eds) Vulnerability of soil and groundwater to pollutants. Proceedings and Information no. 38, TNO Committee on Hydrological Research, The Hague: 69-86

Gasser, G., Rona, M., Voloshenko, A., Shelkov, R., Tal, N., Pankratov, I., Elhanany, S., and Lev, O., 2010. Quantitative evaluation of tracers for quantification of wastewater contamination of potable water sources. Environmental Science Technology, 44, no. 10: 3919-3925

Geyer, T., 2008. Process based characterization of flow and transport in karst aquifers at catchment scale. Ph.D. Dissertation, Mathematisch-naturwissenschaftliche Fakultäten. Georg-August-Universität Göttingen. $103 p p$

Geyer, T., Birk S., Licha T., Liedl R., and Sauter M., 2007. Multitracer Approach to Characterize Reactive Transport in Karst Aquifers. Groundwater, 35, no. 1: 35-45

Goldscheider, N., 2002. Hydrogeology and vulnerability of karst systems: examples from the Northern Alps and Swabian Alb. Ph.D. Thesis, Schr. Angew. Geol Karlsruhe, Karlsruhe, 236pp

Goldscheider, N., Klute, M., Sturm, S., and Hötzl, H., 2000. The PI method- a GIS-based approach to mapping groundwater vulnerability with special consideration of karst aquifers. Zeitschrift für Angewandte Geologie, 46: 157-166

Goldscheider, N., Meiman, J., Pronk, M., and Smart, C., 2008. Tracer tests in karst hydrogeology and speleology. International Journal of Speleology, 37, no. 1: 27-40 
Göppert, N., and Goldscheider, N., 2008. Solute and colloid transport in karst conduits under low- and highflow conditions. Ground Water, 46, no. 1: 61-68

Grasso, A., and Jeannin P.Y., 2002. A global experimental system approach of karst springs hydrographs and chemographs. Groundwater. 40, no. 6: 608-617

Heberer, T., 2002. Occurrence, fate, and removal of pharmaceutical residues in the aquatic environment: a review of recent research data. Toxicology Letter, 131: 5-17

Jeannin, P.Y., Cornaton, F., Zwahlen, F., and Perrochet, P., 2001. 7th Conference on Limestone Hydrology and Fissured Media Mémoires hors Série, (Université de Franche-Comté, Besançon), VULK: a tool for intrinsic vulnerability assessment and validation, eds Zwahlen F., Mudry J. 13: 185-188

Jobson, H., 1997. Prediction of travel time and longitudinal dispersion in rivers and streams. Journal of Hydraulic Engineering, 123, no. 11: 971-978

Kilpatrick, F.A., 1993. Simulation of soluble waste transport and buildup in surface waters using tracers: U.S. Geological Survey Techniques of Water-Resources Investigations, book 3, 37

Kiraly, L., 1998. Introduction à l'hydrogéologie des roches fissurées et karstiques, Bases théoriques à l'intention des hydrogéologues. Université de Neuchâtel, Manuscrit

Kiraly, L., 2002. Karstification and Groundwater flow. In: Proceedings of the conference on Evolution of Karst: From Prekarst to Cessation. Postojna-Ljubljana: 155-190.

Maillet, E., 1905. Essais d'hydraulique souterraine et fluviale. Librairie Sci., A. Hermann, Paris, 218pp

Malík, P., and Vojtková, S., 2007. Physically- based intrinsic groundwater resource vulnerability map of the Tisovec karst. In. Groundwater vulnerability assessment and mapping. eds Witkowski, A., Kowalczyk, A and Vrba, J.: 223-234

Maloszewski, P., and Zuber, A., 1992. On the calibration and validation of mathematical models for the interpretation of tracer experiments in groundwater. Advances in Water Resources, 15: 47-62

Margat, J., 1968. Contamination vulnerability mapping of groundwater, Bureau de Recherches Geologiques et Minieres, Orleans

Morales, T., Fdez de Valderram, I., Uriate, J. A., Antigüedad, I., and Olazar, M., 2007. Predicting Travel Time and Transport Characterization in Karst Conduits by Analyzing Tracer- breakthrough Curves. Journal of Hydrology, 334: 183-198

Mull, R., 1981. Ground-Water Protection Zones. GeoJournal, 5, no. 5: 473-481

Neukum, C., Hötzl, H., and Himmelsbach, T., 2008. Validation of vulnerability mapping methods by field investigations and numerical Modelling. Hydrogeology Journal, 16: 641-658

Padilla, A., Pulio-Bosch, A., and Mangin, A., 1994. Relative importance of baseflow and quickflow from hydrographs of karst springs. Ground Water, 32: 267-277

Perrin, J., Jeannin, P.-Y., and Zwahlen, F., 2003. Epikarst storage in a karst aquifer: a conceptual model based on isotopic data, Milandre test site, Switzerland. Journal of Hydrology, 279: 106-124

Polemio, M., Casarano, D., and Limoni, P.P., 2009. Karstic aquifer vulnerability assessment methods and results at a test site (Apulia, southern Italy). Natural Hazards Earth System Science. 9: 1461-1470 
Pronk, M., Goldscheider, N., and Zopfi, J., 2007. Particle-size distribution as indicator for fecal bacteria contamination of drinking water from karst springs. Environmental Science Technology, 41: 8400-8405

Sauter, M., 1992. Quantification and forecasting of regional groundwater flow and transport in a karst aquifer (Gallusquelle, Malm, SW. Germany). Tübinger Geowissenschaftliche Arbeiten, C13, 150 pp

Sauter, M., 1997. Differentiation of fast and slow flow components in a karst aquifer using the $\delta^{18} \mathrm{O}$ signatureData analysis and Modelling. In Kranjc, A. (Ed.) Tracer Hydrology 97, Balkema: 435-441

Smart, C.C., 1988. Artificial tracer techniques for the determination of the structure of conduit aquifers. Ground Water, 26: 445-453

Smart, P.L., and Hobbs, S.L., 1986. Characterization of carbonate aquifers: a conceptual base, in Environmental problems in karst terranes and their solutions conference (1st, Bowling Green, Kentucky): Dublin, Ohio, National Water Well Association: 1-14

Teutsch, G., and Sauter, M., 1991. Groundwater modelling in karst terranes: Scale effects, data acquisition and field validation. Proc $3^{\text {rd }}$ Conf. on hydrogeology, ecology, monitoring and management of groundwater in karst terranes. Nashville: 17-35

Vías, J. M., Andreo, B., Perles, M. J., Carrasco, F., Vadillo, I., and Jiménez, P., 2006. Proposed method for groundwater vulnerability mapping in carbonate (karstic) aquifers: the COP method Application in two pilot sites in Southern Spain, Hydrogeology Journal, 14: 912-925

White, W.B., 2003. Conceptual models for karstic aquifers, in A.N. Palmer, M.V. Palmer, and I.D. Sasowsky (eds.), Karst Modelling: Charles Town, West Virginia, The Karst Waters Institute Special Publication, 5: 1116.

Williams, P.W., 1983. The role of the subcutaneous zone in karst hydrology. Journal of Hydrology, 61: $45-67$.

Zuccato, E., Chiabrando, C., Castiglioni, S., Calamari, D., Bagnati, R., and Schiarea, S., 2005. Cocaine in surface waters: a new evidence-based tool to monitor community drug abuse. Environmental Health, 4: 14.

Zwahlen, F., (ed.) 2004. Vulnerability and risk mapping for the protection of carbonate (karst) aquifers. COST action 620 Final report. Office for Official Publications of the European Communities, Luxembourg-XVIII: 297 


\section{SIMULATION OF FLOW PROCESSES IN A LARGE SCALE KARST SYSTEM WITH AN INTEGRATED CATCHMENT MODEL (MIKE SHE) - IDENTIFICATION OF RELEVANT PARAMETERS INFLUENCING SPRING DISCHARGE}

Doummar, Joanna $^{1^{*}}$, Sauter, Martin ${ }^{1}$, Geyer, Tobias $^{1}$

(1) Geowissenschaften Zentrum, University of Göttingen, Goldschmidtstr. 3, D-37077 Göttingen, Germany;

*Corresponding author: e-mail: jdoumma@gwdg.de; Phone: (49) 551 397913; Fax: (49) 551399379.

\section{Publication:}

Doummar, J., Sauter, M., Geyer, T., 2012. Simulation of flow processes in a large scale karst system with an integrated catchment model (Mike She) - Identification of relevant parameters influencing spring discharge, Journal of Hydrology, 426-427: 112-123 


\section{Keywords}

Karst; hydrological cycle; integrated modelling; sensitivity analysis

\section{Abstract}

In a complex environment such as karst systems, it is difficult to assess the relative contribution of the different components of the system to the hydrological system response, i.e. spring discharge. Not only is the saturated zone highly heterogeneous due to the presence of highly permeable conduits, but also the recharge processes. The latter are composed of rapid recharge components through shafts and solution channels and diffuse matrix infiltration, generating a highly complex, spatially and temporally variable input signal. The presented study reveals the importance of the compartments vegetation, soils, saturated zone and unsaturated zone. Therefore, the entire water cycle in the catchment area Gallusquelle spring (Southwest Germany) is modeled over a period of ten years using the integrated hydrological modelling system Mike She by $\mathrm{DHI}, 2007$. Sensitivity analyses show that some individual parameters, varied within physically plausible ranges, play an important role in reshaping the recessions and peaks of the recharge functions and consequently the spring discharge. Vegetation parameters especially the Leaf Area Index (LAI) and the root depth as well as empirical parameters in the relationship of Kristensen and Jensen highly influence evapotranspiration, transpiration to evaporation ratios and recharge respectively. In the unsaturated zone, the type of soil (mainly the hydraulic conductivity at saturation in the water retention and hydraulic retention curves) has an effect on the infiltration/evapotranspiration and recharge functions. Additionally in the unsaturated karst, the saturated moisture content is considered as a highly indicative parameter as it significantly affects the peaks and recessions of the recharge curve. At the level of the saturated zone the hydraulic conductivity of the matrix and highly conductive zone representing the conduit are dominant parameters influencing the spring response. Other intermediate significant parameters appear to influence the characteristics of the spring response yet to a smaller extent, as for instance bypass and the parameters $\alpha$ in the Van Genuchten relation for soil moisture content curves.

\subsection{INTRODUCTION}

Each karst catchment is considered unique, as karst features vary significantly from one catchment to another (Ford and Williams, 2007). These variations play a major role in shaping the karst spring discharge curve, therefore physically-based simulation of flow in such systems requires considerable knowledge and investigation about specific hydraulic parameters at a catchment scale. Rapid groundwater flow in karst aquifers is concentrated in the highly permeable conduit system. Low permeability fissured matrix blocks provide aquifer storage. Additionally, karst aquifers are characterized by a duality of recharge (concentrated; fast versus diffuse; slow), which directly influences groundwater flow and spring responses (Atkinson, 1977; Kiraly, 2002). 
Given their complexity, various models focused on simulating flow in the saturated zone in karst systems (Teutsch and Sauter, 1998; Scanlon et al. 2003). Lumped parameter approaches and conceptual models successfully simulated karst spring responses to precipitation events (Jukić and Denić-Jukić, 2004; Geyer et al., 2008). Due to the lack of spatially distributed information on the hydraulic parameter field in karst systems, the application of distributed parameter models is often limited to strongly simplified case studies or parameter studies (e.g. Birk et al., 2005; Reimann and Hill, 2009). However, these models focus only on the simulation of groundwater flow while recharge input is calculated independently, e.g. from simple water balance approaches. In the latter case, most of the physical processes occurring in the soil and unsaturated zone after a precipitation event, are not accounted for. Moreover, different studies show the importance of the unsaturated zone (soil and unsaturated karst; Perrin et al., 2003) for discharge responses and the effect of land surface parameters such as vegetation and soil parameters on the groundwater recharge (Finch, 1998; Sahoo, 2006). In porous aquifers, water balance models relying on lumped parameters were used to calculate the different components of the hydrological cycle such as reference evapotranspiration, interception by canopy, evaporation from soil, runoff, and infiltration to groundwater (Beven, 1979; Finch, 1998). Other integrated distributed models (Sciuto and Diekkrüger, 2010) attribute spatially variable parameters, when available over the entire catchment. The principles adopted in the different models are either empirical (e.g., Kristensen and Jensen empirical model for evapotranspiration) or physically based, (e.g., Van Genuchten for soil characterization). The objective of the modelling in the present work is to better conceptualise and consequently understand the temporally and spatially variable processes as well as their superposition in a karst system at catchment scale and their respective influence on the outflow of a karst system, i.e. spring discharge. In contrast to former studies, water flux through the compartments vegetation, unsaturated zone, and saturated zone is simulated with an integrated distributed numerical modelling approach. Important parameters, which control water flux through each compartment, are successively elaborated by an extensive sensitivity analysis.

The numerical code Mike She (DHI, 2007) was applied and adapted to phenomena found in karst systems. Simulations were performed in a well studied catchment area to reduce the ambiguities and uncertainties resulting from the lack of data, and to account for the spatial variability of all the physical characteristics and processes involved.

\subsection{Methods}

Mike She is a modelling tool developed by $\mathrm{DHI}$ (DHI, 2007), which allows the simulation of flow and transport in catchment areas taking into consideration the different processes occurring in the complete hydrological cycle. In Mike She water flow in the different compartments is simulated by physically based processes or different empirical relationships.

In this study, the Mike She approach is applied for simulation of flow in a karst system at catchment scale. The catchment area of a karst spring is sub-divided vertically into three main compartments (Figure 3-1): atmosphere (A), unsaturated zone (UZ), and saturated zone (SZ). The first domain atmosphere includes the climatic processes (rainfall, snow, evapotranspiration) and interception by vegetation. The second represents 
the unsaturated zone below land surface. The domain is subdivided into an upper and a lower layer. The upper layer is characterized by the physical properties of the soils and the epikarst. The lower layer exhibits the properties of the unsaturated rock matrix. The bypass function provided by Mike She allows for the simulation of the fast flow component (rapid recharge), by rooting infiltrating water directly to the groundwater table. The saturated zone is regarded as a third domain. The saturated zone is simulated as a continuum, with incorporated zone of high hydraulic conductivity representing pathways of high ground water velocities (e.g., conduits).

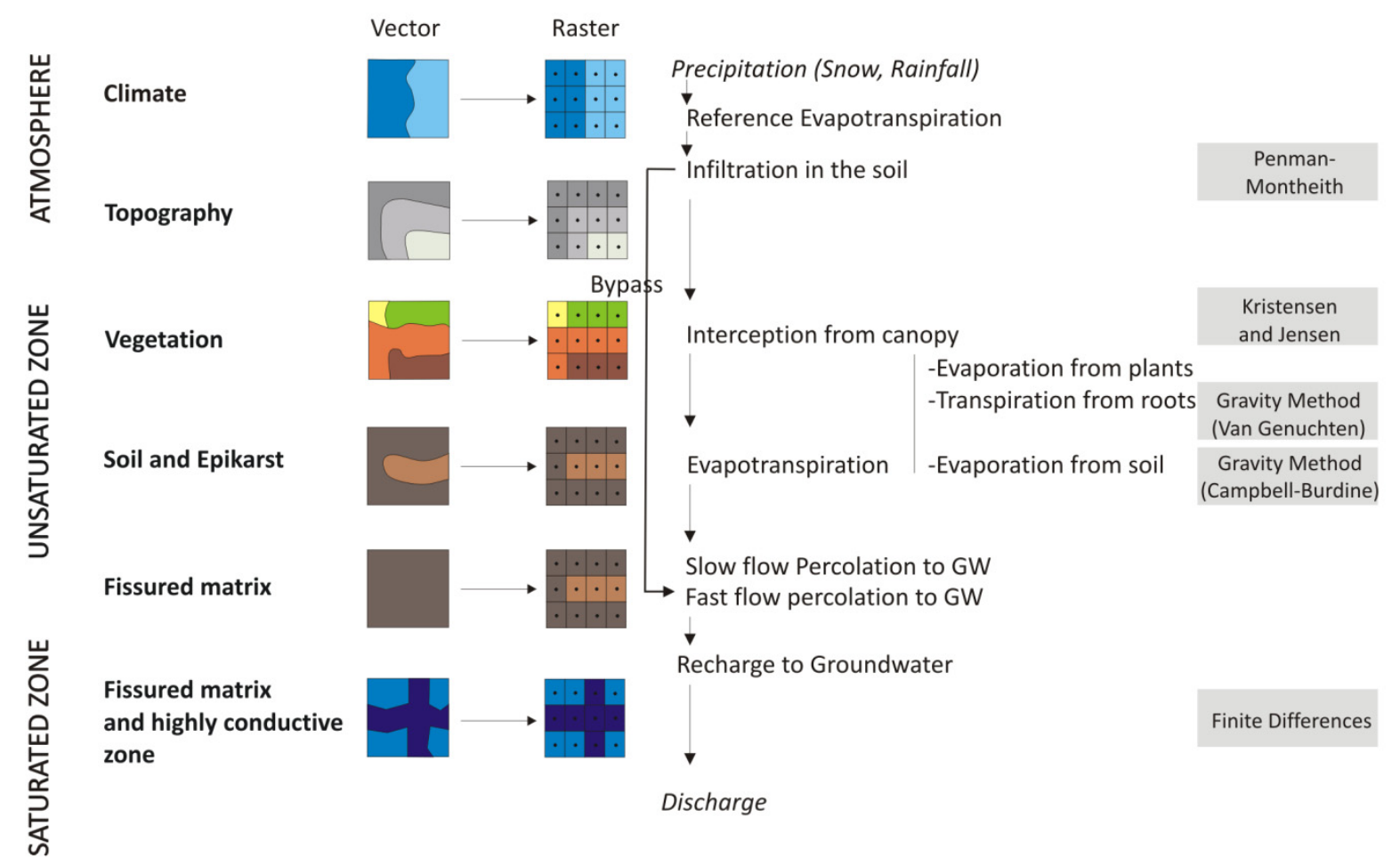

Figure 3-1 Schematic Representation of MIKE-SHE Modelling Principles (adapted from Mike-She User Manual, 2007)

\subsubsection{Compartments}

The three compartments (atmosphere, unsaturated zone, and saturated zone) are defined in terms of geometry and accordingly parameterized as shown in the following section.

The model geometry includes information about the spatial distribution of topography, land use, soil, and the geology. The geometry was set up using polygons that define the boundaries between three main compartments atmosphere, unsaturated zone and saturated zone. The vector layers are processed by Mike She and transformed into gridded files.

\subsubsection{Atmosphere}

Daily data provided from climatic stations at various altitudes, are extrapolated over the entire catchment linearly based on altitude of the weather station and corrected for elevation. Precipitation occurs as either 
rainfall or snow depending on air temperature. For the calculation of snow formation and snow melt, the model requires a degree day coefficient that is derived from literature (Brubaker et al., 1996).

Reference evapotranspiration is calculated following the Penman-Monteith method based on daily climatic data (such as solar radiation, temperature, relative humidity, wind velocity, sunshine hours and cloud cover). Canopy interception and evapotranspiration are mainly related to the type of vegetation and soil. For each type of vegetation yearly records of seasonally variable Leaf Area Index (LAI) and depth to roots (Root) (Zhang et al., 2008, Canadell et al., 1996) are available. Evapotranspiration can be divided into three main components namely: evaporation from canopy, transpiration from plants, and evaporation from soils. The three components are based on a model developed on empirical equations by Kristensen and Jensen (1975). The main parameters required for this model are $C_{1}, C_{2}, C_{3}$, canopy interception $\left(C_{\text {int }}\right)$ and root shape factor $\left(A_{\text {Root }}\right)$. $C_{1}$ and $C_{2}$ regulate the ratio of evaporation to transpiration and $C_{3}$ is an empirical parameter, i.e. not directly measurable. The Kristensen and Jensen parameters were considered constant over the entire catchment (DHI, 2007). The transpiration from roots $\left(E_{a t}\right)$ is defined according to equation 1 . The evaporation from soil is controlled by equation 2 .

$$
\begin{aligned}
& E_{a t}=f_{1}(L A I) \cdot f_{2}(\theta) \cdot R D F \cdot E_{p} \\
& \left\{\begin{array}{l}
f_{1}(L A I)=C_{2}+C_{1} L A I \\
f_{2}(\theta)=1-\frac{\left(\theta_{F C}-\theta\right)}{\left(\theta_{F C}-\theta_{w}\right)} \frac{c_{3}}{E_{p}}
\end{array}\right. \\
& E_{s}=E_{p} \cdot f_{3}(\theta)+\left(E_{p}-E_{a t}-E_{p} \cdot f_{3}(\theta)\right) \cdot f_{3}(\theta) \cdot\left(1-f_{1}(L A I)\right)
\end{aligned}
$$

$f_{1}$ is a function of the Leaf Area Index (LAI) provided seasonally for each type of crop, $C_{1}$, and $C_{2}$, and $f_{2}$ is a function of the soil moisture content, where $\theta_{\mathrm{FC}}$ and $\theta_{\mathrm{w}}$ are the moisture content at respectively field capacity and at the wilting point.

RDF (Root Distribution Function) determines the distribution of roots with depth and $E_{p}$ is the potential evapotranspiration. $f_{3}$ is a function of $C_{2}$ and moisture content, whereas $f_{4}$ is a function of moisture content (DHI, 2007).

\subsubsection{Unsaturated zone (UZ)}

The unsaturated zone domain was modelled using the gravity module. The approach is a simplification of the Richards equation, where the driving force for vertical flow is entirely due to gravity. It assumes a uniform vertical unit gradient flow, where capillarity is ignored (Grahams and Butts, 2005). The module requires a vertical discretization of the unsaturated zone into cells of maximum size of $1 \mathrm{~m}$. The unsaturated zone was divided into two main layers representing the soil cover/epikarst and the unsaturated fissured rock matrix. The hydraulic conductivity and the moisture retention curve for the upper soil layer were defined based on the Van 
Genuchten model (Van Genuchten, 1980). Given the type of soil and proportion of soil textures of the soil, the Genuchten parameters can be estimated (e.g., Hydrus-2D, 1999, Šimůnek et al., 1998).

$$
\begin{aligned}
& \theta(\psi)=\theta(r)+\frac{(\theta s-\theta r)}{\left.\left.1+(\alpha \psi)^{n}\right)^{m}\right]} \\
& K(\psi)=K_{s} \frac{\left(\left(1+|\alpha \psi|^{n}\right)^{m}-|\alpha \psi|^{n-1}\right)^{2}}{\left[1+|\alpha \psi|^{n}\right]^{m(1+2)}}
\end{aligned}
$$

Where $K_{s}$ hydraulic conductivity at saturation in vertical direction $(\mathrm{m} / \mathrm{sec}), \psi$ pressure head $(\mathrm{m}), \theta_{\mathrm{s}}$ saturated moisture content, $\theta_{\mathrm{r}}$ residual moisture content, and $\alpha(1 / \mathrm{m}), \mathrm{n}(-), \mathrm{m}(\mathrm{m})$ being constants.

Roulier et al. (2006) propose Van Genuchten parameters for each of the unsaturated rock matrix and fractures. However, at catchment scale the fissured matrix of karst systems is regarded as one continuum. As it is not possible to measure Van Genuchten parameters for fissured matrix blocks, unsaturated zone parameters were considered as calibration parameters. The retention curve and hydraulic conductivity curve for the unsaturated zone were defined based on Campbell - Burdine equations (Campbell, 1974) as it relies only on two fitting parameters the particle index $(\lambda)$ and the bubbling pressure $\left(\psi_{\mathrm{b}}\right)$. Additional parameters required are the hydraulic conductivity at saturation, which is known from hydraulic borehole tests and the saturated moisture content that corresponds to the porosity. According to Campbell (1974), the hydraulic conductivity varies as a function of the air entry water potential (bubbling pressure; Stakman, 1966), which is a function of the pore diameter and water surface tension. According to the moisture retention curves plotted with varying particle index, an increasing $\lambda$ favors higher saturation moisture contents and therefore allow a higher water retention and greater gravitational flow in the unsaturated karst layer (Figure 3-2). Bubbling pressures relative to fine sand porosities were adopted for the unsaturated rock matrix, especially in the absence of the characteristics of hydraulic conductivity and moisture retention curve of the latter.

Equations 5 and 6 show respectively the moisture and hydraulic conductivity curve as a function of pressure head in the unsaturated rock matrix.

$$
\begin{aligned}
& \theta(\psi)=\frac{\theta s}{\left[1+\left(\frac{\psi}{\psi b}\right)^{5}\right]^{\frac{\lambda}{5}}} \\
& K(\psi)=K_{s}\left(\frac{\psi_{b}}{\psi}\right)^{(2+3 \lambda)}
\end{aligned}
$$


where Ks as the hydraulic conductivity at saturation $(\mathrm{m} / \mathrm{sec}), \psi$, the pressure head $(\mathrm{m}), \theta \mathrm{s}$, the saturated moisture content, $\psi_{\mathrm{b}}$ the bubbling pressure $(\mathrm{m}) ; \psi_{\mathrm{b}}=30 \mathrm{Y} / \mathrm{D}$ ( $\mathrm{D}$ being the pore diameter in microns and $\mathrm{D}$ being the water surface tension in dynes/cm), and $\lambda$, the particle index.
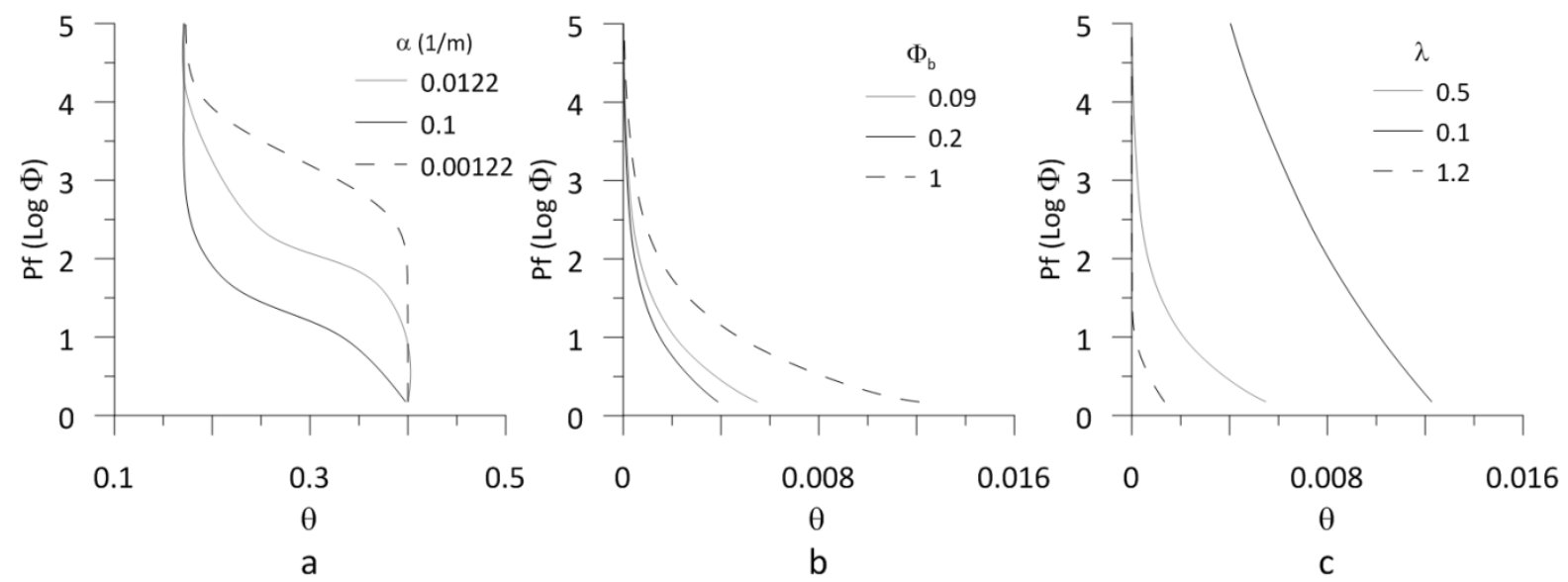

Figure 3-2 Moisture Retention Curves based on Van Genuchten for Soil and Campbell for unsaturated rock matrix showing effect of parameter variation on the curve shape. (a: Soil- Van Genuchten; $\mathbf{n = 2}$, $\theta s=0.395, \theta r=0.171 ; b$ : unsaturated rock matrix- Campbell; $\lambda=0.5, \theta s=0.015$, c: unsaturated rock matrixCampbell; $\psi_{\mathrm{b}}=0.2, \theta \mathrm{s}=0.015$ )

The fast flow component, i.e. that proportion of water diverted directly from the upper soil into the saturated soil, bypassing the unsaturated zone was simulating using the bypass component. This proportion can be estimated for a spring catchment area based on the combined discharge and isotopic water analysis at a spring (Sauter, 1997). The fast flow component is uniformly applied over the entire catchment. The bypass component such as moisture content for reduced bypass flow and minimum water content for bypass flow were regarded as calibration parameters.

\subsubsection{Saturated zone}

The saturated zone module relies on the 3-D Darcy's equation (Equation 7) solved numerically using the finite difference model using the preconditioned conjugate gradient (PCG) solver.

$S \frac{\partial h}{\partial t}=\frac{\partial}{\partial x}\left(K_{x} \frac{\partial h}{\partial x}\right)+\frac{\partial}{\partial y}\left(K_{y} \frac{\partial h}{\partial y}\right)+\frac{\partial}{\partial z}\left(K_{z} \frac{\partial h}{\partial z}\right)-Q$

Where $K_{x}, K_{y}$, and $K_{z}(m / s)$ are the hydraulic conductivities in three dimensions, $h$ is the hydraulic head $(m), Q$ is the sink or source term $(\mathrm{m} / \mathrm{s})$, and $S$ is the specific storage $(1 / \mathrm{m})$.

The saturated zone is discretized into three main layers (matrix), with a highly conductive zone representing the conduit system.

The hydraulic parameters were regarded either as physical parameters or as calibration parameters. The former were varied only within a defined range not exceeding field results data, e.g., hydraulic conductivities of the matrix and the specific yield (from pumping tests) etc., the later being very difficult to assess in the field 
were regarded as calibration parameters and varied within larger ranges, e.g. the conductivity of highly conductive zone $(0.1-10 \mathrm{~m} / \mathrm{s})$.

Specific storage was considered relatively low ranging between $10^{-5}$ and $10^{-6} 1 / \mathrm{m}$ (Batu, 1998). Same values for specific yield were adopted for both highly conductive zone and matrix by considering a continuum for both, thereby decreasing the number of fitting parameters. The water filled conduit volume of the matrix can be estimated from artificial tracer test (Geyer et al., 2008) and is translated into the cell volume of the numerical model considering the specific yield.

\subsubsection{Data processing}

Because of the large demand of input parameters for the catchment model, parameters were grouped into measured and calibrated parameters. Measured parameters vary within a restricted range and are based on field investigations documented in literature. Calibration parameters are physical parameters that cannot be measured in the field, e.g. Van Genuchten parameters for the fissured matrix. The parameters vary within a wider range that is refined solely by calibration (Table 3-1). The influence of the parameters on model results is evaluated with a comprehensive sensitivity analysis.

Table 3-1 Parameters obtained for the best fit simulation and ranges for sensitivity analysis. Type of parameters are separated into measured/literature values and fitted values.

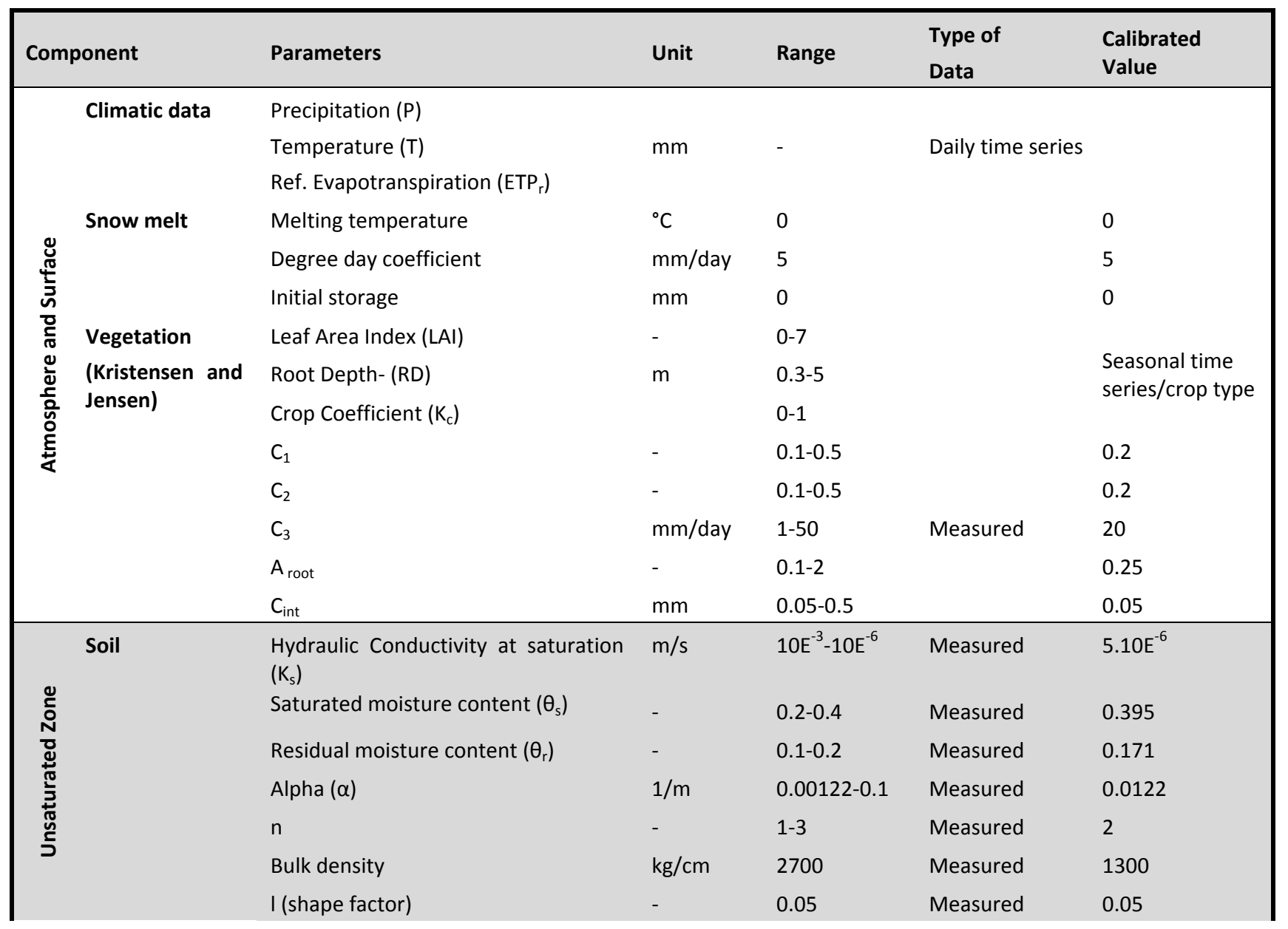




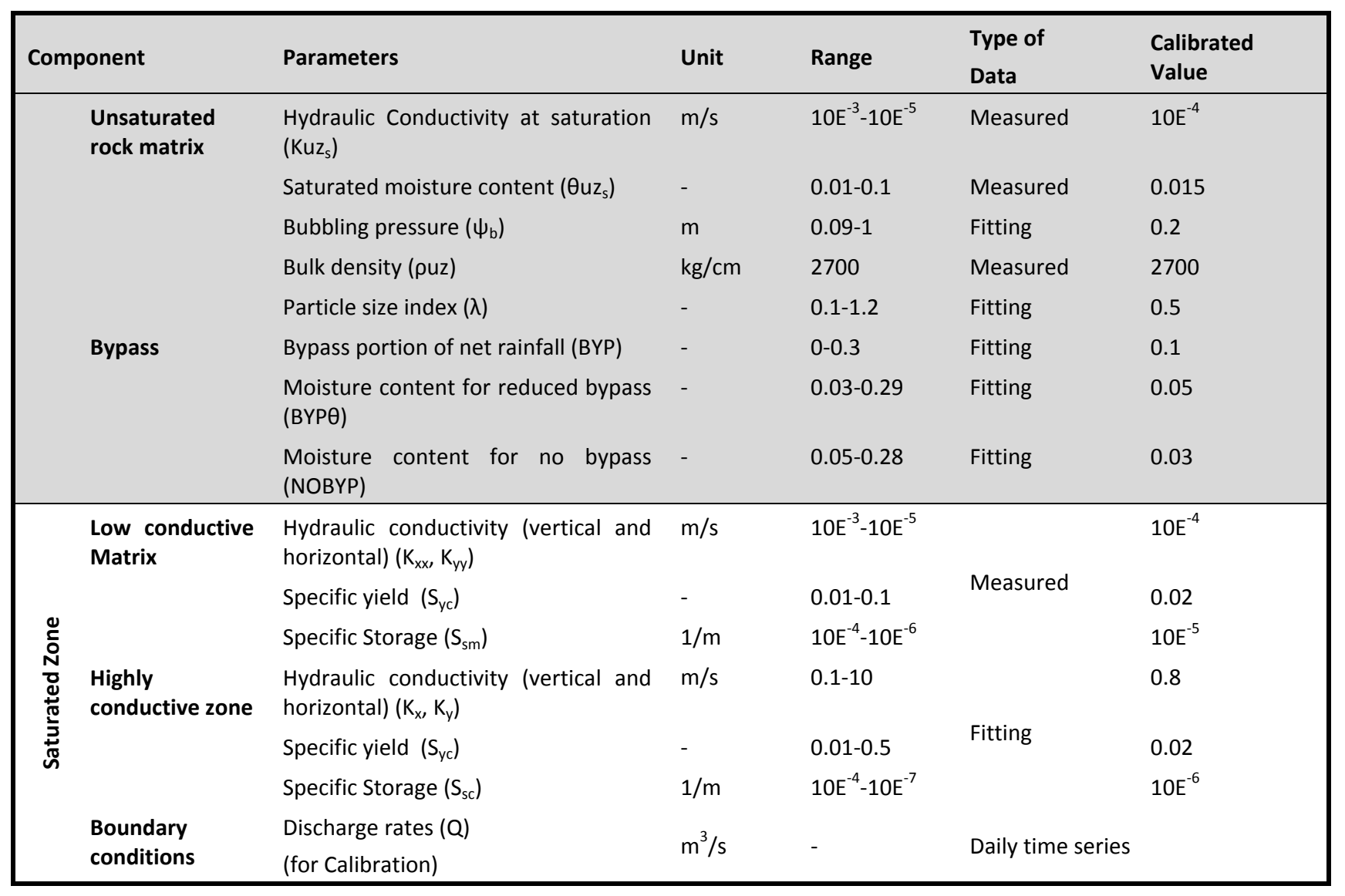

\subsubsection{Calibration and sensitivity analysis}

As a result of their genetic history, flow in large scale karst catchments is often focused into single outlets (Jeannin and Sauter 1998). Therefore, the measurement of discharge on a karst spring allows an integral characterization of the hydraulic and geometric properties as well as the characterization of the recharge response of a karst aquifer.

Observed discharge values at the spring were regarded as objective function for the calibration. Therefore simulated and observed discharge values were compared using two objective functions, the Residual Mean Square Error (RMSE; Equation 8), percentage error in total volume (\%, Equation 9) to acquire a yearly water balance in order to compare the observed and calibrated discharged volumes.

The selection of a best fit was done visually by comparing the residual error and the curve shapes in both peak and recession flow as well. The AutoCal Module for automatic calibration was used to optimize the set of potential best fits obtained.

$$
\begin{aligned}
R M S E_{i} & =\frac{\sqrt{\sum_{t}\left(o b s_{i, t}-\operatorname{Sim}_{i, t}\right)^{2}}}{n} \\
\text { \%error }_{v} & =100 \frac{\left(\left|\int_{0}^{t} Q_{\text {spring }} d t-\int_{0}^{t} Q_{\text {sim }} d t\right|\right)}{\int_{0}^{t} Q_{\text {spring }} d t}
\end{aligned}
$$


Where $\mathrm{Obs}_{i}$ and $\mathrm{Sim}_{i}$ are the observed and simulated data respectively at a location $i, \mathrm{n}$ is the number of observations at the location $i$, and $Q_{\text {spring }}$ and $Q_{\text {sim }}$ are the observed and simulated discharge respectively.

Given that more than 20 parameters were introduced in the model, it was primordial to perform a sensitivity analysis on all the parameters to identify the parameters that play a major role in the physical processes involved in the three components of the hydrological cycle. The sensitivity of each parameter was depicted based on the effect that the variation of this parameter has on the simulated discharge values at the spring with respect to the calibrated ones. The same objective functions adopted in the calibration phase were applied in the sensitivity analysis procedure; the Residual Mean Square Error (RMSE), the total volume error percent as well as the visual interpretation of the discharge residual error curve.

The effect of the variation of the parameters is also evaluated at the level of the hydrological compartments vegetation, soil, unsaturated zone and saturated zone.

\subsection{CASE Study Gallusquelle SPRING}

\subsubsection{Field site}

The modelled area is the Gallusquelle spring catchment (Figure 3-3) located in the Swabian Alb in Southern Germany. The catchment was selected given it is very well investigated since 50 years. The groundwater catchment of the spring was delineated by a number of artificial tracer tests (e.g. Sauter, 1992) and has an area of about $45 \mathrm{~km}^{2}$. The average discharge rate of the Gallusquelle spring is about $0.5 \mathrm{~m}^{3} / \mathrm{s}$, with maxima reaching $2.5 \mathrm{~m}^{3} / \mathrm{s}$.

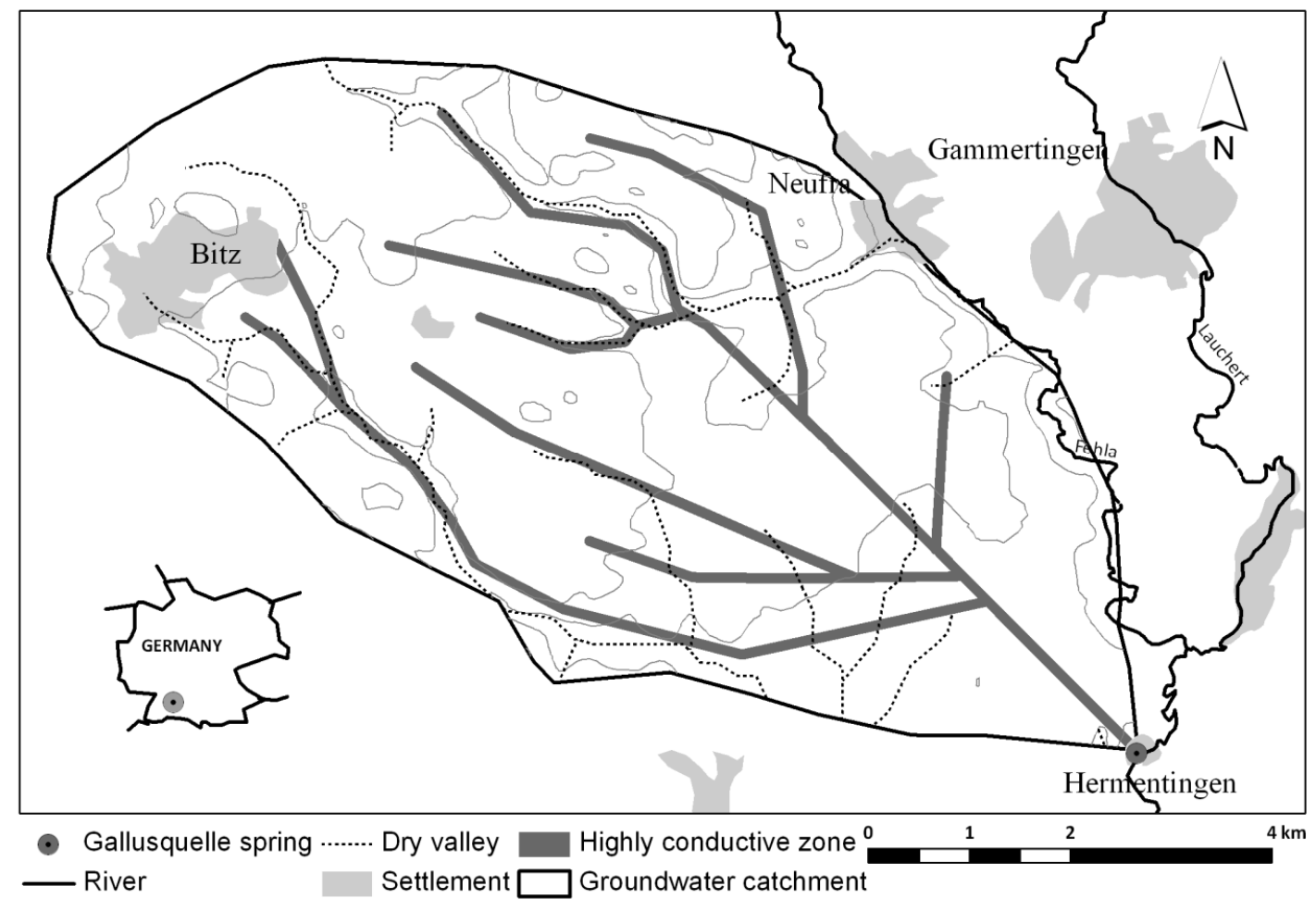

Figure 3-3 Catchment Area of Gallusquelle spring in the Swabian Albs (delineation according to Sauter (1992); location of the highly conductive zone is modified from Mohrlok and Sauter (1997) 
The aquifer is located in bedded and massive limestone of Kimmeridgian age lying over marls of Oxfordian age regarded as impermeable strata. The upper boundary of the aquifer is the water table, i.e. the aquifer is unconfined. The catchment encloses a network of dry valleys regarded as former active water courses. Heinz et al. (2009) showed that dry valleys act as fast infiltration path ways and infiltrating water might arrive at the spring within several days. Sauter (1997) estimated the fast flow component reaching the Gallusquelle spring after rain events to range between $6 \%$ and $10 \%$. The thickness of the unsaturated zone ranges between $90-150$ $\mathrm{m}$.

Observed flow velocities in highly conductive areas in the subsurface were determined with artificial tracer and ranged from 0.005-0.04 m/s (Sauter, 1992). Sauter (1992) also determined the hydraulic conductivities of the fissured matrix to range between $10^{-4}$ and $10^{-5} \mathrm{~m} / \mathrm{s}$ and the effective porosity between 0.01 and 0.02 from borehole testing.

\subsubsection{Model setup and Parameterization}

The model allows for the geometry set up of each individual compartment (atmosphere, unsaturated zone and saturated zone) namely model domain with boundary conditions, topography, vegetation, soil, and bottom to aquifer. The model domain was defined using a gridded polygon shapefile with $70 \times 70 \mathrm{~m}$ grid. Two types of boundary conditions were defined; 1) a no-flow boundary at the border of the catchment area and 2) a cellfixed head boundary at the Gallusquelle spring.

The surface morphology is described by a Digital Elevation Model (DEM) with an elevation resolution of $25 \mathrm{~m}$. The landuse distribution is from Land sat satellite data for the year 2000delineating forests (deciduous, coniferous, and mixed), crop lands, grasslands, and urbanized/ industrialized areas regarded as paved impervious areas.

The bottom to the aquifer was generated by interpolation of aquifer thickness from boreholes lithostratigraphic logs. It corresponds to the bottom of Kimmeridgian formation in the study area (Sauter, 1992).

The highly conductive zone located in the middle layer of the aquifer has a thickness of $10 \mathrm{~m}$ and a $100 \mathrm{~m}$ width. Artificial tracer tests undertaken in the area confirm the presence of high velocity flowpaths at the location of the dry valleys (Heinz et al., 2009). Therefore it was assumed that the highly conductive zone is located at the level of the spring below dry valleys. Additionally, information about the location of dolines was considered (Mohrlok and Sauter, 1997) in the delineation of the highly conductive zone.

Simulations over the years 1989-1993 were performed using a daily time step and calibrated with daily observed discharge time series. Simulations consisted of various runs with different sets of about 28 parameters introduced into the model. 


\subsection{Results AND Discussion}

\subsubsection{Calibration and validation}

The parameters obtained for the best fit are shown in Table 3-1. Additional runs were also performed over 10 years for the years 1989-1999 to validate the model (Figure 3-4). The total precipitation over 10 simulated years ranges between 760 and 1234 mm/year. The total evapotranspiration consists of about 60-70\% of the total precipitation and is in accordance with results from previous water balance studies conducted in the area (Sauter, 1992). The equivalent in water of snow melt amounted to about $6-18 \%$ of the total rainfall. A summary of the yearly water balance of the system in each of the three compartments is provided in Table 32. The total volume of recharge to the saturated zone consists of about $24-38 \%$ of the total rainfall. The error in the spring modelled total annual volume with respect to the observed ones range between $4-15 \%$ depending on the year. The bypass component is rooted directly to the saturated zone and represents about $10 \%$ of the net rainfall.

Table 3-2 Summary of the water balance results

\begin{tabular}{|llll|}
\hline Domain & Item & $\begin{array}{l}\text { Amount (1989-2000)- } \\
\text { (mm/year) }\end{array}$ & $\begin{array}{l}\text { Ratio (1989-2000)- (\% } \\
\text { from total Rainfall) }\end{array}$ \\
Atmosphere & Rainfall & $760-1234$ & 100 \\
& Snow & $59-216$ & $6-18$ \\
Unsaturated Zone & Canopy Interception $C_{\mathrm{I}}$ & $30-50$ & $4-5$ \\
& Infiltration to Unsaturated Zone & $728-1181$ & $94-96$ \\
& Transpiration from roots $\mathrm{T}_{\mathrm{r}}$ & $219-274$ & $22-28$ \\
& Evaporation from soil Ev & $33-44$ \\
& Total Evapotranspiration & $316-436$ & $60-70$ \\
& (C) & $568-765$ & $10 \%$ from precipitation \\
& Fast Recharge Component & & \\
Saturated Zone & (Bypass) & $70-115$ & $24-38$ \\
& Recharge to Saturated Zone & $200-473$ & $24-37$ \\
\hline
\end{tabular}




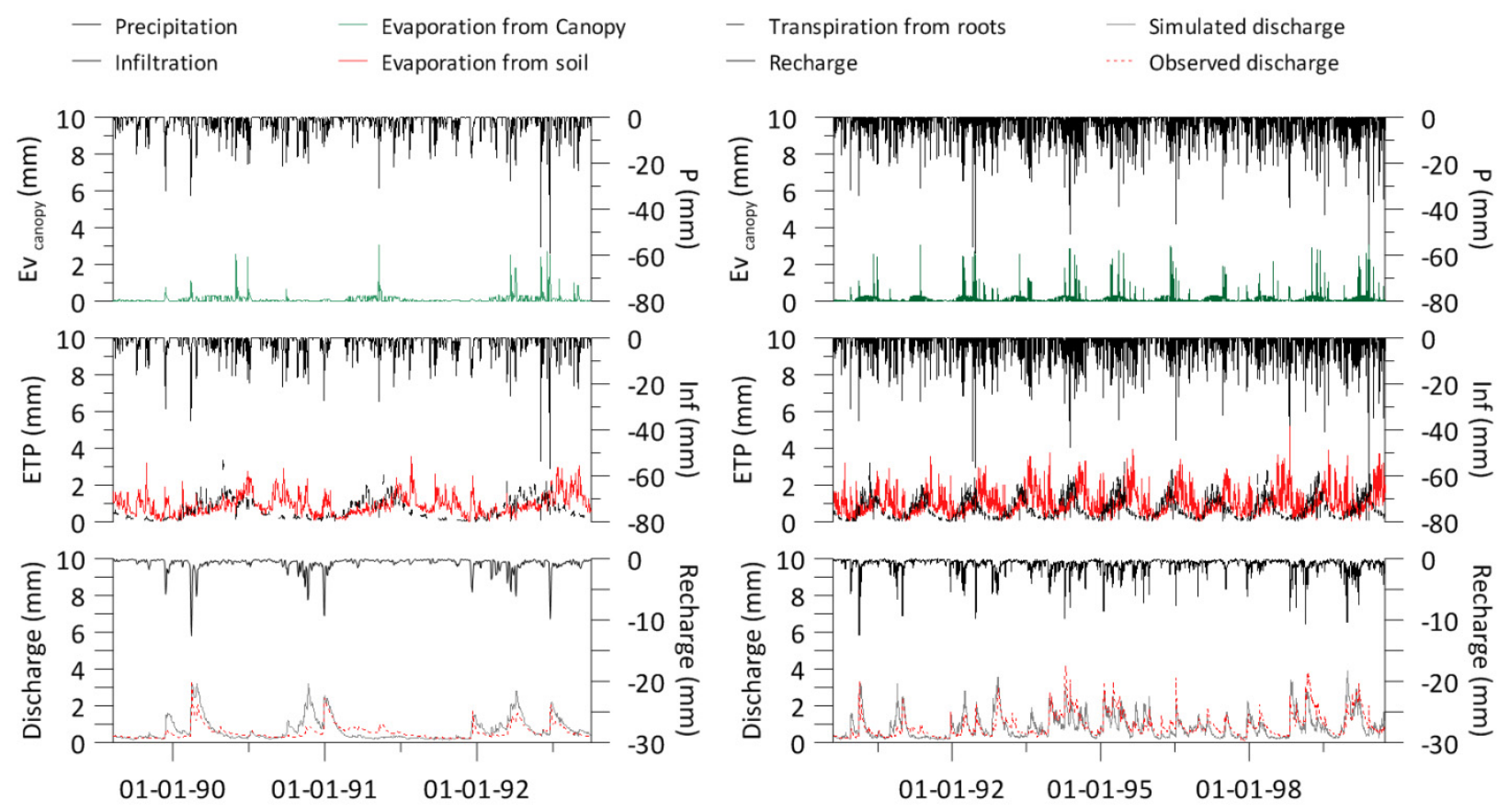

$\begin{array}{lll}- \text { Transpiration from roots } & \text { Simulated discharge } \\ \text { - Recharge } & \cdots & \text { Observed discharge }\end{array}$

Figure 3-4 Comparison of simulated and observed discharge rates at the Gallusquelle spring for the years 1989-2000 and 1989-1992, daily precipitation and evapotranspiration curves are also displayed.

\subsubsection{Sensitivity analysis}

Figure 3-5 and Figure 3-6 present RMSE and error volume percentages respectively for the sensitivity analysis performed on all the parameters. The results of the simulation from 1989-1992 were taken into account for the classification of parameters in order of significance in the model.

About 12 parameters appear to influence at least one of the components of the hydrological cycle and consequently the calibrated discharge curve. Following sensitivity analysis, four types of parameters were identified (Table 3-3). The highly indicative parameters are considered those, which varied within a range, generate a Root Mean Square Error (RMSE) higher than $0.2 \mathrm{~m} 3 / \mathrm{sec}$ with respect to the modeled adopted discharge curve. The variation of those parameters has an important influence on the total volume and shape of the simulated discharge. The medium indicative parameters yield upon variation an RMSE greater than 0.1 $\mathrm{m} 3 / \mathrm{sec}$, but lower than $0.2 \mathrm{~m} 3 / \mathrm{sec}$. The negligible indicator parameters have no influence on the RMSE, the water volume below the discharge curve or the shape of the curve even when varied within relatively large ranges. Finally some parameters such as alpha (Van Genuchten), varied within some physically reasonable range have no influence on the output of the model, yet could affect the end result if they exceed critical values. 

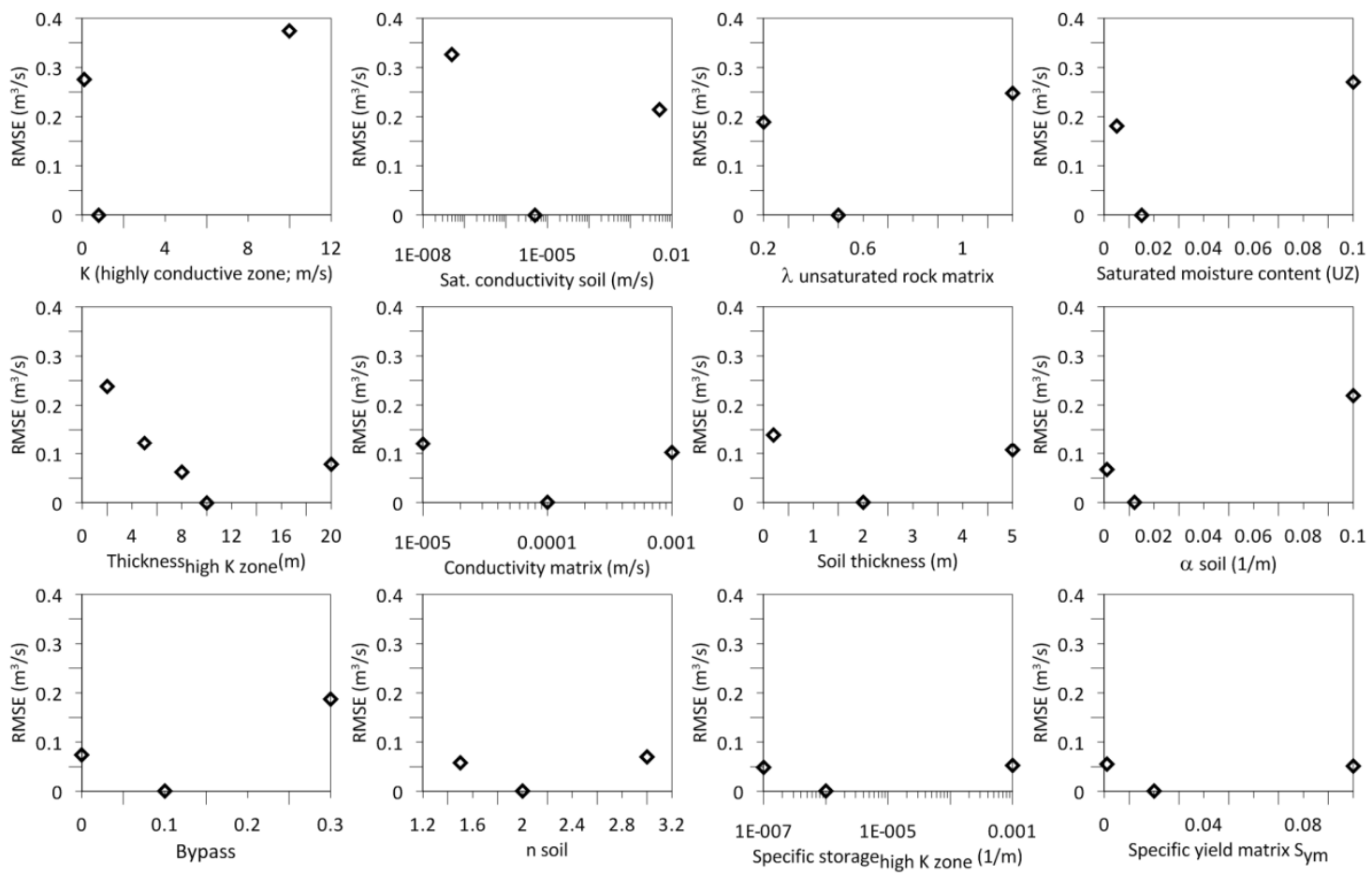

Figure 3-5

Results of the sensitivity analysis (RMSE) of the fitting and calibration parameters
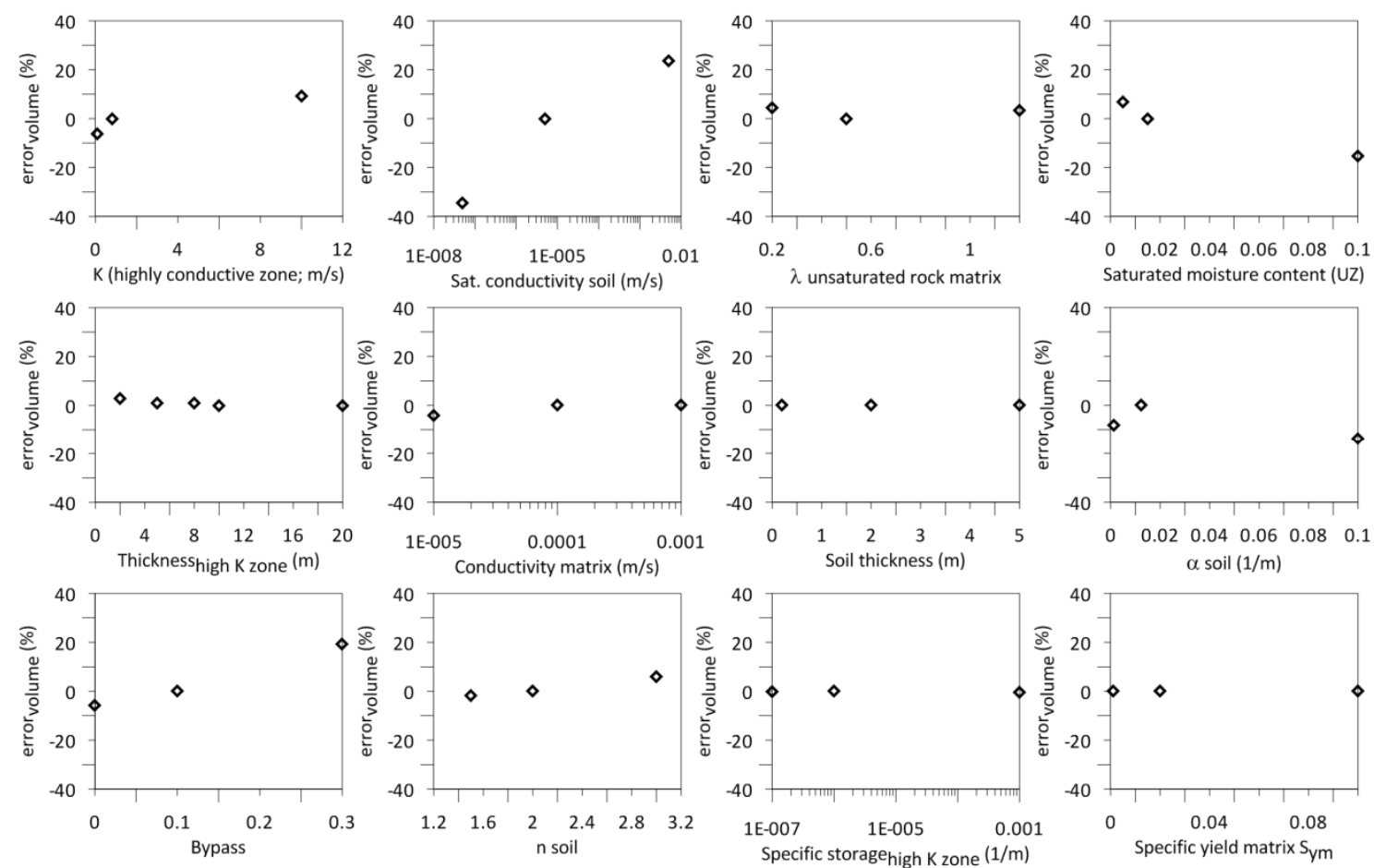

Figure 3-6

Results of the sensitivity analysis (\% error volume) of the fitting and calibration parameters 


\begin{tabular}{|c|c|c|c|c|c|c|c|c|}
\hline \multirow[t]{2}{*}{ Type } & \multirow[t]{2}{*}{ Parameters } & \multicolumn{2}{|c|}{ Range } & \multicolumn{2}{|c|}{$\operatorname{RMSE}\left(\mathrm{m}^{3} / \mathrm{s}\right)$} & \multicolumn{2}{|c|}{$\begin{array}{l}\text { Average Yearly } \\
\text { Volume error; } \\
\text { 1989-1992) }\end{array}$} & \multirow{2}{*}{$\begin{array}{c}\begin{array}{c}\text { Discharge curve } \\
\text { (recession/peaks) }\end{array} \\
\text { Influence }(\mathrm{Y} / \mathrm{N})\end{array}$} \\
\hline & & low & high & low & high & low & high & \\
\hline \multirow{5}{*}{$\begin{array}{l}\text { Highly } \\
\text { Indicative } \\
(\text { RMSE }>0.2 \\
\left.\mathrm{m}^{3} / \mathrm{s}\right)\end{array}$} & $\begin{array}{l}\text { Hydraulic Conductivity } \\
\text { Soil } K_{s}\end{array}$ & 5.E-08 & 5.E-03 & 0.32 & 0.21 & $-34 \%$ & $23 \%$ & $\mathrm{Y}$ \\
\hline & $\operatorname{Lambda}(\lambda)$ & 0.1 & 1.2 & 0.19 & 0.24 & $4 \%$ & $3 \%$ & Y \\
\hline & $\begin{array}{l}\text { Moisture Content } \\
\text { unsaturated rock matrix } \\
\theta \mathrm{uz}_{\mathrm{s}}\end{array}$ & 0.005 & 0.1 & 0.18 & 0.27 & $6 \%$ & $-15 \%$ & $\mathrm{Y}$ \\
\hline & $\begin{array}{l}\text { Hydraulic conductivity } \\
\text { zone }\left(\mathrm{K}_{\mathrm{c}}\right)\end{array}$ & 0.1 & 10 & 0.27 & 0.37 & $-6 \%$ & $9 \%$ & Y \\
\hline & $\begin{array}{l}\text { Van Genuchten } \\
\text { Parameters: moisture } \\
\text { contents (saturated and } \\
\text { residual) and hydraulic } \\
\text { conductivity }\end{array}$ & $\begin{array}{r}\text { various } \\
\text { soil (cl }\end{array}$ & $\begin{array}{l}\text { ypes of } \\
y, \text { soil) }\end{array}$ & $0.1-$ & .34 & $\begin{array}{r}33 \% \text { (cc } \\
41 \%\end{array}$ & $\begin{array}{l}\text { se) } \\
\text { ner) }\end{array}$ & $\mathrm{Y}$ \\
\hline \multirow{3}{*}{$\begin{array}{l}\text { Medium } \\
\text { indicative } \\
(0.2>\mathrm{RMSE}> \\
0.1 \mathrm{~m} 3 / \mathrm{s})\end{array}$} & Soil thickness & 0.2 & 5 & 0.13 & 0.1 & $-17 \%$ & $15 \%$ & Peaks \\
\hline & $\begin{array}{l}\text { Hydraulic conductivity } \\
\text { unsaturated matrix/ } \\
\text { hydraulic conductivity } \\
\text { matrix }\end{array}$ & 1.E-05 & 1.E-03 & 0.19 & 0.2 & $3 \%$ & $-2 \%$ & Peaks \\
\hline & $\begin{array}{l}\text { Hydraulic conductivity } \\
\text { matrix }\end{array}$ & 1.E-05 & 1.E-03 & 0.12 & 0.1 & $0 \%$ & $-5 \%$ & $\mathrm{Y}$ \\
\hline \multirow{6}{*}{$\begin{array}{l}\text { Negligible } \\
(\text { RMSE< } 0.1 \\
\left.\mathrm{m}^{3} / \mathrm{s}\right)\end{array}$} & n (soil) & 1.5 & 3 & 0.07 & 0.06 & $-2 \%$ & $6 \%$ & $\mathrm{~N}$ \\
\hline & Bubbling Pressure $\left(\psi_{b}\right)$ & 0.09 & 1 & 0.05 & 0.2 & $2 \%$ & $0 \%$ & $\mathrm{~N}$ \\
\hline & $\begin{array}{l}\text { Hydraulic Conductivity } \\
\text { unsaturated matrix } \\
\left(\mathrm{Kuz}_{\mathrm{s}}\right)\end{array}$ & 1.E-05 & 1.E-03 & 0.15 & 0.05 & $0 \%$ & $0 \%$ & $\mathrm{~N}$ \\
\hline & $\begin{array}{l}\text { Specific yield Sym } \\
\text { (matrix) }\end{array}$ & 0.001 & 0.1 & 0.05 & 0.05 & $0 \%$ & $0 \%$ & $\mathrm{~N}$ \\
\hline & Specific yield Syc (Lens) & 0.001 & 0.5 & 0.05 & 0.05 & $0 \%$ & $0 \%$ & $\mathrm{~N}$ \\
\hline & $\begin{array}{l}\text { Storativity of highly } \\
\text { conductive zone } \mathrm{S}_{\mathrm{sc}}\end{array}$ & 1.E-07 & 1.E-03 & 0.05 & 0.05 & $0 \%$ & $0 \%$ & $\mathrm{~N}$ \\
\hline \multirow{3}{*}{$\begin{array}{l}\text { Negligible } \\
\text { within a range }\end{array}$} & $\alpha$ (soil) & 0.0012 & 0.1 & 0.066 & 0.22 & $-8 \%$ & $-13 \%$ & Peaks \\
\hline & Bypass (BYP) & 0 & 0.3 & 0.07 & 0.18 & $-6 \%$ & $20 \%$ & Recession \\
\hline & $\begin{array}{l}\text { Thickness highly } \\
\text { conductive zone }\end{array}$ & 2 & 20 & 0.24 & 0.078 & $-0.9 \%$ & $-3 \%$ & $\mathrm{Y}$ \\
\hline
\end{tabular}

The water volume below the curve was considered as a criterion in the classification of indicator parameters. It was used as a criterion to identify the effect of the parameters on the total discharged volume. Only a few parameters influence the total yearly volume, in spite of the presence of various parameters playing a significant role in the shape of the curve, especially in recession and peak times. 


\subsubsection{Effects on compartment signals}

Each of the parameters identified as strong or intermediate indicator plays a role in each reshaping the output of each compartment (Table 3-4). In addition to their effect on the recession and peaks of the outputs, their influence was depicted by assessing the error volume occurring for each individual process of the hydrological cycle namely precipitation, infiltration to the unsaturated zone, evaporation from soil, transpiration from roots, total evapotranspiration, recharge to the saturated zone, and outflow at the spring (Table 3-5) with respect to the total volume (Equation 6) from simulated data.

\subsubsection{Atmosphere}

Three main output curves are generated in the compartment atmosphere: the spatial and temporal distribution of precipitation (including snow), the canopy interception and the infiltration to the unsaturated zone. The main parameters influencing the three components are mainly the climatic data, as well as the land use (Kristensen Jensen Parameters; $C_{1}, C_{2}, C_{\text {int }}$ and $A_{\text {root }}$ LAl and Depth to Root). The $C_{1}$ and $C_{2}$ parameters control mainly the ratio of evaporation to transpiration. However an increase of both decreases the final discharge volume. $C_{3}$ cannot be physically measured and figures as a parameter in the plant transpiration computation. Sensitivity analysis performed on the empirical parameters $C_{1}$ and $C_{2}$ show the importance of both in controlling soil evaporation and transpiration from roots (Sahoo et al., 2006). Nevertheless $C_{1}$ is more regarded as an indicator parameter; a larger $\mathrm{C}_{1}$ yields higher transpiration and lower evaporation rates and changes the ratio of both component yielding generally a higher evapotranspiration rate and consequently a lower discharge. The RMSE varies between $0.11-0.12 \mathrm{~m}^{3} / \mathrm{s}$ for a variation of $C_{1}$ from its calibrated value (0.2). Furthermore $C_{2}$ and $C_{3}$ start influencing the model results beyond a certain range (for $C_{2}$ 0.1-0.4 and $C_{3}$ greater than 1). The $A_{\text {root }}$ which defines the root distribution and the $C_{i n t}$ which regulates the maximum interception from canopy appear to have a negligible influence on the final results of the model, despite the fact that they slightly vary the absolute transpiration and evaporation amounts, with the ratio, however, more or less the same.

Table 3-4 Parameters playing a major role in the model results (highly indicator in bold)

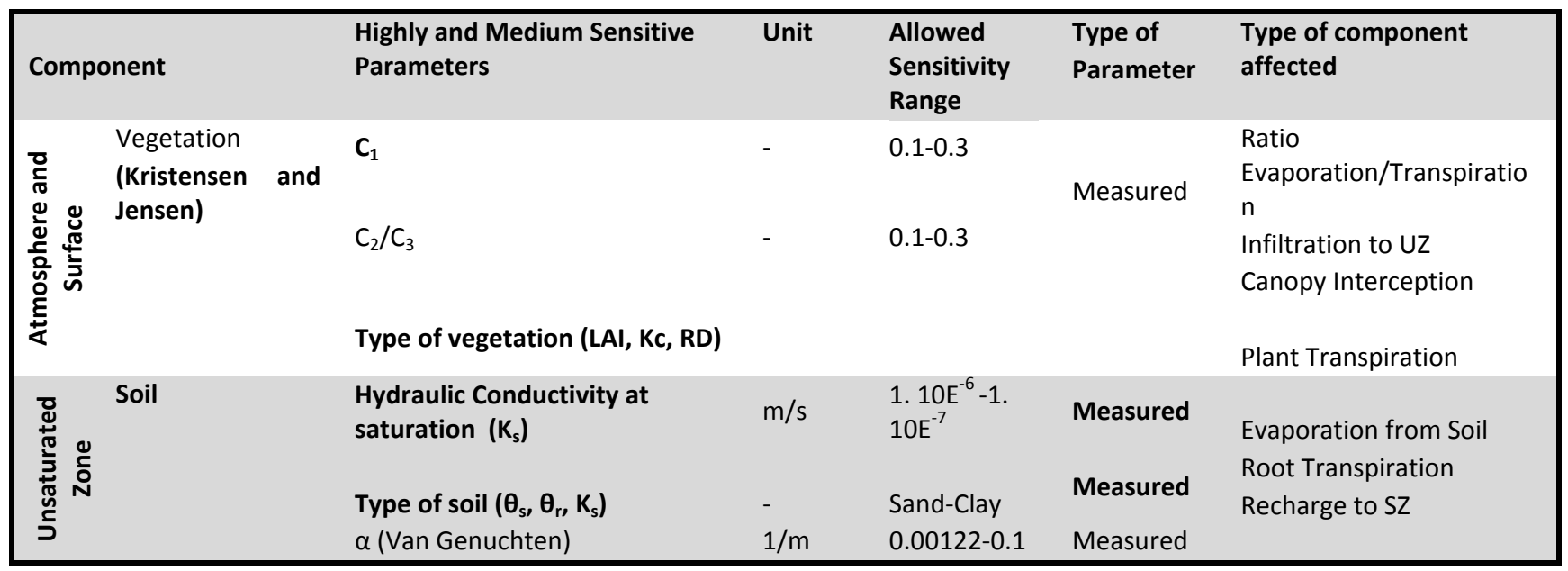




\begin{tabular}{|c|c|c|c|c|c|c|}
\hline \multicolumn{2}{|c|}{ Component } & $\begin{array}{l}\text { Highly and Medium Sensitive } \\
\text { Parameters }\end{array}$ & Unit & $\begin{array}{l}\text { Allowed } \\
\text { Sensitivity }\end{array}$ & $\begin{array}{l}\text { Type of } \\
\text { Parameter }\end{array}$ & $\begin{array}{l}\text { Type of component } \\
\text { affected }\end{array}$ \\
\hline \multirow{2}{*}{\multicolumn{2}{|c|}{ Epikarst }} & $\begin{array}{l}\text { Saturated moisture content } \\
\left(\theta u z_{s}\right)\end{array}$ & - & 0.01 & Measured & \multirow[t]{2}{*}{ Recharge to SZ } \\
\hline & & Particle Index $(\lambda)$ & - & $0.2-0.8$ & Fitting & \\
\hline & Bypass & $\begin{array}{l}\text { Bypass portion of net rainfall } \\
\text { (BYP) }\end{array}$ & - & $0.05-0.1$ & Fitting & Fast Recharge to SZ \\
\hline \multirow{2}{*}{ 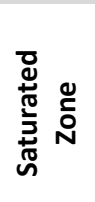 } & Matrix & $\begin{array}{l}\text { Hydraulic conductivity (vertical } \\
\text { and horizontal) }\left(\mathrm{K}_{\mathrm{x}}, \mathrm{K}_{\mathrm{z}}\right)\end{array}$ & $\mathrm{m} / \mathrm{s}$ & $10 E^{-3}-10 E^{-5}$ & Measured & \multirow[b]{2}{*}{ Discharge } \\
\hline & $\begin{array}{l}\text { Highly } \\
\text { conductive zone }\end{array}$ & $\begin{array}{l}\text { Hydraulic conductivity (vertical } \\
\text { and horizontal) }\left(K_{x}, K_{z}\right)\end{array}$ & $\mathrm{m} / \mathrm{s}$ & $0.1-10$ & Fitting & \\
\hline
\end{tabular}

The type of crops also influences the output. The variation of the type of crops is reflected by the variation of both LAI and Root depth. A spatial analysis on each type of vegetation was conducted to determine the output (infiltration, evapotranspiration, recharge, etc.) per unit area of each type of crop. The type of crop namely the LAI and root depth influence mainly the transpiration signal and the canopy interception consequently the evapotranspiration rate (Figure 3-7). These results were obtained as well in other studies where sensitivity analysis shows the importance of both LAI and root depth in influencing the recharge (Finch, 1998). For instance, in areas of coniferous forests, the total recharge is $10 \%$ lower than in crop lands. This is due to a lower evapotranspiration from lower transpiration from roots and relatively low evaporation from canopy in crops (Figure 3-7).

Table 3-5 Influence of the indicator parameters on the output curve of the three compartments

\begin{tabular}{|c|c|c|c|c|c|c|c|c|c|}
\hline \multirow[b]{2}{*}{ Parameters } & \multirow[b]{2}{*}{ Range } & \multicolumn{8}{|c|}{ Influence on average error yearly volume (\%; 1989-1992) } \\
\hline & & $\mathbf{P}$ & I to UZ & Evap $_{\mathrm{s}}$ & $\mathbf{T}_{\text {root }}$ & $\operatorname{Evap}_{\mathrm{c}}$ & ETP & $\mathrm{R}$ to $\mathrm{SZ}$ & $\mathbf{Q}$ \\
\hline \multirow{2}{*}{$\mathrm{Ks}(\mathrm{m} / \mathrm{s})$} & 1. $10 \mathrm{E}^{-8}$ & - & -23 & -17 & -21 & -32 & 13 & -33 & -34 \\
\hline & 1. $10 \mathrm{E}^{-3}$ & - & -0.4 & -15 & -5 & 7 & -9 & 22 & 23 \\
\hline \multirow{2}{*}{$\lambda_{\mathrm{uz}}$} & 0.1 & - & - & 2 & -6 & & -1.5 & 3.5 & 4 \\
\hline & 1.2 & - & - & 2 & -6 & - & -2.5 & 5.5 & 3.5 \\
\hline \multirow{2}{*}{$\theta_{\mathrm{uz}}$} & 0.005 & - & - & 3 & -10 & - & -3 & 6.4 & 6.4 \\
\hline & 0.1 & - & - & -1.8 & 12 & - & 3.5 & -9.6 & -15 \\
\hline \multirow{2}{*}{$\mathrm{K}_{\mathrm{c}}(\mathrm{m} / \mathrm{s})$} & 0.1 & - & - & - & - & - & - & -2 & -6 \\
\hline & 10 & - & - & - & - & - & - & 0.4 & 9 \\
\hline \multirow{2}{*}{$\begin{array}{l}\text { Soil Thickness } \\
\text { (m) }\end{array}$} & 0.2 & - & - & 2 & -21 & 0 & -7 & 17 & 17 \\
\hline & 5 & & & -3 & 19 & 0 & 5 & -14 & 14 \\
\hline \multirow{2}{*}{$\mathrm{K}_{\mathrm{m}}(\mathrm{m} / \mathrm{s})$} & 1. $10 \mathrm{E}^{-5}$ & - & - & - & - & - & - & 0 & -4 \\
\hline & 1. $10 \mathrm{E}^{-3}$ & - & - & - & - & - & - & -2 & 0 \\
\hline \multirow{2}{*}{$\alpha$ (soil; $1 / m$ ) } & 0.00122 & - & - & 5 & 0.75 & 0 & 3 & -8 & -8 \\
\hline & 0.1 & - & - & 17 & -12 & 0 & 5.3 & -12 & -13 \\
\hline \multirow{2}{*}{ Bypass } & 0 & - & - & 2 & 4 & 0 & 2 & -6 & -6 \\
\hline & 0.3 & & & -6 & -13 & 0 & -8 & 20 & 20 \\
\hline
\end{tabular}




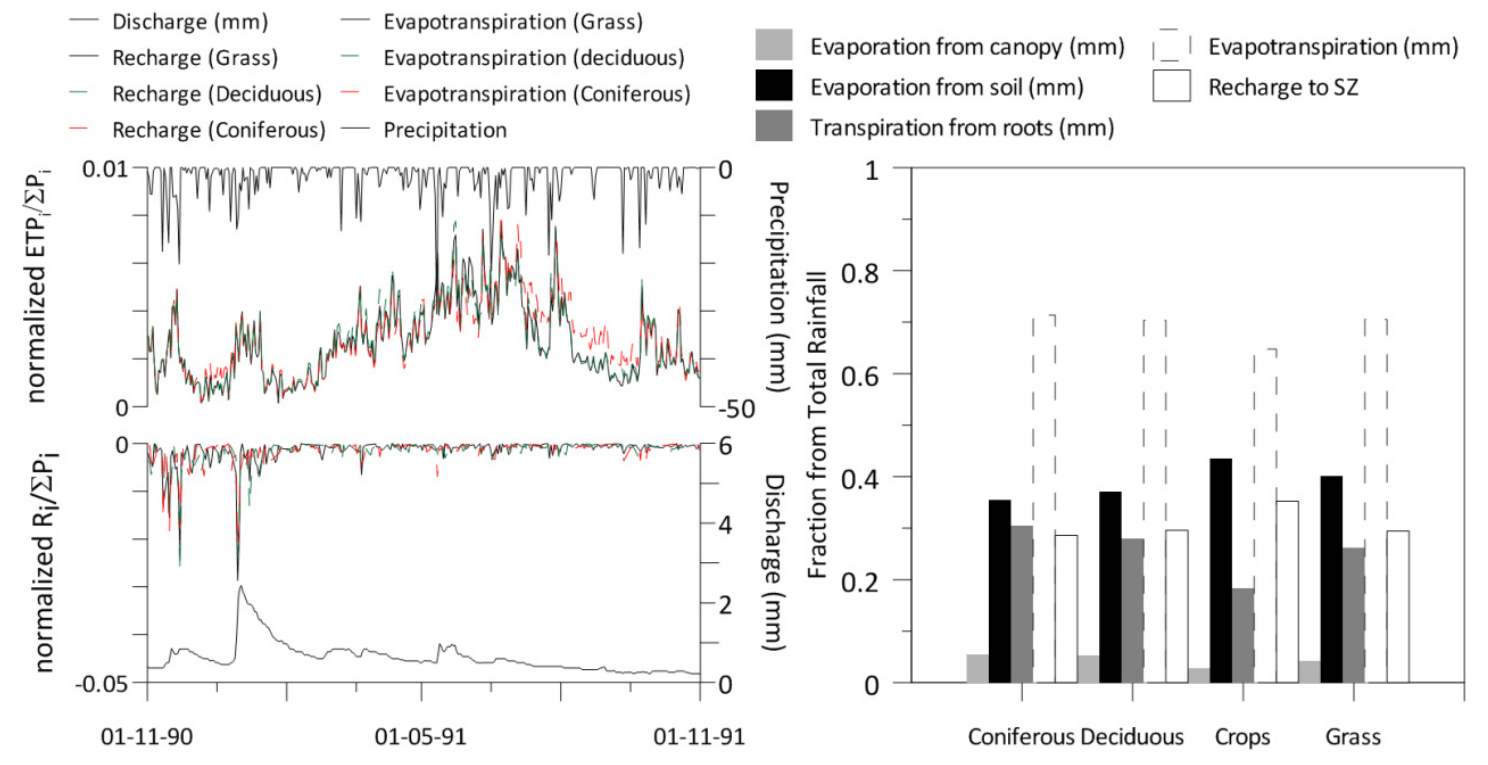

Figure 3-7 Results of the spatial evaluation of recharge per unit area in different types of crops

\subsubsection{Unsaturated Zone (UZ)}

In the unsaturated zone, there are mainly two main components; the upper layer consisting of the soil/epikarst cover underlain by the unsaturated rock matrix. Three main output curves are generated in this zone; transpiration from the root zone, evaporation from soil, and recharge to saturated zone. The soil type plays a role in varying the output results of the soil layer in the UZ; the latter is portrayed mainly by the hydraulic conductivity and the water retention curves (saturated hydraulic conductivity and saturated and residual moisture content). For example, a decrease in the hydraulic conductivity yields a shift in the peaks of the recharge curve and consequently the modelled discharge curve (Figure 3-8). Moreover decreasing $\mathrm{K}_{\mathrm{s}}$ yield a less pronounced peak signal. The sensitivity analysis of various types of soils (parameters for Van Genuchten relationship were based on the Hydrus prediction tool for different soil texture (medium sand to clay loam), Hydrus-2D, 1999) shows that the total recharge per unit area and consequently the total discharge with varying type of soil increases with coarsening soils. Therefore the spatial variation of soil hydraulic properties highly influences the recharge function. Recharge to the saturated zone increases by $20 \%$ on average with respect to the clayey and clayey loam soils, due to a lower evaporation from soil and lower retention (Figure 3-8). Depending on the intensity of the event, the peaks and recession in both the recharge and discharge curves are more important in the case of a sandy soil, which generate a higher total volume. Furthermore, the peaks of the recharge/discharge signals in clayey soils are delayed with respect to the calibrated ones. 


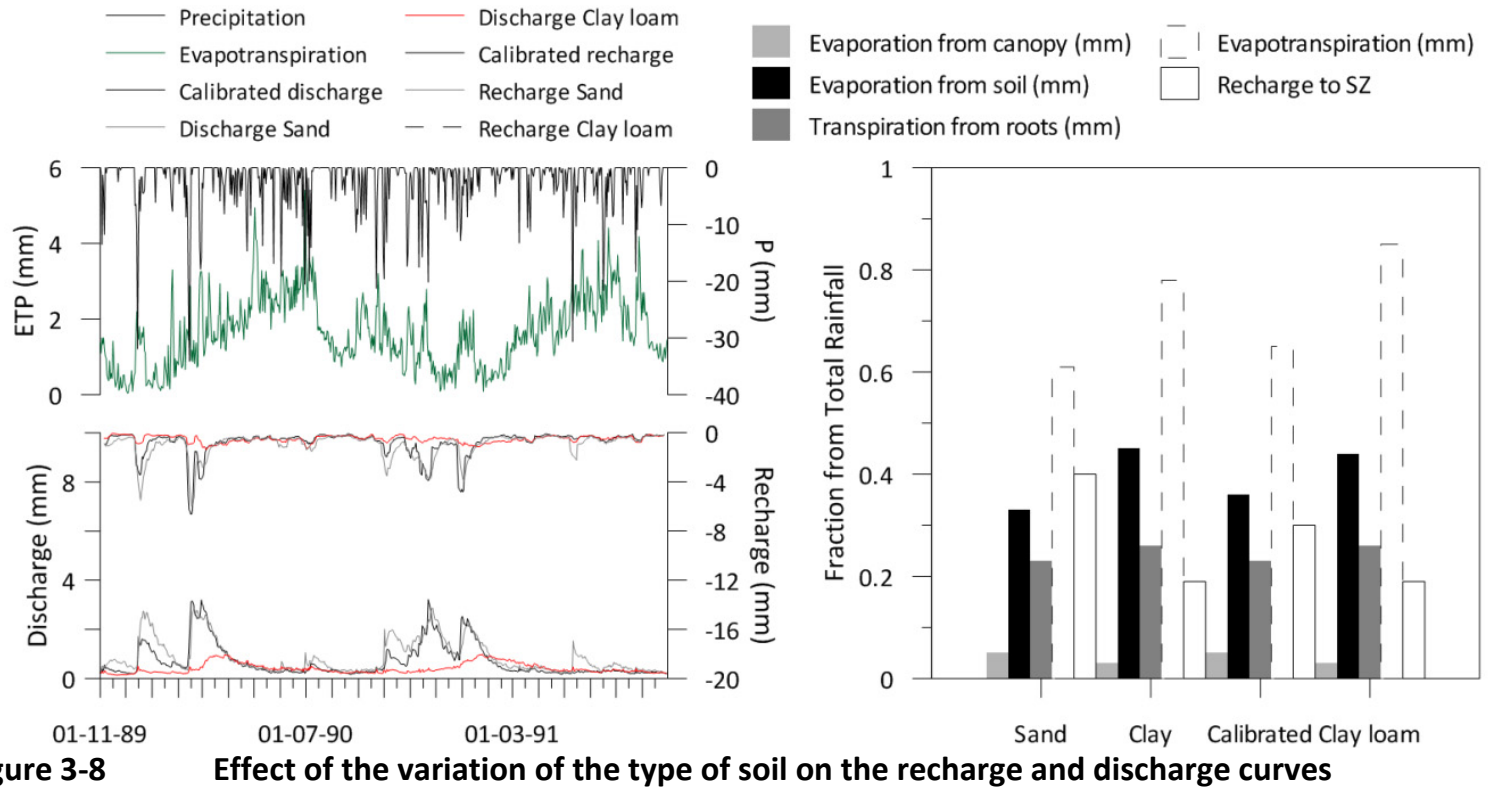

The soil thickness is considered as a medium indicator parameter, as it influences the peaks. This is particularly prominent when soils are absent, or when they exceed $5 \mathrm{~m}$ in depth. The unsaturated rock matrix is regarded as an equivalent porous medium, which hydraulic conductivity and moisture contents being defined based on a simple relationship Campbell/Campbell-Burdine. Two main parameters in the unsaturated rock matrix layer influence mainly the recharge to the saturated zone. The particle size index $\left(\lambda_{\mathrm{uz}}\right)$ and the saturation moisture content influence the shape of the hydraulic conductivity and moisture retention curves. The particle index $\left(\lambda_{\mathrm{uz}}\right)$ is regarded as an empirical parameter as it cannot be verified in the field. However, it seems to play a role mainly in the intensity and the timing of the peaks of the recharge function and the discharge curve. The saturation moisture content decreases with respect to the set one with increasing particle index. Therefore lower holding capacity and gravitational flow are achieved within smaller ranges of moisture content than the calibrated ones. This explains why peaks are drastically decreased and delayed with higher particle index (Figure 3-9). On the other hand, it is noted that with increasing saturated moisture content, the recharge function decreases drastically especially during events, which leads to the buffering of the peak signal (Figure 3-9). 


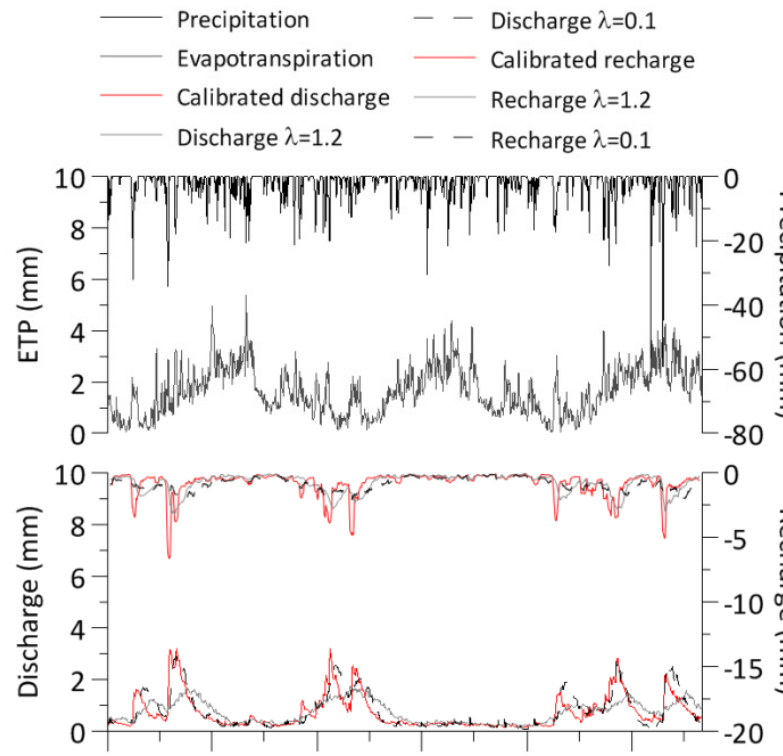

01-11-89
01-11-90
01-11-91
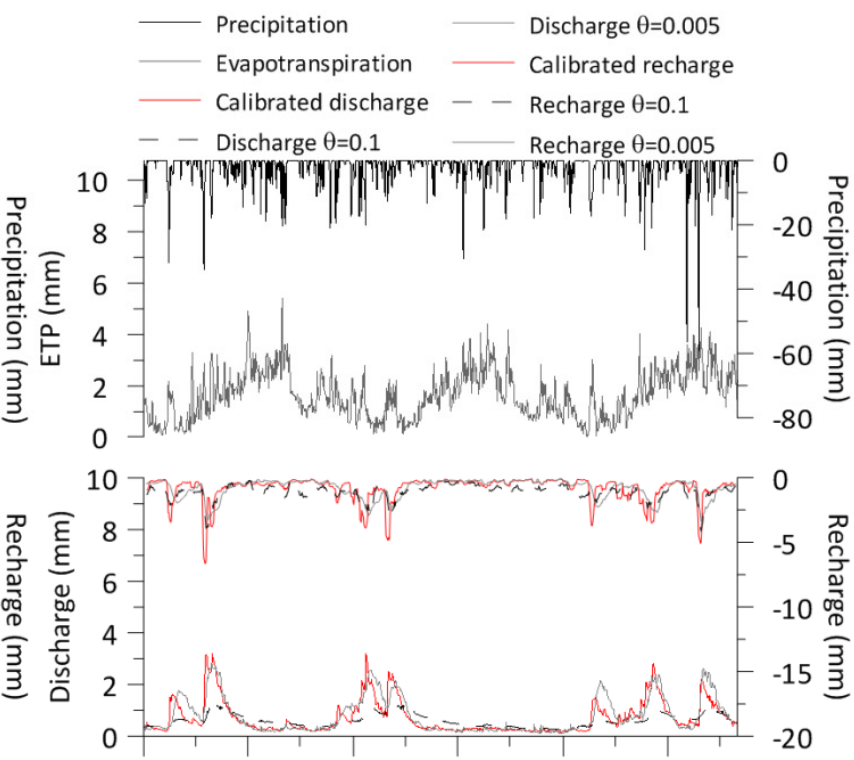

01-11-89

01-11-90

01-11-91

b

Figure 3-9 Effect of the variation of the the particle index $(\lambda ; b)$ and saturated moisture content (a) in the unsaturated rock matrix on the recharge and discharge curves

The variation of the hydraulic conductivity of the unsaturated rock matrix influences the results, when it is assigned a different value than that of the low permeability matrix in the saturated zone. Since the unsaturated matrix is considered to be in continuity with the SZ, it was always assigned the same value as the hydraulic conductivity of the low permeability saturated zone. The bypass function affects the output mainly the recession of the recharge and discharge curve, only when exceeding a certain value.

\subsubsection{Saturated Zone (SZ)}

The hydraulic conductivity of the matrix plays a role in the amplitude of peak and recession; however it has no significant role in varying the total water volume at the model outlet. The hydraulic conductivity of the highly conductive zone is the major controlling factor in the saturated zone, whereby a variation of the hydraulic conductivity by about $20 \%$ leads to an outflow signal, with no peak signals despite the fact that the recharge function shows peak recharge events (Figure 3-10). According to simulated groundwater heads in the catchment, and with the hydraulic conductivity $(0.8 \mathrm{~m} / \mathrm{s})$ adopted for the highly conductive zone, groundwater velocities in the high conductive zone vary between 0.015 and $0.04 \mathrm{~m} / \mathrm{s}$ which are concordant with the velocities determined with tracer tests.

The thickness of the highly conductive zone was varied between $2 \mathrm{~m}$ and $20 \mathrm{~m}$. From the results of sensitivity analysis, increasing zone thicknesses leads to increasing peaks and decreasing recessions because of the possibility of accommodation of a greater volume during high flow periods. As a result of which, the thickness of the conduit becomes a critical value when it is lower than $5 \mathrm{~m}$, where RMSE starts to exceed $0.1 \mathrm{~m}^{3} / \mathrm{s}$. Nevertheless, the thickness of the highly conductive zone yields insignificant percentage error in the total yearly volume. 


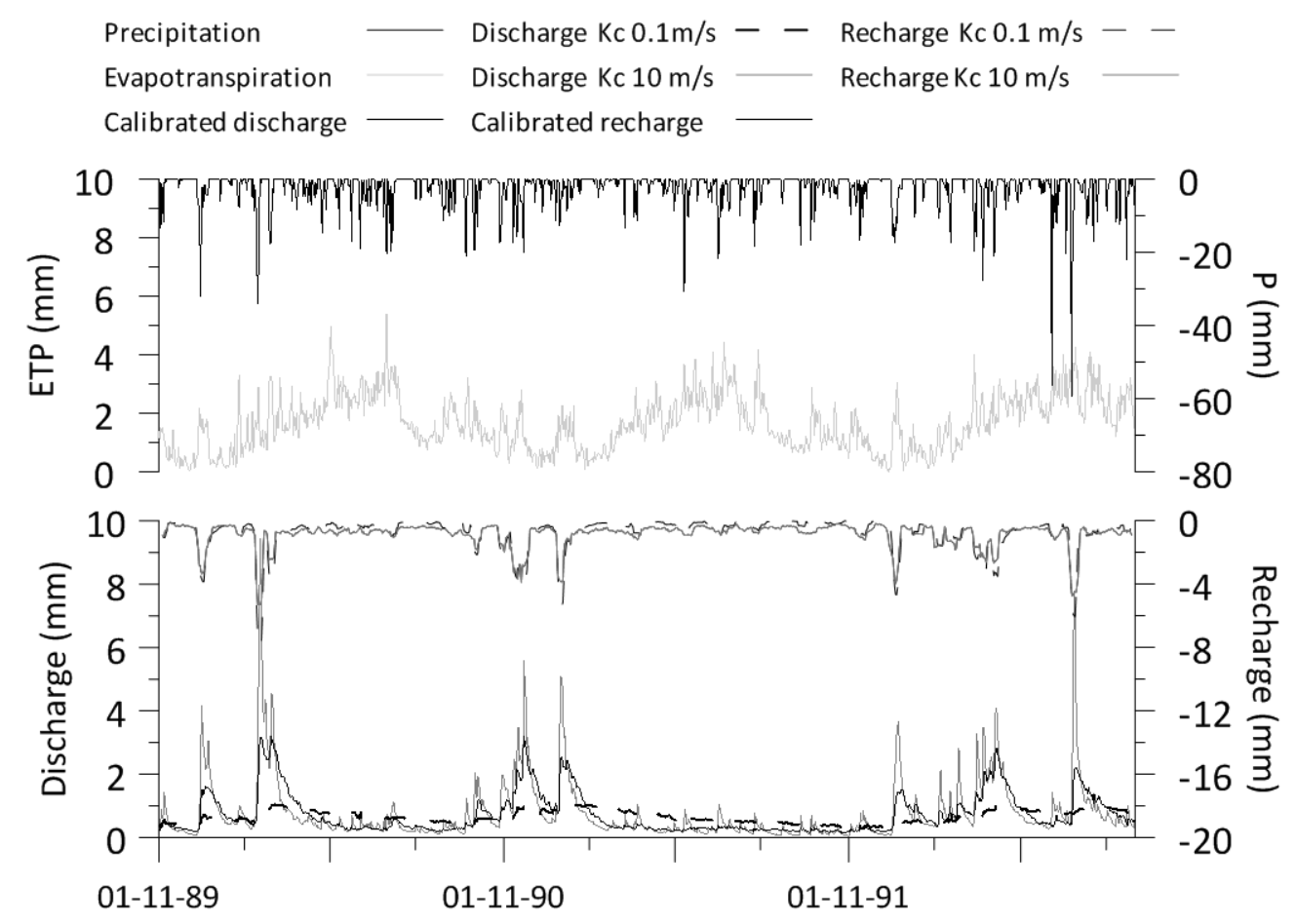

\section{Figure 3-10 Effect of the variation of the hydraulic conductivity of the highly conductive zone on the discharge curve}

\subsection{ConcLusions}

The Mike She model is able to simulate the entire hydrological cycle in a well investigated karst catchment especially that it accounts for the fast water component responsible for the high fluctuations observed in spring responses. Parameters used for the model calibration were within physical ranges, a few were fitting parameters. This work aimed at the understanding and quantification of the physical processes occurring within the hydrological cycle, including atmosphere, unsaturated zone and saturated zone and the assessment of the relative importance. Sensitivity analyses of the different parameters revealed their respective impact on the model output. Each of the indicator parameters has an effect on the various recharge signals within the hydrological cycle, and therefore highly impacts the shape of the discharge curve as well as the total volume. The indicator parameters play a role in reshaping the simulated discharge at the spring; therefore, they are key parameters which effect can be tracked in the spring response. In addition to parameters associated to vegetation, the hydraulic conductivity at saturation and the moisture content of the soil are important parameters affecting mainly the evapotranspiration, whereas the saturation moisture content and particle index revealed to be significant parameters in the unsaturated karst. The hydraulic conductivity of the highly conductive zone highly influences the amplitude of spring responses.

Other parameters such as bypass, soil thickness and alpha (Van Genuchten) and the hydraulic conductivity of the matrix influence the results to a lesser extent.

Unlike in groundwater models, turbulent flow considered as an important process especially in conduit flow is not taken into account in the integrated model adopted in this work. Since the modelling exercise is aimed at 
long-term investigations and comprises numerous contributions of the different flow processes in the catchment, the added effect of turbulent flow is regarded as negligible. Additionally the epikarst is lumped within the soil especially that no information about its geometry and its hydraulic characteristics is available. As a result, all of the above were not addressed, given that the objective of the modelling adopted in this work is mainly to better understand the processes within the entire hydrological cycle.

Further work would include the validation of the model with transport simulations. Moreover, the applicability of the numerical model Mike She for the simulation of spring discharge on other karst catchments is still to be validated.

\section{Acknowledgement}

This research is part of a PhD study funded by the Deutscher Akademischer Austausch Dienst (DAAD, Referat 441). The authors would like to thank DHI (Danish Hydraulic Institute) for kindly providing the Mike She software for the purpose of this research. The authors express their gratitude to Nico Goldscheider for his review and valuable comments. Peter Knaus and the water supply company of Hermentingen are also thanked for their kind cooperation.

\subsection{REFERENCES}

Atkinson, T.C., 1977. Diffuse flow and conduit flow in limestone terrain in the Mendip Hills, Somerset (Great Britain) Journal of Hydrology, 35: 93-110

Batu, V., 1998. Aquifer Hydraulics: a comprehensive guide to hydrogeologic data analysis. Wiley-Interscience, $727 \mathrm{pp}$

Birk, S., Geyer, T., Liedl, R., Sauter, M., 2005. Process-based interpretation of tracer tests in carbonate aquifers. Ground Water, 43, no. 3: 381-388

Beven, K. J., 1979. A sensitivity analysis of the Penman-Monteith actual evapotranspiration estimates. Journal of Hydrology, 44: 169-190

Brubaker, K., Rango, A., Kustas, W., 1996. Incorporating radiation inputs into the snowmelt runoff model. Hydrological Processes, 10: 1329-1343

Campbell, G., 1974. A simple method for determining unsaturated conductivity from moisture retention data. Soil Science 117, no. 6: 311-314

Canadell, J., Jackson, R.B., Ehleringer, J.R., Mooney, H.A., Sala, O.E., and Schulze, E.-D., 1996. Maximum rooting depth of vegetation types at the global scale. Oecologia, 108: 583-595

DHI (Denmark hydrology Institute), 2007. Mike She User Manual and Reference Guide, Ed. Dec 2007. Denmark. (V1 \& 2)

Finch, J. W., 1998. Estimating direct groundwater recharge using a simple water balance model- sensitivity to land surface parameters. Journal of Hydrology, 211: 112-125

Ford, D., and Williams, P., 2007. Karst hydrogeology and Geomorphology. John Wiley \& Sons Ltd., West Sussex, $562 \mathrm{pp}$ 
Geyer, T., Birk, S., Licha, T., Liedl, R., and Sauter, M., 2008. Quantification of temporal distribution of recharge in karst systems from spring hydrographs. Journal of Hydrology, 348: 452-463

Graham, D.N., and Butts, M.B., 2005. Flexible integrated watershed modeling with Mike She. in watershed Models. Ed. V.P.Singh and D.K. Frevert, CRC Press: 245-271

Heinz, B., Birk, S., Liedl, R., Geyer, T., Straub, K. L., Andresen, J., Bester, K., and Kappler, A., 2009. Water quality deterioration at a karst spring (Gallusquelle, Germany) due to combined sewer overflow: Evidence of bacterial and micro-pollutant contamination. Environmental Geology, 57, no. 4: 797-808

HYDRUS-2D, 1999. Computer Program for Simulating Water Flow, Heat, and Solute Transport in Variably Saturated Porous Media. USDA, Riverside, CA

Jeannin, P.-Y., and Sauter, M., 1998. Analysis of karst hydrodynamic behaviour using global approach: a review, Bulletin d'Hydrogéologie (Neuchâtel) 16: 9-30

Jukić, D., and Denić-Jukić, V., 2009. Groundwater balance estimation in karst by using a conceptual rainfallrunoff model, Journal of Hydrology, 373: 302-315

Király, L., 2002. Karstification and Groundwater Flow. In: Proceedings of the Conference on Evolution of Karst: From Prekarst to Cessation. Postojna-Ljubljana: 155-190

Kovacs, G., 1981. Seepage hydraulics, developments in water science, 10: Elsevier, Amsterdam/Oxford/New York

Kristensen, K.J, and Jensen, S.E., 1975. A model for estimating actual evapotranspiration from potential transpiration. Nordic Hydrology, 6: 70-88

Mohrlok, U., and Sauter, M., 1997. Modelling groundwater flow in a karst terrane using discrete and double continuum approaches: Importance of spatial and temporal distribution of groundwater recharge. In 6th Conference on Limestone Hydrology and Fissured Media, Proc. of the 12th International Congress of Speleology, 10-17 August 1997, La Chaux-de-Fonds, Switzerland, 2: 167-170

Perrin, J., Jeannin, P.-Y., and Zwahlen, F., 2003. Epikarst storage in a karst aquifer: a conceptual model based on isotopic data, Milandre test site, Switzerland. Journal of Hydrology, 279: 106-124

Reimann, T., and Hill, M.E., 2009. MODFLOW-CFP: A new conduit flow process for MODFLOW-2005: Ground Water, 47: 321-325

Roulier, S., Baran, N., Stenemo, F., Morvan, X., Albrechtsen, H.J., Clausen, L., Mouvet, C., and Jarvis, N. 2006. Controls on atrazine leaching through a soil-unsaturated fractured limestone sequence at Brévilles, France. Journal of Contaminant Hydrology, 84: 81-105

Sahoo, G.B., Ray, R, and De Carlo E.H., 2006. Calibration and validation of a physically distributed hydrological model, Mike She, to predict streamflow at high frequency in a flashy mountainous Hawaii stream. Journal of Hydrology, 327: 94-109

Sauter, M., 1992. Quantification and forecasting of regional groundwater flow and transport in a karst aquifer (Gallusquelle, Malm, SW. Germany). Tübinger Geowissenschaftliche Arbeiten, C13, 150pp

Sauter, M., 1997. Differentiation of fast and slow flow components in a karst aquifer using the $\delta^{18} \mathrm{O}$ signature Data analysis and modeling. In: Kranjc, A. (ed), Tracer Hydrology 97, Balkema: 435-441 
Scanlon, B., Mace, R., Barrett, M., and Smith, B., 2003. Can we simulate regional groundwater flow in a karst system using equivalent porous media models? Case study, Barton Springs Edwards aquifer, USA. Journal of Hydrology, 276: 137-158

Sciuto, G., and Diekkrüger B., 2010. Influence of soil heterogeneity and spatial discretization on catchment water balance modelling. Vadose Zone Journal, 9: 955-969

Šimůnek, J., Huang, K., and van Genuchten M.H., 1998. The HYDRUS code for simulating the one-dimensional movement of water, heat, and multiple solutes in variably-saturated media. Version 6.0. Res. Rep. 144. U.S. Salinity Lab., Riverside, CA

Stakman, W.P., 1966. The relation between particle size, pore size and hydraulic conductivity of sand separates. Proceeding Unesco Symposium on water in the consaturated zone: 373-383

Teutsch, G., and Sauter, M., 1998. Distributed parameter modelling approaches in karst-hydrological investigations. Bull. D’Hydrogéologie, 16: 99-109

Van Genuchten, M. Th., 1980. A closed-form equation for predicting thehydraulic conductivity of unsaturated soils. Soil Science Society of America Journal, 44: 892-898

Zhang, Z., Wang, S., Sun, G., McNulty, S., Zhang, H., Li, J., Zhang, M., Klaghofer, E., and Stauss P., 2008. Evaluation of the Mike She model for application in the Loess Plateau. China. JAWRA, 44: 1108-1120 


\section{ASSESSMENT OF EFFECTIVE TRANSPORT PARAMETERS IN A KARST SYSTEM UNDER DYNAMIC FLOW CONDITIONS BY ARTIFICIAL TRACER EXPERIMENTS}

Doummar, Joanna ${ }^{1} *$, Margane, $\operatorname{Armin}^{2}$, Sauter, Martin ${ }^{1}$, Geyer, Tobias ${ }^{1}$

(2) Geowissenschaften Zentrum, University of Göttingen, Goldschmidtstr. 3, D-37077 Göttingen, Germany;

(3) Bundesanstalt für Geowissenschaften und Rohstoffe (BGR), Hannover, Germany

*Corresponding author: e-mail: jdoumma@gwdg.de; Phone: (49) 551 397913; Fax: (49) 551399379.

Doummar, J., Margane, A., Sauter, M., and Geyer, T., 2012. Assessment of effective transport parameters in a karst system under dynamic flow conditions by artificial tracer experiments. In preparation for submission to a peer-reviewed journal

\section{Keywords}

Artificial tracer tests; transport parameters; karst; relationships; 2RNEM 


\section{Abstract}

The understanding of the sensitivity of a catchment to contamination is a prerequisite for a sustainable water resource management in karst aquifers. Artificial tracer tests have been demonstrated as excellent tools for the investigation of conservative contaminant transport within an aquifer since they provide information about transit times, dispersivities and therefore insight into the vulnerability of a water body to contamination. For this purpose, extensive analyses of artificial tracer tests were undertaken in a mature karst system in order to estimate conservative transport parameters along fast and slow flow pathways under variable flow conditions. Approximately, 30 artificial tracer experiments were conducted in the of the Jeita spring catchment area in Lebanon $\left(Q=1\right.$ to $25 \mathrm{~m}^{3} / \mathrm{s}$ ) under various flow conditions and with different injection points (dolines, sinkholes, subsurface, and underground channel).

Tracer breakthrough curves (TBC) observed at karst springs and in the channel system (saturated zone) were interpreted using the Two Regional Non Equilibrium approach (2RNEM). The approach accounts for the skewness in the TBCs long tailings, which cannot be described with a one dimensional advective-dispersive transport model (ADM). Relationships between the Modelling parameters estimated from the TBC were established under various flow periods. Rating curves for velocity and discharge show that the mean flow velocity increases with spring discharge (polynomial relationship due to the variation of the flow section area during different flow conditions). The calibrated proportion of immobile region (portrayed by a partition coefficient $\beta ; 0.93-0.99)$ in the conduit system is small. Estimated longitudinal dispersivity $(\alpha)$ in the conduit system ranges between 7 and $10 \mathrm{~m}$ in high flow periods and decreases linearly with increasing flow as advection control over dispersion becomes more prominent with increasing flow rates. During low flow periods, this relationship doesn't hold because longitudinal dispersivities range randomly between 4 and $7 \mathrm{~m}$. Therefore the variance $\left(\sigma^{2}\right)$ of the TBC is controlled on the one hand by dispersivity during high flow periods and on the other hand by an increasing immobile region in low flow periods due to an increase of the portion of immobile zones (pools and ripples) as water level decreases. A relationship was established between the peak concentration $\left(C_{p}\right)$ and longitudinal dispersion to depict the role of dispersion in the attenuation of the tracer under different flow dynamics. Apparent phreatic conduit diameters $(4-7 \mathrm{~m})$ increase with increasing discharge and velocities.

For tracer injections at the surface, longitudinal dispersivities are found to be of higher ranges (8-27 $\mathrm{m}$ ) and highly reflective of the compartments in which tracer is flowing (unsaturated rock matrix, fast flow pathways or channel). The comparison of artificial tracer tests with different injection points shows clearly that the tailing observed in some of the breakthrough curves is mainly generated in the unsaturated zone before the tracer arrives to the main channel draining the system.

\subsection{INTRODUCTION}

In a karst catchment, artificial tracer tests are frequently used for the delineation of catchment boundaries and recharge areas and to investigate fast contaminant transport through a system from a potential source of pollution (Perrin and Luetscher, 2008, Ford and Williams, 2007, Birk et al., 2005). At a catchment scale, karst aquifers consist of a conduit network draining a fissured matrix. The conduits can be of several meters in 
diameter and may carry large amounts of contaminants at high velocities with little abilities for degradation. The analysis of tracer breakthrough curves (TBC) help assess quantitatively the transport characteristics along a flow path, for instance, transport velocities and their variance with respect to the mean transit time (longitudinal dispersivity; Field and Nash, 1997, and Perrin and Luetscher, 2008). Many authors have shown that transport parameters reflect conduit geometries (Hauns et al., 2001, Perrin and Luetscher, 2008) and that dispersivity increases with distance (Hauns et al., 2001, Seiler et al., 1989). In addition to the spatial information provided by artificial tracer tests, the understanding of transport in a karst environment under various flow dynamics is important for the definition of vulnerability of the karst system, especially as vulnerability is regarded as varying temporarily depending on the flow conditions and response to precipitation events (Butscher and Huggenberger, 2008). The selection of mathematical models to analyze artificial tracer tests depends on the shape of the observed TBC. Symmetrical TBCS are often analyzed with a conventional Advection Dispersion Model (ADM), however when the latter fails to reproduce the asymmetrical shape of the TBC. Non equilibrium models might be applied and tailing due to exchange between mobile and immobile fluid regions such as stagnant zones or irregularities at the walls are considered (Field and Pinsky, 2000). The analysis of a single TBC with the non-equilibrium model might yield different sets of calibration parameters. The repetition of experiments under different flow conditions provides additional important information for understanding of transport in karst conduits. Furthermore, the performance of experiments at different locations or along different tracer flow pathways gives insights into the variability of transport parameters within the compartments of a karst system.

The present work aims at identifying transport parameters and the potential conservative transport processes, which play a role in tailoring the TBC such as dilution, dispersion, and tracer exchange, in a karst system under various flow dynamics through different compartments (Smart 1988, Field and Nash, 1997). For this purpose, artificial tracers were injected (Dirac pulse) in a phreatic channel and at karst surface features, e.g. in sinkholes. The results are analyzed mainly with respect to mean velocities and transit times.

\subsection{FIELD SITE}

The artificial tracer tests were carried out in the groundwater catchment of the Jeita spring, which is located north to Beirut in Jounieh area. It constitutes the main water source for the Beirut area and its northern suburbs for domestic use (about 1.5 million inhabitants). The discharge of the Jeita spring ranges from $1 \mathrm{~m}^{3} / \mathrm{s}$ during low flow periods to about $25 \mathrm{~m} \mathrm{~m}^{3} / \mathrm{s}$ during high flow periods mostly as response to precipitation events (based on continuous monitoring since 2009). The Jeita Spring drains a catchment composed of limestone of Jurassic age, ranging in altitude from 90 to $2000 \mathrm{~m}$ above sea level, and extending east in the Lebanese Mountains (Figure 4-1).

The total annual precipitation on the Jeita Catchment is estimated to about $1200 \mathrm{~mm}$ on average (2009-2011, Beirut International Airport). The spring is connected to the Jeita cave, which acts as underground drainage channel developed in limestone of the Jurassic age. The total length of the surveyed cave (excluding subsidiaries) is around $5300 \mathrm{~m}$ (Karkabi, 1988) from the last accessible point to the cave outlet. 


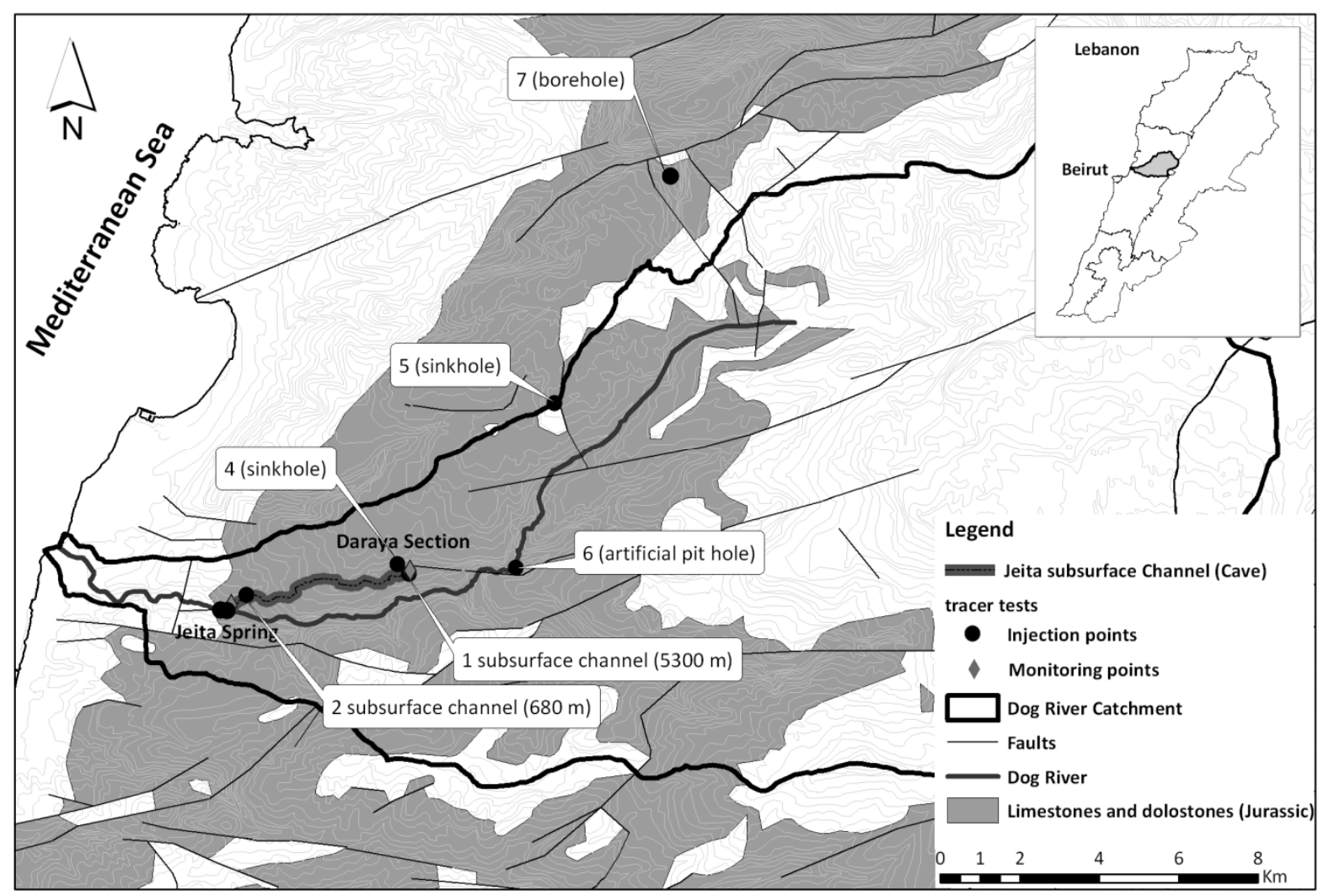

Figure 4-1 Location of the artificial tracer experiments undertaken on the catchment of Jeita Spring, northern Lebanon

\subsection{Methods}

\subsubsection{Field experiments}

The three tracers, uranine (sodium fluorescein, BASF, CAS 518-47-8, $\left.\mathrm{C}_{20} \mathrm{H}_{10} \mathrm{O}_{5} \mathrm{Na}_{2}\right)$, amidorhodamin $\mathrm{G}\left(\mathrm{C}_{25} \mathrm{H}_{26}\right.$ $\mathrm{N}_{2} \mathrm{O}_{7} \mathrm{Na}$ ) and sodium naphtionate $\left(\mathrm{C}_{20} \mathrm{H}_{8} \mathrm{O}_{3} \mathrm{~N} \mathrm{~S} \mathrm{Na}\right.$ ) were selected as they are considered non toxic (Kaess, 1998). Tracer concentrations were simultaneously monitored in the springs with field fluorometers (GGUNFL30; Schnegg 2002). The fluorometer measures at specific time interval dye concentrations at the monitoring site which are then stored in a data logger. The field fluorometers were calibrated for the three applied tracers. The limit of detection of the field fluorometer is a concentration of $0.02 \mu \mathrm{g} / \mathrm{l}$ for uranine, $0.2 \mu \mathrm{g} / \mathrm{l}$ for amidorhodamine $\mathrm{G}$, and $0.07 \mu \mathrm{g} / \mathrm{l}$ for sodium naphtionate. Fluorometers were deployed at the Jeita spring (J) at the entrance of the subsurface channel (cave), at the end of the phreatic cave (D), and at various distances within the cave outlet (Figure 4-2, (1, 2, and 3)). 


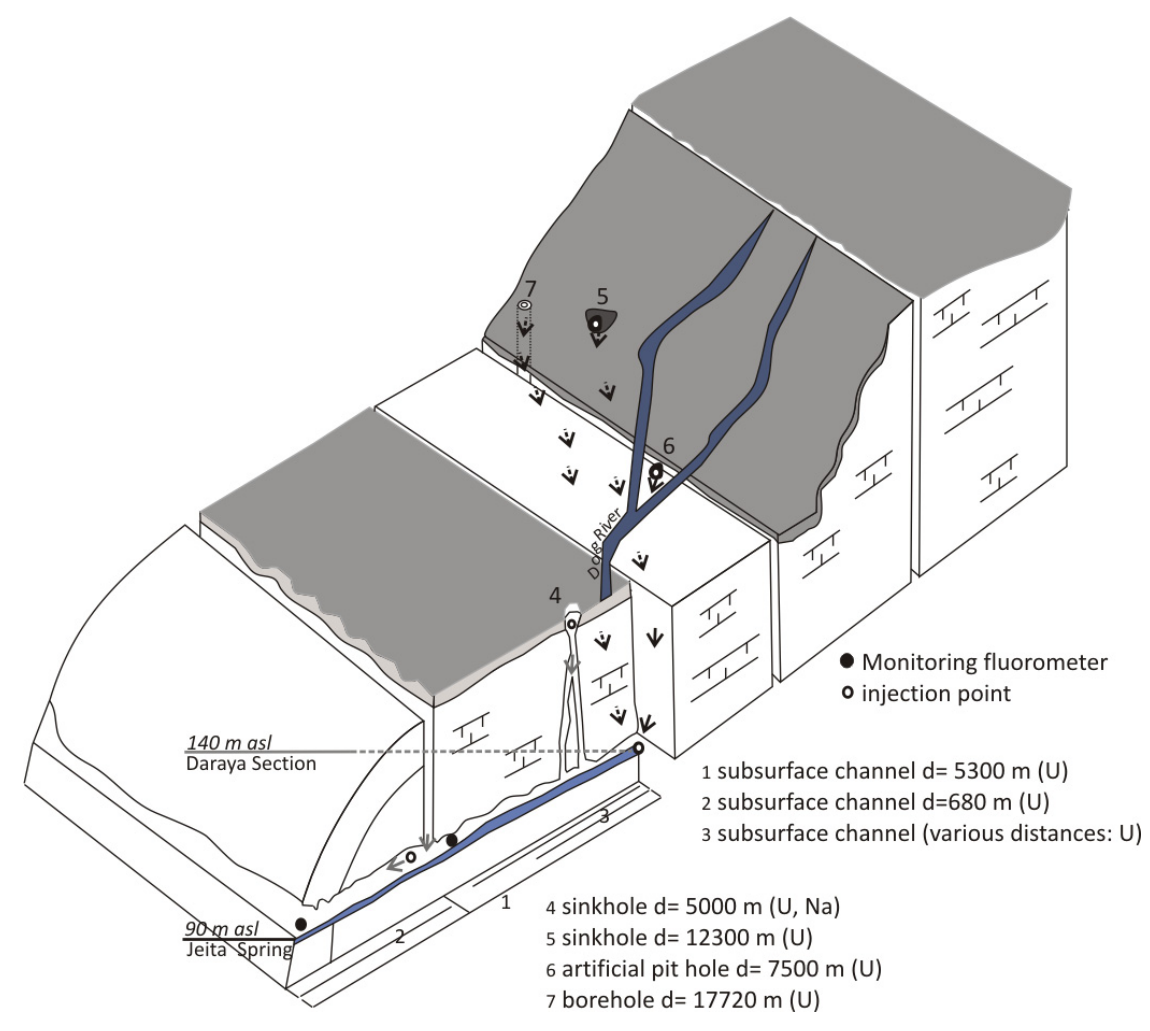

Figure 4-2 Artificial tracer experiments at the Jeita spring (U: uranine, AG: amidorhodamine, Na: sodium naphtionate)

In total 32 artificial tracer tests were performed in the Jeita spring catchment in the period from April 2010 to December 2011. Twenty three tracer injections were performed directly in the Jeita subsurface channel under different flow conditions (BGR; Doummar et al., 2011; Appendix A).

Artificial tracers were also injected in two sinkholes (Figure 4-2, (4, 5)), in an artificial pit hole (Figure 4-2, (6)) and in a borehole (Figure 4-2, (7) to acquire transport parameters in the media before the tracer reaches the subsurface channel and within the phreatic cave.

\subsubsection{Modelling Technique}

The observed tracer breakthrough curves (TBCs) were analyzed numerically with the process-based Modelling approach CXTFIT 2.1 (Toride et al. 1999). TBCs were analyzed with the Two Region Non Equilibrium Model (2RNEM) based on the assumption that the tracer moves within a mobile fluid region and exchanges with an immobile fraction, which is hosted in dead end passages and sediments pools (Field and Pinsky, 2000, Geyer et al., 2007). The exchange between mobile and immobile fluid region simulates the strong tailing of a TBC, which cannot be explained with a simple ADM approach. The Modelling of the TBCs with 2RNEM allows in addition to the estimation of the mean transit times, mean velocities $\left(v_{m}\right)$, and longitudinal dispersion (D), the assessment of the portion of immobile region and the exchange between immobile and mobile regions (partition coefficient; $\beta$ and $1^{\text {st }}$ order mass transfer rate; $\omega$ ). The corresponding equations of the 2RNEM are (Toride et al. 1999; Equation 1, Equation 2) 
$\beta R \frac{\partial c_{m}}{\partial t}=D \frac{\partial^{2} c_{m}}{\partial x^{2}}-v_{m} \frac{\partial c_{m}}{\partial x}-\omega\left(c_{m}-c_{i m}\right)-\theta_{m} \mu_{1} c_{m}$

$(1-\beta) R \frac{\partial c_{i m}}{\partial t}=\omega\left(c_{m}-c_{i m}\right)-\theta_{i m} \mu_{1} c_{i m}$

where $v_{m}$ is the mean velocity $[L / T], D$ is the dispersion coefficient $\left[L^{2} / T\right], \beta$ is fraction of the mobile fluid region $[-], R$ is retardation coefficient [-], $\omega$ is the first order mass transfer coefficient [1/T], $c_{i m}$ and $c_{m}$ are the respective concentration of mobile and immobile fluid regions $\left[\mathrm{M} / \mathrm{L}^{3}\right], \mu_{1}$ is the is a first-order degradation coefficient in the liquid region of mobile and immobile fluid regions and $x$ is the space coordinate $[\mathrm{L}]$ and $t$ is time [T]. Reactive transport, i.e., $\mu_{1}$ and $\mathrm{R}$ will be discarded for the purpose of this work.

Tracer injection is simulated by a Dirac pulse, i.e. tracer injection period is negligible compared to the observed tracer travel time. The estimation of transport parameters with CXTFIT is performed inversely, i.e. the numerical model iterates, based on transport preset parameters, to reproduce an observed tracer breakthrough curve. Based on the calibrated parameter an equivalent phreatic diameter $(\phi)$ was calculated for various flow periods using the total volume elapsed during the mean transit time divided by the total length of the channel (Equation 3)

$\phi=2 \sqrt{\frac{\int_{0}^{t_{m}} Q(t) d t}{\pi d}}$

where $\phi$ is the phreatic diameter $[\mathrm{L}], \mathrm{Q}$ the discharge $\left[\mathrm{L}^{3} T\right], \mathrm{t}_{\mathrm{m}}$ the mean transit time $[\mathrm{T}]$, d the distance between injection and observation points [L]; (Field, 2002).

Based on the calibrated transport parameters longitudinal dispersivity $\left(\alpha=D / v_{m}\right)$ and Peclet number $(d / \alpha)$, were estimated for all of the simulated TBCs.

The model was calibrated by fitting all four parameters $\left(v_{m}, D, \beta\right.$ and $\left.\omega\right)$ using two objective functions (the Mean Square Error (MSE; Equation 4) and the coefficient of correlation $\left(R^{2}\right)$. Sensitivity analysis was conducted on a set of parameters on selected curves to depict the importance of each parameter in the calibration process. It shows that unlike for dispersion $(D)$ and mass transfer coefficient $(\omega)$, the variation of mean velocity $\left(v_{m}\right)$ and the partition coefficient increase the MSE by one order of magnitude and consequently affect the correlation between fitted and observed data.

$\operatorname{MSE}(t)=\frac{1}{n} \sum_{i=1}^{k} f_{i}\left(x_{i}-t\right)^{2}$

where $\mathrm{n}$ is the total number of observation data, $f_{i}$ is the frequency of the $i^{\text {th }}, \mathrm{x}_{\mathrm{i}}$ is the class mark of the $i^{\text {th }}$ class, and $\mathrm{t}$ is the modeled point. 


\subsection{RESULTS}

The TBCs obtained for the artificial tracer tests conducted in the subsurface channel are presented normalized with respect to the peak concentration in Figure 4-3. TBCs normalized with respect to peak concentration $\left(C_{p}\right)$ obtained from tracer tests conducted on surface features are provided in Figure 4-4.

Various estimated/modeled parameters under different flow periods were correlated for a better understanding of the transport within the rapid flow system, in both the saturated, unsaturated media and the underground channel.

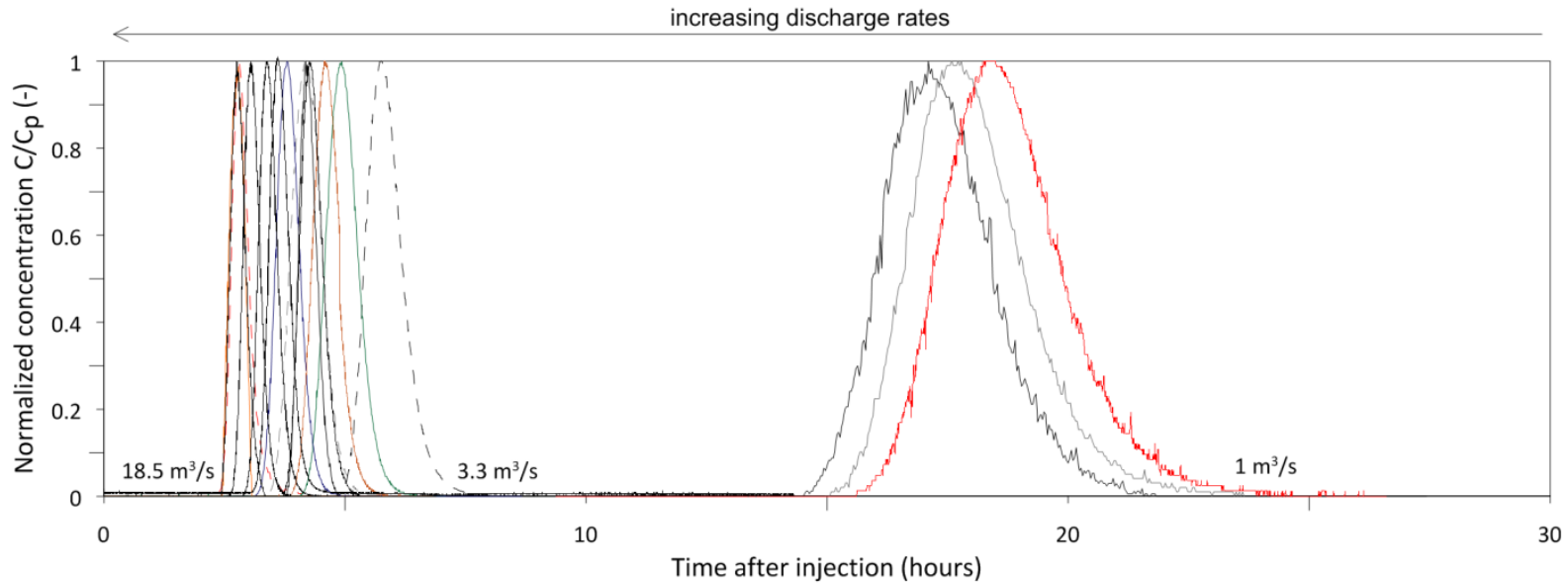

Figure 4-3 Measured normalized TBCs $\left(C / C_{p}\right)$ in the subsurface channel (over $\left.5300 \mathrm{~m}\right)$ as a function of time after injection

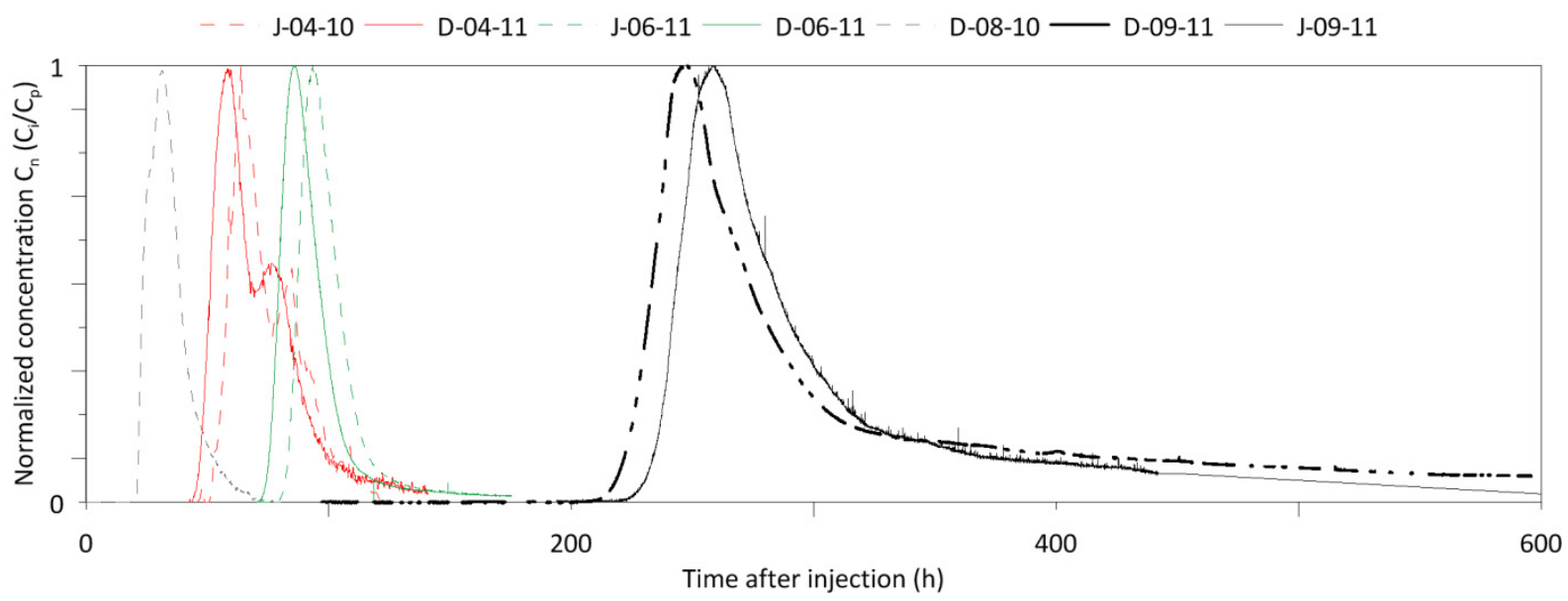

Figure 4-4 Measured TBCs from surface injections as observed in the main spring ( $\mathrm{J}$ at the end of the subsurface channel) and at the beginning of the channel (D); J refers to TBCs at the spring outlet, and D is the beginning of the subsurface channel 


\subsubsection{Transport in the channel}

\subsubsection{Velocities and transit times}

The tracer breakthrough curves (TBCs) retrieved from the 23 artificial tracer experiments undertaken in the underground channel displaying slight to very slight tailing (Figure 4-4). Mean velocities estimated for discharge rates varying between 1.0 and $18.5 \mathrm{~m}$ /s range respectively between 285 and $1910 \mathrm{~m} / \mathrm{hour}(0.08$ and $0.53 \mathrm{~m} / \mathrm{s})$. The velocity in the channel correlates $(\mathrm{R}=0.997)$ with the discharge rate according to a fourth degree polynomial relationship. The conduit network and its geometry may vary under varying flow conditions (Smart, 1988). Therefore, this relationship is not linear (Figure 4-5) due to the change in the cross-sectional area and the head difference which creates quadratic effects during various flow periods. The wetted phreatic diameter $(\phi)$ averaged over the entire distance $(5300 \mathrm{~m})$ varies proportionally with varying discharges, with a minimal apparent diameter during low flow periods of $4 \mathrm{~m}$ reaching a maximum of $7 \mathrm{~m}$ during high flow period. As a result, the slope of velocity as a function of discharge is less steep when the wetted section is widened (Figure 4-5). Times of first arrival $\left(t_{f}\right)$ and transit times of the peak concentration $\left(t_{p}\right)$ correlate $(R>0.99)$ with the mean transit time $\left(t_{m}=1.202 t_{f}=1.021 t_{p}\right)$. The transit time - discharge relationship over the distance of the subsurface channel $(5300 \mathrm{~m})$ is a power function. The duration of the tracer breakthrough curve, which ranges between 0.6 and 4.3 hours is also a power function of the discharge.
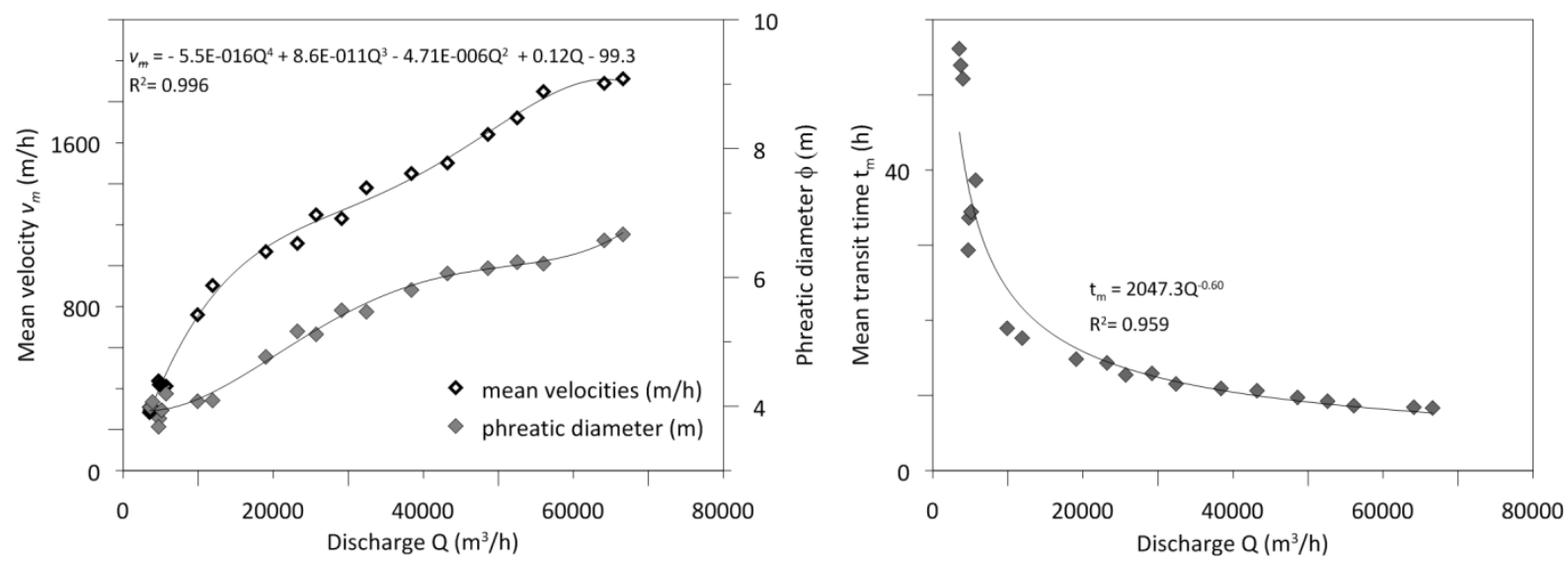

Figure 4-5 diameter ( $\phi)$

\subsubsection{Longitudinal dispersion and dispersivity}

Longitudinal dispersion (D) and mean velocity $\left(v_{m}\right)$ increase with the discharge rate according to a polynomial of the third degree $(R=0.977)$. Peclet numbers are greater than 100 indicating a predominant advective transport (Field, 2002).

In high flow periods, longitudinal dispersivities (over the same distance $5300 \mathrm{~m}$ ) range from $7.0 \mathrm{~m}$ to $9.0 \mathrm{~m}$ decreasing with increasing discharge rates. The relationship between the longitudinal dispersivity and the discharge rate is linear ( $R=0.924$; Figure 4-6) for high flow periods. During low flow ( $Q$ less than $3.5 \mathrm{~m}^{3} / \mathrm{s}$ ) periods this relationship does not apply as dispersivity varies between 3 and $6 \mathrm{~m}$. 

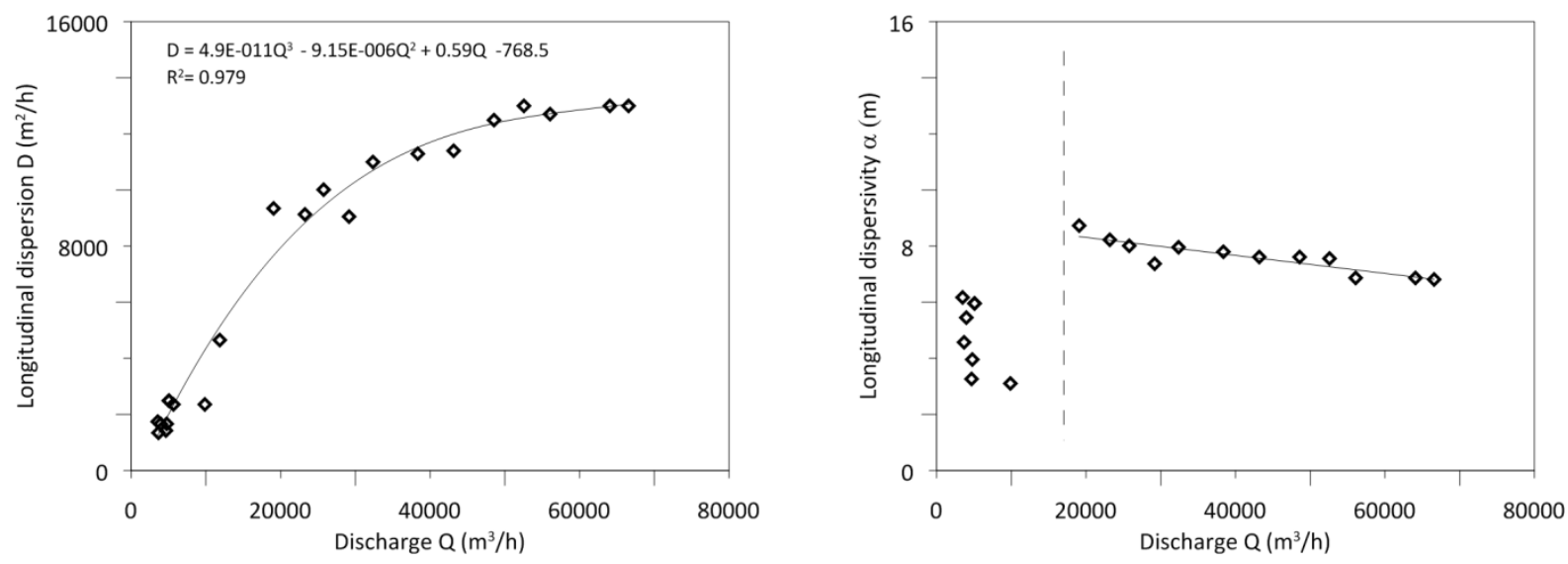

Figure 4-6 Relationships between longitudinal dispersion (D) and longitudinal dispersivity ( $\alpha$ ) and discharge (Q)

\subsubsection{Attenuation of peak concentration}

The normalized concentration peak ( $C_{n}$; peak concentration to recovered mass) decreases with increasing longitudinal dispersion showing the effect of dispersion on dilution with increasing discharge rates. Different slopes are observed during high and low flow periods (Figure 4-7).
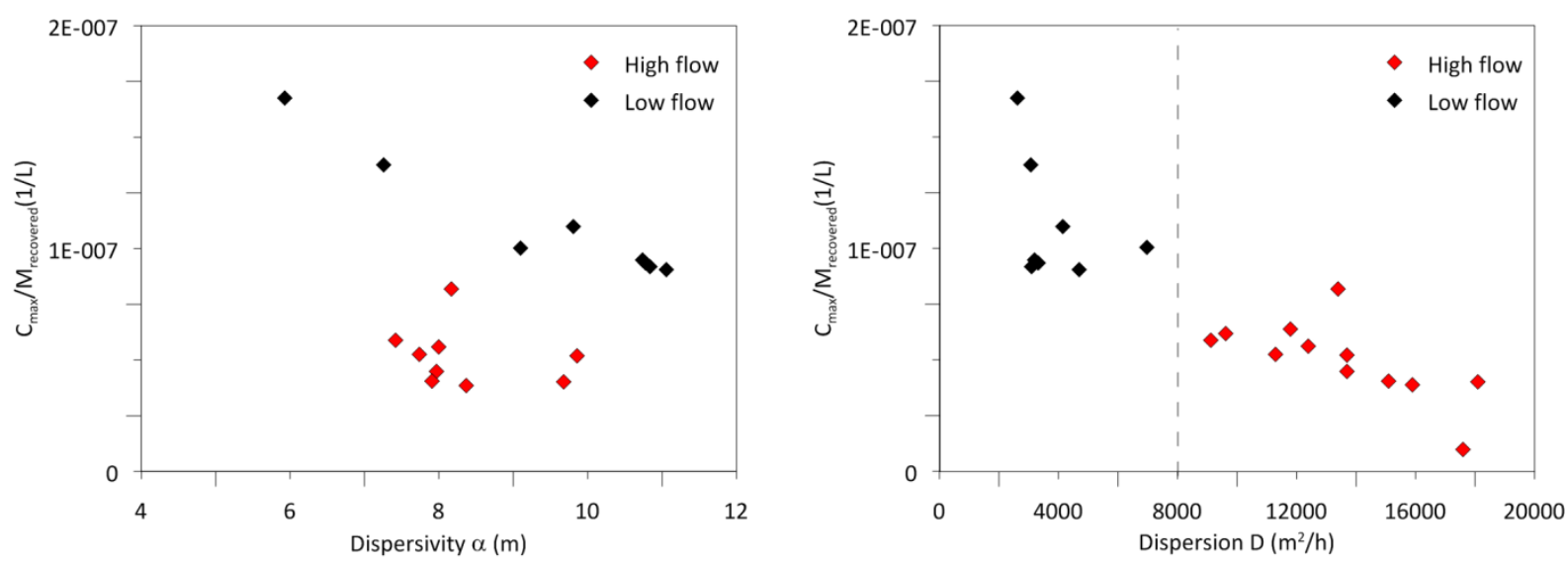

Figure 4-7 Correlation between longitudinal dispersion and longitudinal dispersivity and attenuation of the artificial tracer peak concentration $\left(\mathrm{C}_{\mathrm{p}} / \mathrm{M}_{\text {recovered }}\right)$

\subsubsection{Immobile regions}

The portion of immobile region in the channel is not very prominent, as the partition coefficient ranges between 0.93 and 1 (Figure 4-8) portrayed by a subtle tailing. Nevertheless, the partition coefficient $(\beta)$ increases with increasing velocities and distances. Additionally, the higher the percentage of immobile region, the higher is the exchange of tracer between mobile and immobile region with time $(\omega)$. 

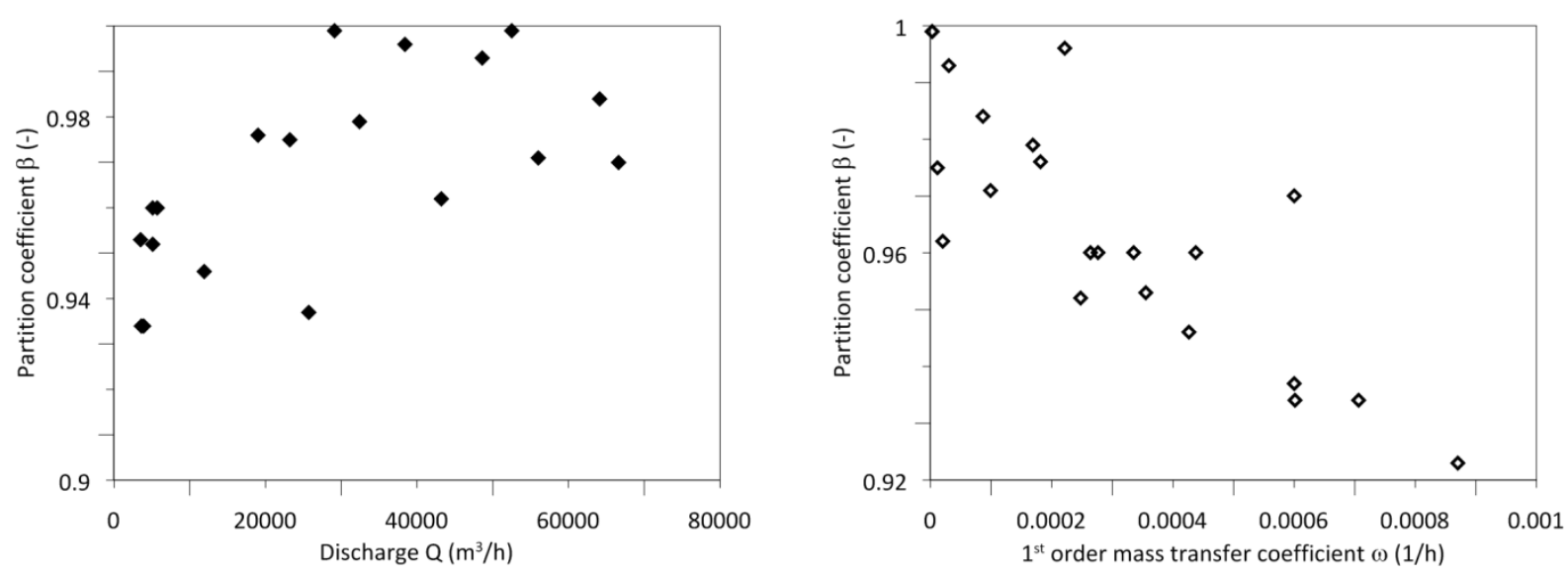

Figure 4-8 Correlation between partition coefficient $(\beta)$ and discharge $(Q)$ as well as with the mass transfer coefficient $(\omega)$

\subsubsection{Transport parameters over varying distances}

Dispersivities over a transport distance of $680 \mathrm{~m}$ range between $2 \mathrm{~m}$ and $4 \mathrm{~m}$ and decreases with discharge rates, whereas dispersivities over $5300 \mathrm{~m}$ vary between $4 \mathrm{~m}$ and $9 \mathrm{~m}$ under different flow periods. The dispersivities appear to be increasing with distances; such correlation is observed also by Seiler et al., (1989). The artificial tracer test monitored at various observation points within the channel shows that mean velocity decreases with distance, while estimated longitudinal dispersivity increases with distance. The TBC shows a dilution effect by additional inflow of water within the channel between the monitored locations.

\subsubsection{Transport outside the channel (compartments of the karst systems)}

The results discussed hereafter are those of the tests conducted in a sinkhole leading directly to the subsurface channel (Figure 4-2, (4)), in a sinkhole (Figure 4-2, (5)), in an artificially dug pit hole (Figure 4-2, (6)) and a borehole (Figure 4-2, (7)). The results therefore portray the transport in the following media:

1. Sinkhole leading directly to the subsurface channel (phreatic cave)

2. Fissured saturated matrix (borehole)

3. Unsaturated rock matrix overlying the subsurface channel

4. Mixed media including the unsaturated zone and the subsurface channel

\subsubsection{Velocities and transit times}

The velocities vary between 40 and $200 \mathrm{~m} / \mathrm{h}$, with lowest velocities being reflective of the transport in the unsaturated zone, highest values portraying transport in the sinkhole linked directly to the cave. The mean velocity for transport in the unsaturated zone and in the subsurface channel is about $120 \mathrm{~m} / \mathrm{h}$ for the two undertaken artificial tracer tests, However it should be noted that the observed velocities depend on the injection/ infiltration rates, and are therefore maximum velocities triggered by flushing (Figure 4-9, a). 


\subsubsection{Longitudinal dispersion and dispersivity}

The artificial tracer tests conducted on the catchment area reveal that estimated longitudinal dispersivities range between 8 and $27 \mathrm{~m}$. The estimated longitudinal dispersivities generally decrease with increasing velocities, as a result of which they are highest than the one observed in the subsurface channel (Figure 4-9, b). The calculated apparent phreatic diameter varies between 7 and $14 \mathrm{~m}, 7-11$ meters reflecting the flow in the sinkhole directly linked to the main sub channel system and $11-14 \mathrm{~m}$ reflecting the phreatic diameter in the unsaturated zone.

The mobile region estimated from TBCs in tracer tests conducted in sinkholes or directly on the surface varies between 0.80 and 0.93 (Figure 4-9, c). The partition coefficient is lowest as portrayed by the prominent tailing of the TBC for tracer tests performed on pit holes. The partition coefficient increases (decrease of immobile region) with increasing Peclet number which varies between 72 and 1000 (Figure 4-9, d). As observed in the subsurface channel, longitudinal dispersion plays a role in the attenuation of the tracer (peak concentration), especially in low flow periods (steeper slope; Figure 4-10).
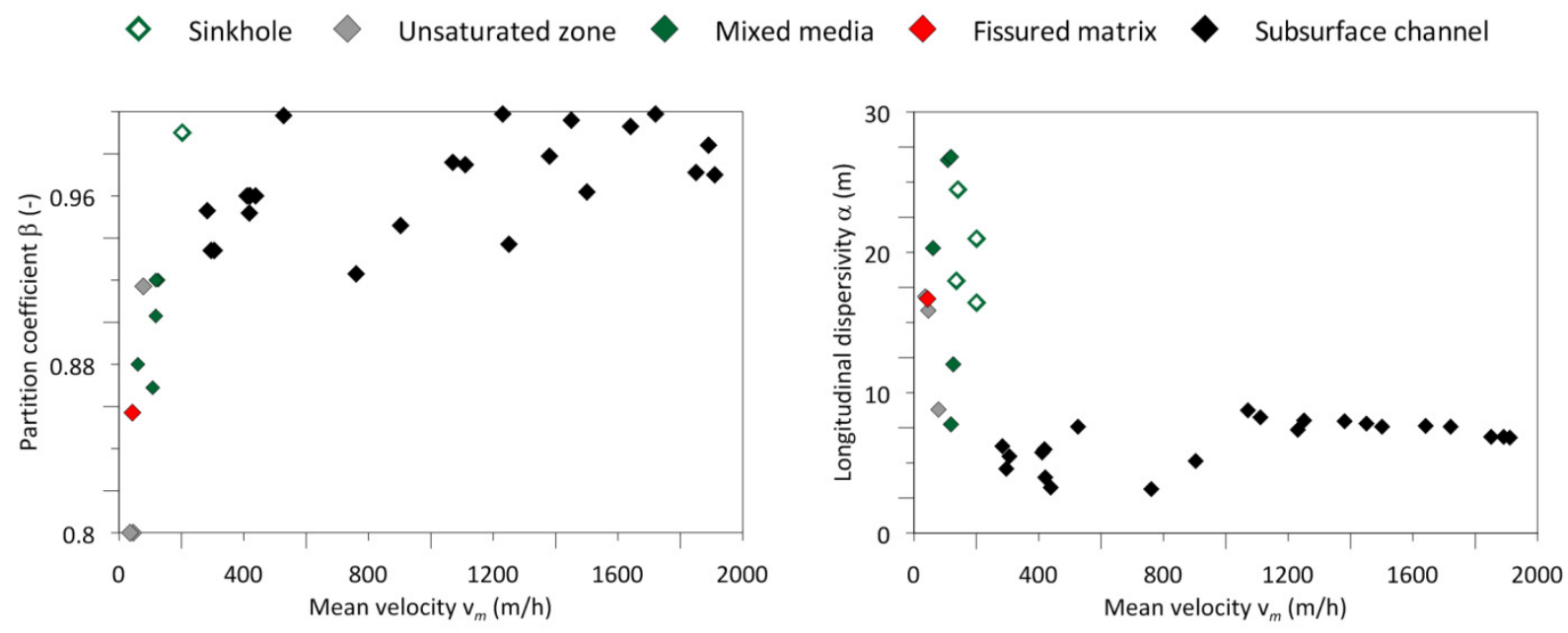

a
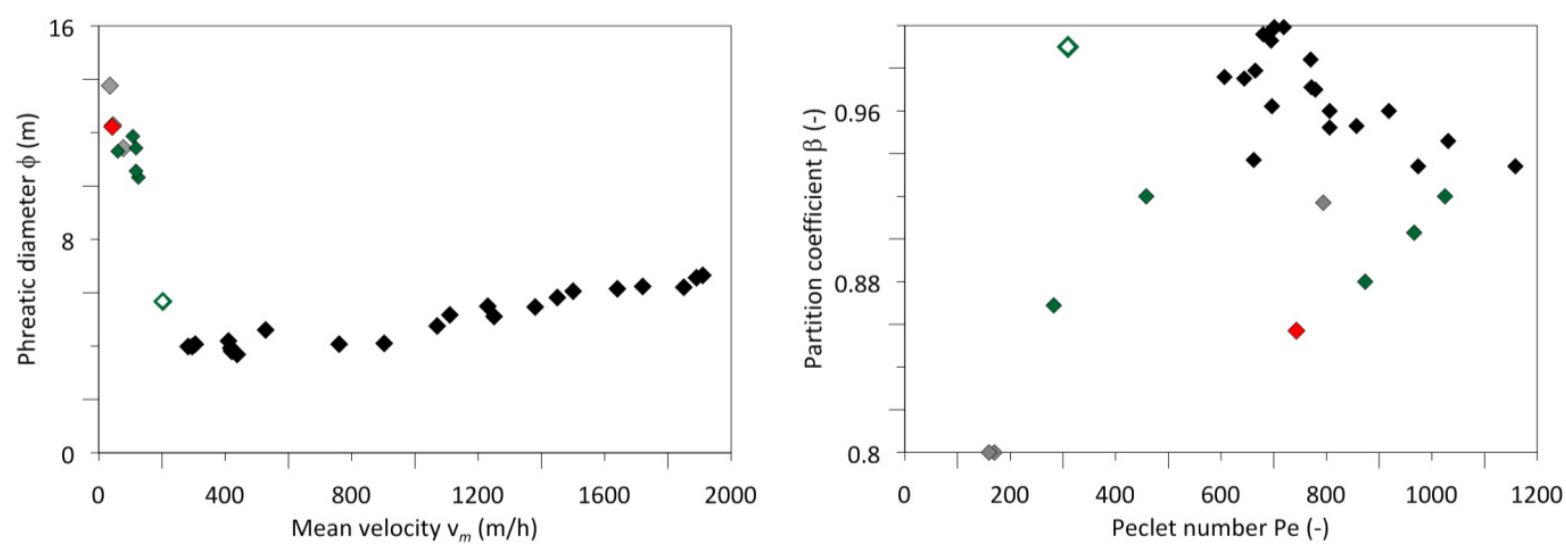

C

d

Figure 4-9 Relationships between various transport parameters (mean velocity to partition coefficient; a, longitudinal dispersivity; $b$, and phreatic diameter; $c$ ) from the tracer tests performed in the subsurface channel as well as from surface injections (different compartments in the karst aquifer). Control of advection (Pe number) over partition coefficient (d) 


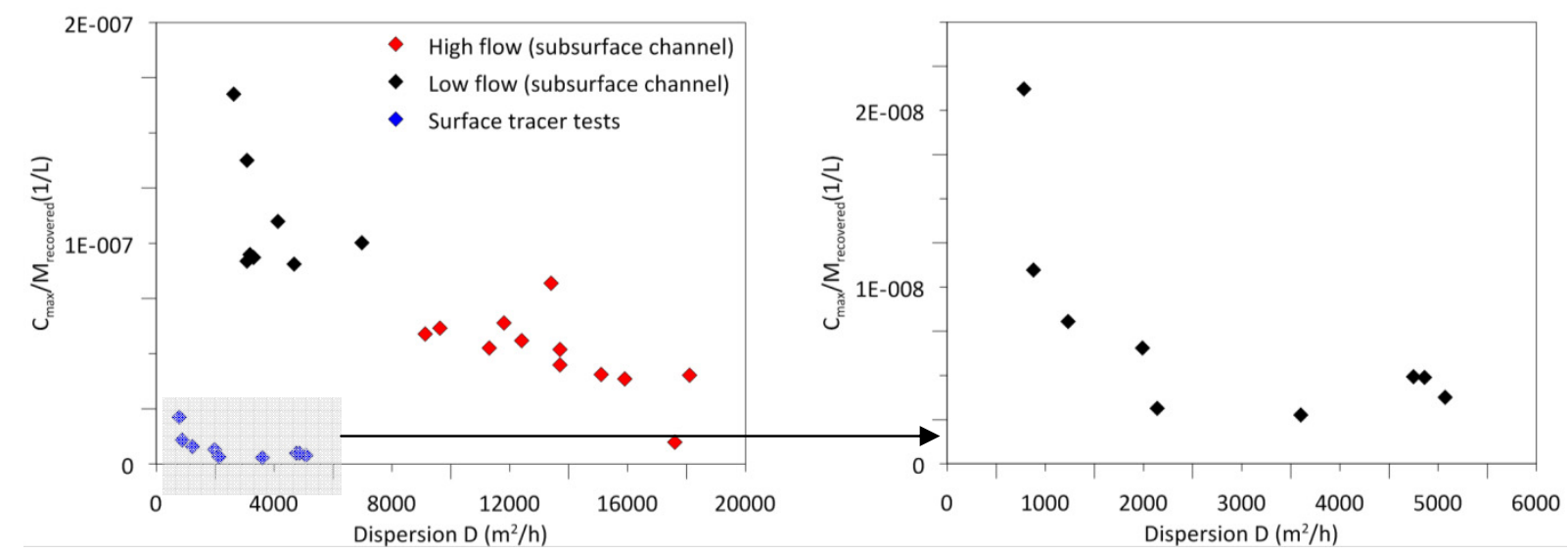

Figure 4-10 Importance of dispersion in the attenuation of the maximum observed peak in all the compartments of the investigated karst system under various flow dynamics

\subsection{Discussion}

Through an extensive artificial tracer tests analysis, different transport parameters are respectively attributed to flow distance and flow regime in the subsurface channel, unsaturated zone (UZ) or mixed media (UZ and subsurface channel) in a karst system.

According to Smart (1988), the discharge of an aquifer is not linearly connected with the conduit diameter; therefore it is important to determine discharge thresholds, beyond which the aquifer behaves differently. In the subsurface channel, for discharge rates below $12600 \mathrm{~m}^{3} / \mathrm{h}\left(3.5 \mathrm{~m}^{3} / \mathrm{s}\right)$, the variation of transit time decreases exponentially with discharge, i.e., the tracer transit time is variable in higher ranges for discharge rates between 3530 and $12600 \mathrm{~m}^{3} / \mathrm{h}$, between 19 and 6 hours, whereas for discharge rates above $12600 \mathrm{~m}^{3} / \mathrm{h}$, they only range between 2.8 and 5.0 hours. In other words, $12600 \mathrm{~m}^{3} / \mathrm{h}$ can be considered as a threshold beyond which velocities increase drastically, especially during responses to rain events, and the longitudinal dispersivities $(\alpha)$ have different trends as well as a different degree for attenuation of tracer peak concentration.

This discrepancy can be either attributed to a widening of the wetted area of the channel beyond this level and/or to the change in gradient in flow periods from events to base flow beyond this level. TBCs during low flow periods $\left(Q<12600 \mathrm{~m}^{3} / \mathrm{h}\right.$ ) generally display an asymmetrical shape (Werner et al., 1997) where a longer tailing of the falling limb is observed. The strong tailing during low flow periods leads to a high variance in the TBC and can be attributed to the higher portion of immobile regions while longitudinal dispersivity remains small. The percentage of the mobile region which contributes to the tracer breakthrough curve increases with decreasing velocities. The decrease of water level during low flow period and decrease of the wetted flow area lead to emergence of irregularities which enhance the proportion of the immobile region. The increasing turbulence of flow associated with high velocities during high flow periods is thought to increase the exchange between mobile and immobile flow regions and decrease tailing effects.

Dispersion is not linearly proportional to the mean flow velocity, and a constant dispersivity cannot be assigned to the channel under different flow periods. The slight decrease of dispersivity during increasing discharge rate may be due to an increasing dilution effect from water inflowing to the channel with high flow periods. 
Dispersivity is found to increase with distance within the subsurface channel because of the increase of heterogeneities in the channel (Seiler et al., 1989).

In all the analyzed TBCs, dispersion is inversely proportional to the normalized peak concentration, i.e., the higher the dispersion the lower the normalized concentration peak $(C p)$ and the higher the attenuation of the artificial tracer. It shows how mean flow velocity together with, diffusion and dispersion play a role in the dilution of the contaminant in the saturated zone (Civita, 2010). Over a certain threshold $\left(8000 \mathrm{~m}^{2} / \mathrm{h}\right.$ ), dispersion appears to have less control on the attenuation of tracer peak concentration. This relationship between dispersion and normalized peak concentration can also be observed in surface tracer tests, i.e., in the other compartments of the karst system as well beside the subsurface channel.

The apparent phreatic conduit diameter estimated from an artificial tracer test undertaken in a sinkhole connected directly to the subsurface channel is in the range of phreatic diameters of the latter. Whereas the phreatic diameters estimated from the artificial tracer tests conducted on other surface features are beyond that range and decrease with increasing velocities.

Three ranges of mean velocities are retrieved from artificial tracer tests undertaken on surface features. Mean velocities in the unsaturated zone (percolation through unsaturated fissured matrix blocks, around $40 \mathrm{~m} / \mathrm{h}$ ), mean velocities in sinkholes directly linked to the main sub channel system, and mean velocities which integrate both media. The partition coefficient i.e., portion of mobile region is lower for tracer tests conducted on the surface features (sinkhole, unsaturated zone; 0.80-0.92) with respect to that in the subsurface channel (0.92-1.0). The latter suggests that the significant tailing is generated before the tracer arrives to the subsurface channel. The increasing partition coefficient with increasing Peclet number shows that the higher the advective control over transport the lower the immobile region and tracer partitioning.

\subsection{CONCLUSIONS}

Artificial tracer tests are a powerful tool for the analysis of transport in karst media and vulnerability assessment. They allow understanding the behaviour of a conservative contaminant under different flow periods, in terms of velocities, transit times, duration of the conservative tracer breakthrough curve, longitudinal dispersivities and the variation of the peak concentration. For this purpose, an extensive campaign of artificial tracer tests was undertaken in a mature karst catchment area drained by the Jeita Spring in Lebanon which is dominated by a single phreatic conduit. The TBCs were analyzed using the 2RNEM to account for tailing generated in karst aquifers.

Relationships between discharge and other transport parameters could be established under various flow periods (e.g., velocity, longitudinal dispersion and dispersivity, partition coefficient reflective of immobile region, peak concentrations). A different transport behavior is observed beyond a certain discharge threshold. Lower dispersivities are observed during low flow period as variance of the TBC is controlled by the immobile region (i.e., tracer partitioning; tailing). The latter is greater during low flow periods due to dispersive irregularities such as pools and riffles occurring with the lowering of the water level. Longitudinal dispersivity appears also to decrease with increasing flow rate in high flow periods probably due to the effect of dilution. Flow and transport parameters in the unsaturated zone, including sinkholes or pit holes as well as for the 
draining subsurface channel could be defined. Mean velocities observed in the unsaturated zone are in the range of $30-200 \mathrm{~m} / \mathrm{h}$. Higher velocities are associated with sinkholes connected to the subsurface channel. The analysis of the TBCs with the Two Non Regional Equilibrium Model (2RNEM) allows quantifying the variation of the immobile region, which is mainly generated in the unsaturated zone before the tracer reaches the main draining channel.

Finally dispersion appears to be closely related to the attenuation of the peak concentration in all the compartments of the investigated karst system.

\section{Acknowledgement}

This study is part of a PhD study funded by the Deutscher Akademischer Austausch Dienst (DAAD; Referat 441). Data in this work was collected in the framework of the cooperation project "Protection of the Jeita Spring" undertaken by the Bundesanstalt für Geowissenschaften and Rohstoffe (BGR; Germany) in Lebanon. Data was provided by the BGR to Georg- August University (Göttingen) in the framework of cooperation between the two parties.

\subsection{References}

Birk, S., Geyer, T., Liedl, R., and Sauter, M., 2005. Process-based interpretation of tracer tests in carbonate aquifers. Ground Water, 43, no. 3: 381-388

Butscher, C., and Huggenberger, P., 2009. Enhanced vulnerability assessment in karst areas by combining mapping with Modelling approaches. Science of the Total Environment, 407, no. 3: 1153-1163

Civita, M., 2010. The combined approach when assessing and mapping groundwater vulnerability to contamination. J. Water Resource and Protection, 2: 14-28

Doummar, J., Margane, A., Geyer, T., and Sauter, M., 2010-2011. Protection of the Jeita Spring: Tracer tests analysis. Special reports I-V. Protection of the Jeita Spring. Applied Geosciences. Georg August University

Field, M.S., and Nash, S.G., 1997. Risk assessment methodology for karst aquifers: Estimating karst conduit-flow parameters. Environmental Monitoring and Assessment 47: 1-21

Field, M.S., and Pinsky, P.F., 2000. A two-region non equilibrium model for solute transport in solution conduits in karstic aquifers. Journal of Contaminant Hydrology 44, no. 1, 329-351

Field, M.S., 2002. The QTRACER2 program for tracer-breakthrough curve analysis for tracer tests in karstic aquifers and other hydrologic systems. EPA/600/R-02/001. Washington, D.C.:U.S. EPA

Ford, D.C., and Williams, P.W., 2007. Karst Geomorphology and Hydrology. London, UK: Chapman \& Hall

Geyer, T., Birk S., Licha T., Liedl R., and Sauter M., 2008. Multitracer Approach to Characterize Reactive Transport in Karst Aquifers. Ground Water, 35, no. 1: 35-45

Hauns, M., Jeannin, P.-Y., and Atteia, O., 2001. Dispersion, retardation and scale effect in tracer breakthrough curves in karst conduits. Journal of Hydrology, 241, no. 3-4: 177-193

Kaess, W., 1998. Tracing technique in geohydrology. A.A Balkema. Rotterdam, Netherlands. 589pp 
Karkabi, S., 1988. Al Ouat'Ouate, special coloration. Revue Libanaise de Spéléologie et de Karstologie, SpéléoClub du Liban, Al Ouat'Ouate, no. 3: 80

Perrin, J., and Luetscher, M., 2008. Interference of the structure of karst conduits using quantitative tracer tests and geological information: example of the Swiss Jura. Hydrogeology Journal, 16: 951-967

Schnegg, P.A., 2002. An inexpensive field fluorometer for hydrogeological tracer tests with three tracers and turbidity measurement. Groundwater and Human Development, ed. E. Bocanegra, D. Martinez, and H. Massone: 1484-1488. Mar Del Plata, Argentina

Smart, C.C., 1988. Artificial tracer techniques for the determination of the structure of conduit aquifers. Ground Water, 26, no. 4: 445-453

Toride, N., Leij, F.J., and van Genuchten, M.T., 1999. The CXTFIT code (version 2.1) for estimating transport parameters from laboratory or field tracer experiments. U.S. Salinity Laboratory Agricultural Research Service, U.S. Department of Agriculture Riverside, California. Research Report 137

Werner, A., Hoetzl, H., Kaess, W., and Maloszewski, P., 1997. Interpretation of tracer experiments in the Danube-Aach-System (Western Swabian Alb, Germany) with analytical models. In: Guenay, Johnson (Eds.). Karst Waters Environmental Impacts. Balkema, Rotterdam: 153-160

Seiler, K.-P., Maloszewski, P., and Behrens. H., 1989. Hydrodynamic dispersion in karstified limestones and dolomites in the upper Jurassic of the Franconian Alb, F.R.G. Journal of Hydrology, 108: 235-247 


\section{SPATIAL AND TEMPORAL DISTRIBUTION OF CARBAMAZEPINE, CAFFEINE AND BENZOYLECGONINE AS WASTE WATER INDICATORS IN GROUNDWATER: APPLICATION ON THE JEITA SPRING (LEBANON)*}

Doummar, Joanna ${ }^{1 *}$, Karsten Nödler ${ }^{1}$, Sauter, Martin ${ }^{1}$, Geyer, Tobias $^{1}$

(4) Geowissenschaften Zentrum, University of Göttingen, Goldschmidtstr. 3, D-37077 Göttingen, Germany;

*Corresponding author: e-mail: jdoumma@gwdg.de; Phone: (49) 551 397913; Fax: (49) 551399379.

Based on report submitted to Bundesanstalt für Geowissenschaften und Rohstoffe (BGR):

Doummar, J., Nödler, K., Geyer, T., and Sauter, M., 2012. Protection of the Jeita Spring: Analysis of organic micropollutants in the Jeita Spring catchment. Special report VII. Protection of the Jeita Spring. Applied Geosciences. Georg August University, Göttingen 


\subsection{INTRODUCTION}

A sustainable management of groundwater resources is needed for the protection of karst aquifers against potential sources of contamination. The risk assessment involves the assessment of both intrinsic and specific vulnerabilities. The later includes the identification of the sources of pollution present on a catchment area (e.g., wastewater). Wastewater indicators are compounds introduced to a natural environment usually by anthropogenic activities; these include ionic species (e.g., chloride; Gasser et al., 2010), bacteriological species (E-Coliform; Pronk et al., 2007) or organic micropollutants (pharmaceuticals, pesticides, or industrial compounds etc).

Stimulants and pharmaceuticals are not completely metabolized by the human body, and are excreted unchanged or metabolized into the environment (Heberer, 2002). These products in addition to other industrial or agricultural micropollutants can leach into the soil, to surface water, and eventually from the unsaturated zone (Scheytt et al., 2006) to groundwater especially those which are not degraded under natural conditions. The detection of these substances in groundwater and surface water can give insights into the type of pollutants existing on the catchment area, especially in areas where wastewater is discharged without prior treatment. Despite that little is known about the potential infiltration of a drug to groundwater (Terner, 1998), it is still possible estimate loads of some substances consumed/discharged on a catchment based on concentrations detected in water bodies and track them back (e.g., cocaine).

The analysis of micropollutants is challenging in karst aquifers, because they are characterized by a duality of recharge; diffuse or concentrated (dolines, sinkholes ...; Chapter 2). Consequently, wastewater can be either transported by fast flow pathways and have short term effect on groundwater quality or infiltrate into fractures and matrix and therefore have a long term effect on the aquifer (Einsiedl et al., 2010). The latter depends on the type of recharge, the fate of the compounds present in wastewater, and on the importance of discharge rates in the dilution processes.

The objective of the present work is to assess the occurrence and fate of three organic micropollutants (caffeine, carbamazepine, and benzoylecgonine) under different flow conditions in a karst system over a twoyear period. Very few effective wastewater treatment plants (WWTP) are present on the investigated catchment area. Raw wastewater is discharged onto the entire catchment with no prior treatment. The three compounds caffeine, carbamazepine and benzoylecgonine are indicator for contamination with domestic wastewater. Carbamazepine is believed to be highly persistent in water systems, and is therefore an indicator for long term contamination (Gasser et al., 2010). Caffeine, which is characterized by a high biodegradability (Clara et al., 2004), and benzoylecgonine will be evaluated for comparison purposes.

For this purpose, samples were collected from the Jeita spring in Lebanon under high, low and intermediate flow conditions over a total period of 2 years (2010-2011) within the framework of a cooperation between the BGR and University of Göttingen (Doummar et al., 2012b) in the project Protection of Jeita Spring conducted by the BGR in Lebanon. 


\subsection{MATERIALS AND METHOdS}

Samples were retrieved each in $1 \mathrm{~L}$ glass bottles during four sampling campaigns (Table 5-1; Figure 5-1 and Figure 5-2) for the analysis of carbamazepine, caffeine, and benzoylecgonine (Table 5-2). The samples were stored at $4^{\circ} \mathrm{C}$ until extraction. Extraction was performed within $24 \mathrm{~h}$. A multi- residue analytical method based on solid phase extraction (SPE) was performed on the samples for micropollutant analysis (Nödler et al., 2010) within not more than 24 hours following sampling. For springs and river samples, $500 \mathrm{~mL}$ were extracted, whereas only $10 \mathrm{~mL}$ and $20 \mathrm{~mL}$ of wastewater were extracted. The cartridges of the solid extract were stored at $-19^{\circ} \mathrm{C}$ until analysis. Discharge rates for the major springs were either measured during sampling or retrieved from discharge curves of the spring under prevailing conditions. Daily loads (mass flux) of micropollutants especially the persistent ones can be calculated as follows:

$$
M=\frac{\mathrm{QC}_{\mathrm{i}}}{10^{9}}
$$

Where $M$ is the daily mass flux $(g / d), Q$ is the daily discharge $(l / d), C_{i}$ is the concentration (ng/l)

Table 5-1 Sampling campaigns, sampled locations and flow conditions

\begin{tabular}{|lll|}
\hline Period & Sampled locations & Discharge rate (L/s) \\
September 2010 & Jeita Spring & 1500 (low flow) \\
March 2011 & Jeita Spring & 8000 (high flow) \\
September 2011 & Jeita Spring (along 1500 m in the cave; Figure 5-1) & at outlet: 1500 (low flow) \\
December 2011 & Jeita Spring (along 1000 m in the cave; Figure 5-2) & at outlet: 5700 (intermediate \\
& & flow)
\end{tabular}

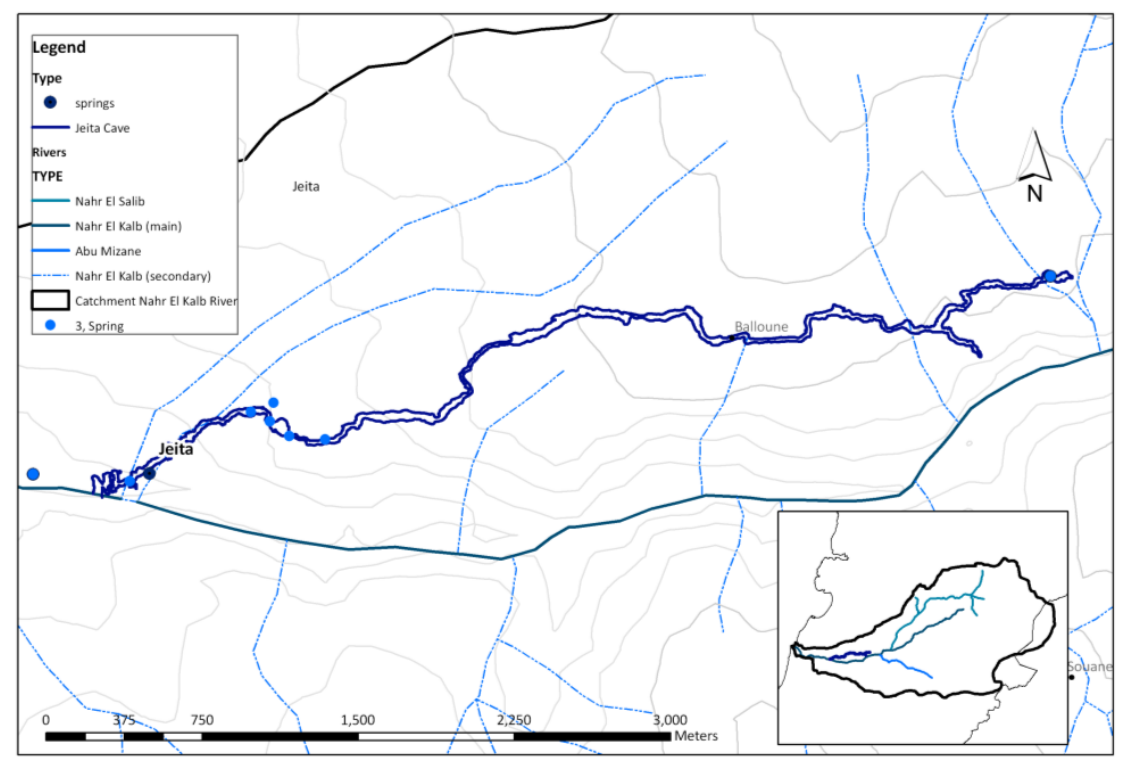

Figure 5-1 Sampling locations within the Jeita cave (September 2011) 


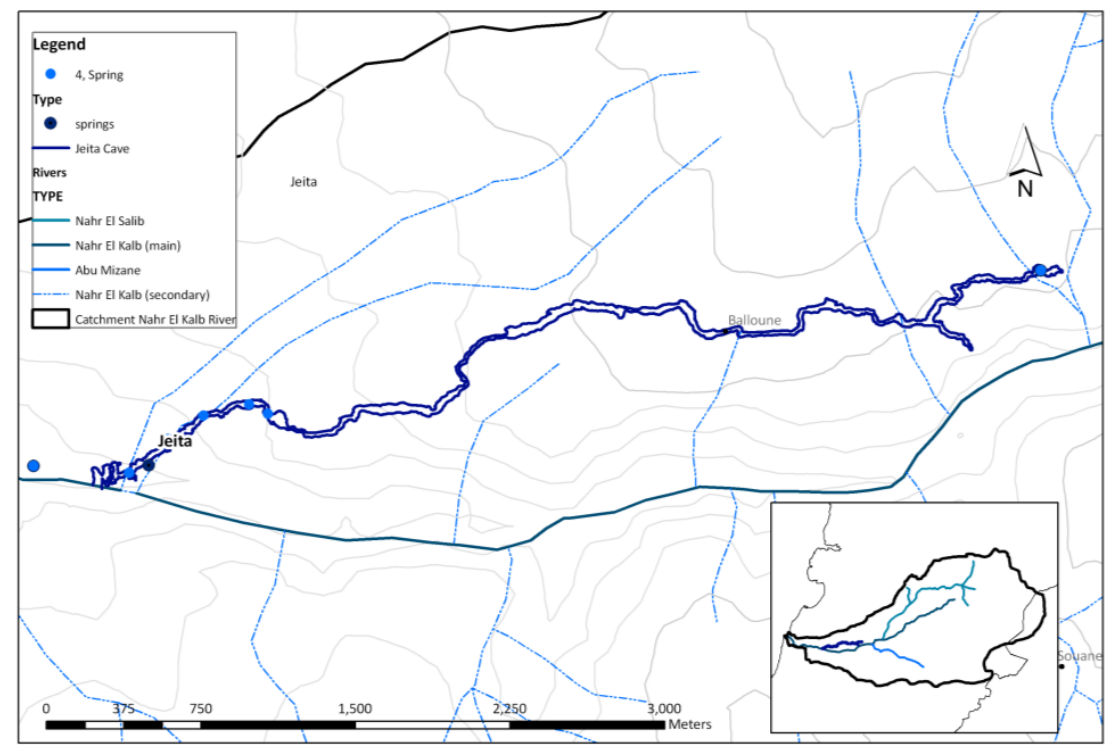

Figure 5-2 Sampling locations within the Jeita cave (December 2011)

Table 5-2 Characteristics of the three analyzed compounds

\begin{tabular}{|llll|}
\hline Analyte & Type and application & $\begin{array}{l}\text { Method Quantification Limit } \\
\text { (ng/l; Nödler et al., 2010) }\end{array}$ & $\begin{array}{l}\text { Relative Signal Response } \\
\text { (\%; Nödler et al., 2010) }\end{array}$ \\
Carbamazepine & Anticonvulsant & 2.2 & 3.1 \\
Benzoylecgonine & Cocaine metabolite & 2.3 & 3.2 \\
Caffeine & Stimulant & 4.3 & 6.1 \\
\hline
\end{tabular}

\subsection{ResUlts}

The four sampling campaigns gave insights to the occurrence of three above mentioned compounds in the spring water, as well as their fate in the subsurface channel (cave) and allowed depicting the variations in concentrations and mass fluxes under different flow dynamics.

\subsubsection{Overview on the investigated micropollutants}

\subsubsection{Stimulants and caffeine metabolites}

The stimulants caffeine and its metabolites paraxanthine, theobromine, and theophylline were found in the spring and surface water samples collected from the catchment. These stimulants are easily degradable compounds (Hillebrand et al., 2012) and thus the presence of significant concentrations of these compounds is a strong indication for a contamination with untreated wastewater occurring on the catchment.

\subsubsection{Carbamazepine}

Carbamazepine is an anti-epileptical drug used in most of the countries (Scheytt, 2005). It is also used for the treatment of manic-depressive illnesses. It was frequently detected in surface water as well as in effluents of 
sewage treatment plants, as less than $10 \%$ of carbamazepine are usually eliminated during sewage treatment and not attenuated during bank infiltration (Heberer, 2002). The body metabolizes about $98-99 \%$ of the carbamazepine into metabolites (metabolite carbamazepine-10,11-epoxide) (Clara et al., 2004, Leclercq et al., 2009, Ternes, 1998, Frey and Janz 1985). According to other sources, only $3 \%$ of the carbamazepine is metabolized by the body (Ghauch et al., 2010). Carbamazepine is still considered to be fairly persistent in groundwater (Tixier et al., 2003), and is consequently regarded as an effective wastewater indicator because it is unlikely degradable or adsorbed. Therefore it can be present over detection limits in groundwater (Clara et al., 2004). In Lebanon, carbamazepine is known commercially by Tegretol (Ghauch et al., 2011) and is used as an antiepileptic, for treatment of schizophrenia, bipolar problems and alcohol withdrawal.

\subsubsection{Cocaine Metabolite}

Cocaine is considered as an illicit drug used worldwide to stimulate psychological effects and enhance the activity of the nervous system (Van Nuijs et al., 2009). Cocaine is directly either injected in the blood, inhaled directly through the nose or through smoking. The urine of a cocaine addict contains excreted cocaine as well as its metabolite benzoylecgonine. The latter allows tracing back the loads of metabolized consumed street cocaine (Zuccato et al., 2005).

5.3.2 Spatial and temporal distribution of caffeine, carbamazepine, and benzoylecgonine under various flow conditions

Analysis of carbamazepine performed repeatedly during high and low flow periods show that concentrations of carbamazepine in the Jeita spring varies between $10 \mathrm{ng} / \mathrm{l}$ under high flow periods (march $2011 \approx 8 \mathrm{~m}^{3} / \mathrm{s}$ ), 30 $\mathrm{ng} / \mathrm{l}$ under low flow periods (September 2010, $2011 \mathrm{Q} \approx 1.5 \mathrm{~m}^{3} / \mathrm{s}$ ) and $6.1 \mathrm{ng} / \mathrm{l}$ under intermediate flow periods $\left(5.7 \mathrm{~m}^{3} / \mathrm{s}\right)$. The equivalent daily mass flux of carbamazepine calculated from concentrations under low flow periods is 3.3-3.5 g/d. Carbamazepine mass flux increases as discharge rate increases beyond a certain threshold during high flow periods (Figure 5-3).

The concentration of benzoylecgonine observed in low flow periods (respectively in September 2010 and September 2011) in the Jeita spring varies between 3.8 and $7.0 \mathrm{ng} / \mathrm{l}$, which is equivalent to 0.3 to $0.4 \mathrm{~g} / \mathrm{day}$ of benzoylecgonine under prevailing conditions (respective discharge rates of 1.4 and $1.57 \mathrm{~m}^{3} / \mathrm{s}$ ). Zuccato et al., 2005, showed that $390 \mathrm{~g}$ of benzoylecgonine is the metabolic product of $1 \mathrm{~kg}$ of consumed commercial cocaine. Therefore the equivalent cocaine loads under low flow periods (namely September 2010 and 2011) vary between 0.8 and 0.85 gram. Under high flow conditions independent of precipitation events, the concentration of benzoylecgonine is below detection limit due to high dilution (limit of detection being 2.3 $\mathrm{ng} / \mathrm{l})$.

Concentrations of caffeine in the Jeita spring vary between 13 and $16 \mathrm{ng} / \mathrm{l}$, which is equivalent to loads of 1.7 $2.1 \mathrm{~g} / \mathrm{d}$ under low flow conditions. Caffeine concentration in the Jeita spring increases under high flow conditions (Figure 5-3). 

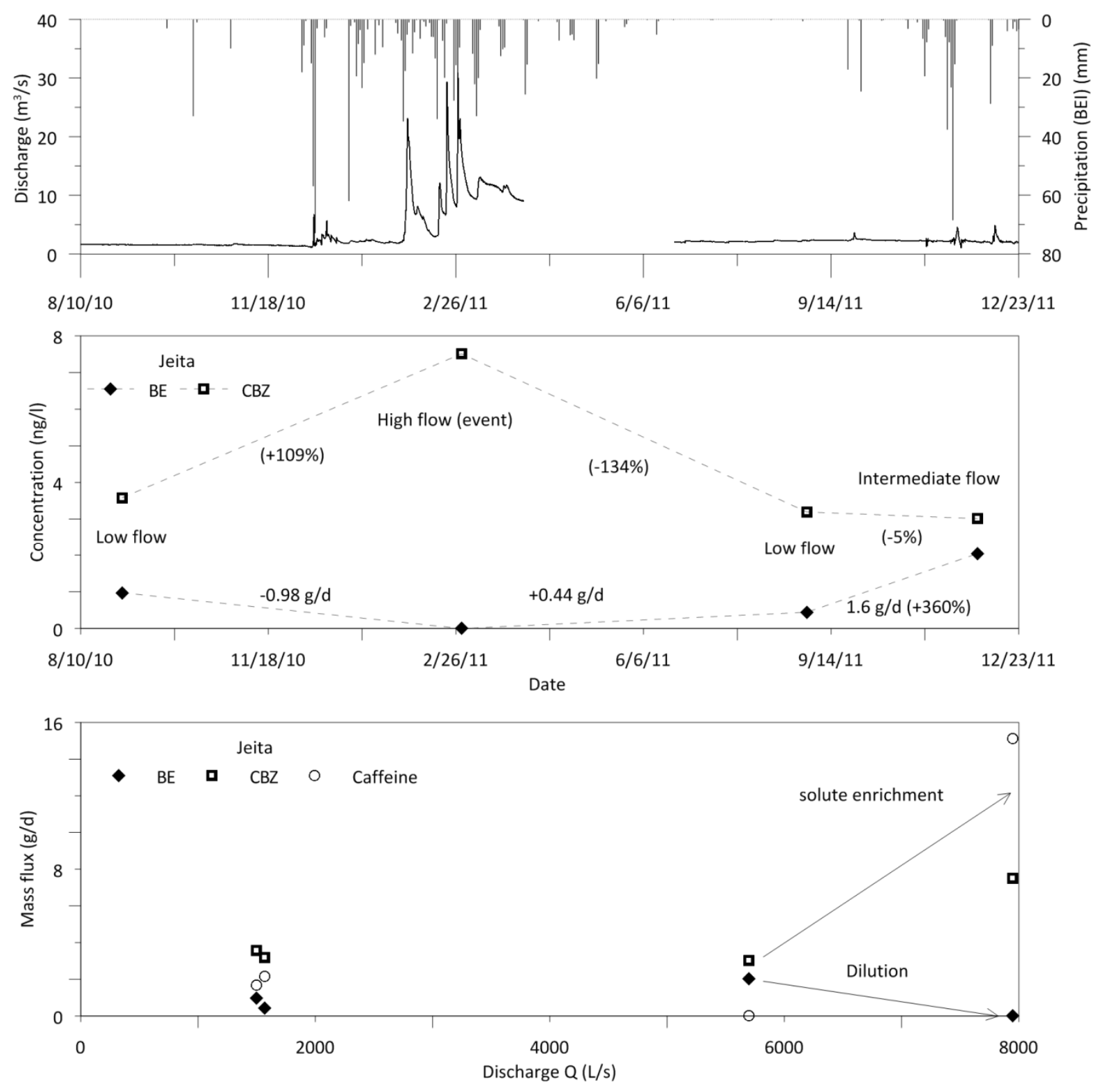

Figure 5-3 Mass flux ( $\mathrm{g} / \mathrm{d}$ ) of various compounds in Jeita Spring during different sampling periods (Low flow, high flow and Intermediate flow, when discharge measurements are available)

\subsection{FATE OF MICROPOLLUTANTS WITHIN THE SUBSURFACE CHANNEL}

Samples were taken in September 2011 (Figure 5-4) and in December 2011 (Figure 5-5) in the subsurface channel over a total distance of $5300 \mathrm{~m}$ starting from the last accessible point on the cave (Daraya tunnel) to the spring outlet in potential accessible locations. Concentrations $(\mathrm{ng} / \mathrm{l})$ and loads $(\mathrm{g} / \mathrm{d})$ of benzoylecgonine (BE) and carbamazepine (CBZ) were plotted against distance in September and December 2011. Dilution tests were performed during sampling for discharge estimation at each point of sampling. As shown in Figure 5-4 and Figure 5-5, an inflow of water converging to the subsurface channel at about $4620 \mathrm{~m}$ affects locally the mass fluxes of the investigated compounds. The amount of the inflow is about $240 \mathrm{l} / \mathrm{s}$ (1/6 of total flow) in September 2011 and 1500 l/s during December 2011 (about 1/4 of the total flow). 


\subsubsection{September 2011 (low flow periods; Figure 5-4)}

Benzoylecgonine and carbamazepine remain constant generally constant over the channel. Variations in the mass fluxes can be observed locally as follows:

- About $16-17 \%$ increase of mass flux occurs between Daraya (5300 m) and $3800 \mathrm{~m}$ downstream to it, the increase amounts to 0.47 and $0.05 \mathrm{~g} / \mathrm{d}$ for carbamazepine and benzoylecgonine respectively.

- A dilution effect is observed following the inflow location. The inflow located at $4620 \mathrm{~m}$ contains loads of carbamazepine (about $0.43 \mathrm{~g} / \mathrm{d}$ ), whereas it contains no detectable traces of benzoylecgonine. Therefore after inflow location, mass fluxes of carbamazepine increase, while concentrations of benzoylecgonine decreases due to dilution.

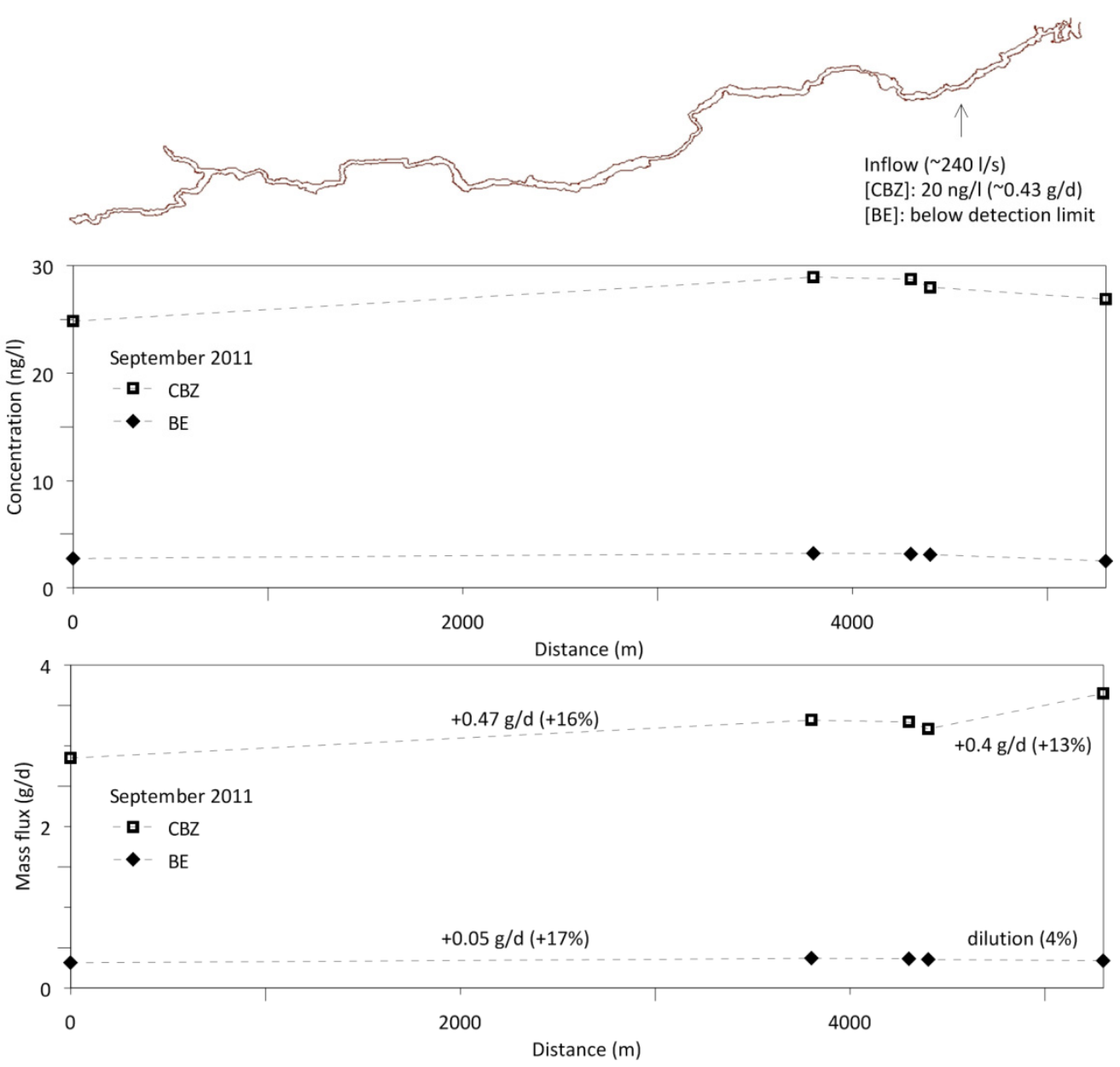

Figure 5-4 Behavior of benzoylecgonine and carbamazepine (mass flux and concentrations) in samples collected along the subsurface channel showing in some locations the input of additional compounds and/or effect of dilution (September 2011)

\subsubsection{December 2012 (intermediate flow periods; Figure 5-5)}

A different behaviour of both benzoylecgonine and carbamazepine is observed under intermediate flow with respect to low flow periods: 
- About $15-18 \%$ increase of mass flux occurs between Daraya (5300 m) and $3800 \mathrm{~m}$ downstream to it, the increase in mass fluxes amounts to 0.34 and $0.24 \mathrm{~g} / \mathrm{d}$ for carbamazepine and benzoylecgonine respectively.

- Downstream to the inflow located at $4620 \mathrm{~m}$, mass fluxes increase of $15 \%$ for carbamazepine $(+0.44$ $\mathrm{g} / \mathrm{d})$ and $33 \%$ for benzoylecgonine $(+0.67 \mathrm{~g} / \mathrm{d})$. Based on a simple mixing model, the concentration of the inflow is estimated to be $3.4 \mathrm{ng} / \mathrm{l}$ and $5.2 \mathrm{ng} / \mathrm{l}$ respectively.

- The mass fluxes of both benzoylecgonine and carbamazepine remain constant over the last $500 \mathrm{~m}$.

- In December concentrations of caffeine in the Jeita spring are below detection limits, this could be explained by either a high degradation of caffeine, or high dilution of relatively low concentrations of caffeine present in the system from low flow periods.
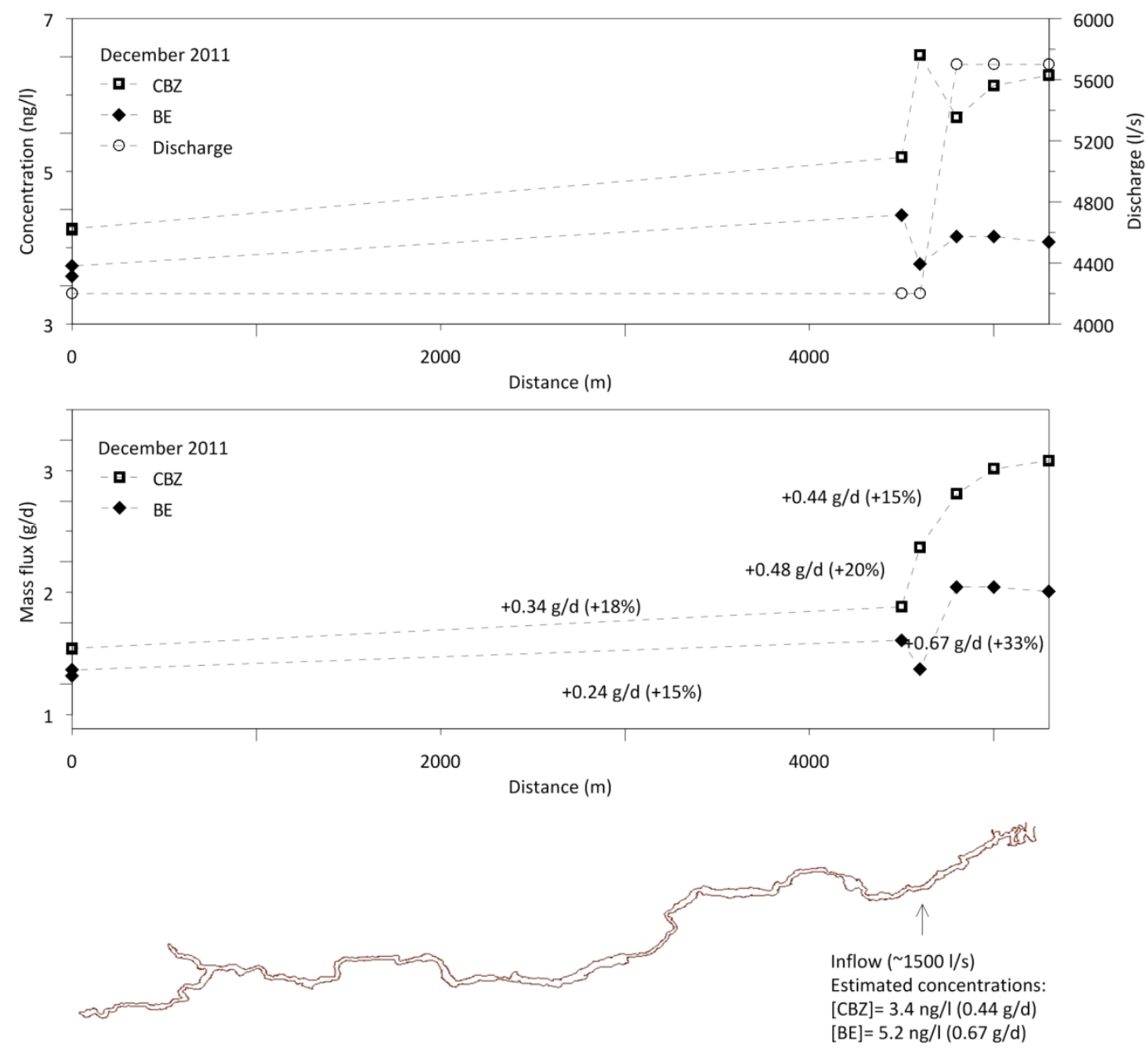

Figure 5-5 Behavior of benzoylecgonine and carbamazepine (mass flux and concentrations) in samples collected along the subsurface channel showing in some locations the input of additional compounds and/or effect of dilution (December 2011)

Since benzoylecgonine and carbamazepine are found at the beginning of the channel (at Daraya location) in both sampling campaigns (September 2011, December 2011), a major source of wastewater exist upstream to this location. Additionally, the concentration of benzoylecgonine and carbamazepine increases between Daraya and the next sampling locations (about $3800 \mathrm{~m}$ ) downstream. An increase of those compounds can 
only be enhanced by wastewater; therefore, this implies that additional sources of carbamazepine/benzoylecgonine exist between the two points, if the quantity of wastewater is considered negligible with respect to the discharge of the spring (concentrated wastewater).

The inflow converging to the main cave is characterized by a constant mass flux of carbamazepine $(0.47 \mathrm{~g} / \mathrm{d})$ in September and December 2011. Benzoylecgonine is only found under intermediate flow periods in this same inflow $(0.67 \mathrm{~g} / \mathrm{d})$, equivalent to $1.5 \mathrm{~g} / \mathrm{d}$ street cocaine. Concentrations of benzoylecgonine fall below detection limits under low flow periods.

\subsection{SYNOPSIS AND CONCLUSIONS}

Three sources of carbamazepine and benzoylecgonine, i.e., wastewater exists upstream to Daraya, and within the subsurface channel as portrayed by the following:

i. Presence of carbamazepine and benzoylecgonine in Daraya implies that a continuous source of wastewater leaching to the aquifer is discharged upstream to Daraya even during low flow periods.

ii. Increase of concentrations of both compounds between Daraya and a location about $3500 \mathrm{~m}$ downstream to it, suggests that an additional inflow of carbamazepine and benzoylecgonine rich waters is responsible for the increase of concentration and mass fluxes (from $4.2 \mathrm{ng} / \mathrm{l}$ to $5 \mathrm{ng} / \mathrm{l}$ ), as processes like dilution and potential degradation will result in a decrease of the concentrations.

iii. Carbamazepine is also found in the inflow to the phreatic cave, implying the discharge of wastewater $(0.43 \mathrm{~g} / \mathrm{d})$ from northern recharge areas/ villages. This mass flux remains constant under low and intermediate flow periods. Benzoylecgonine is detected in this inflow only in December 2011 with mass fluxes equivalent to $1.5 \mathrm{~g} / \mathrm{d}$ of street cocaine.

Mass fluxes of carbamazepine and benzoylecgonine in the Jeita Spring are constant during low flow periods (2010, 2011). Different behaviours are observed during high flow periods:

i. Effective dilution of benzoylecgonine concentrations (to below detection limits) are due to the high discharge rates and the low concentration of this compound.

ii. The concentration of carbamazepine remains constant under low flow periods (2010-2011), it is thought that the increase of carbamazepine loads with respect to background concentrations is only due to the concentrated infiltration of carbamazepine following precipitation events (Chapter 6$)$. The presence of a background value could be explained by a continuous source of carbamazepine (waste water) existing on the catchment mainly upstream to Daraya. It can also be assumed that given that it is highly persistent, the source of carbamazepine is present in the karst system (fissured matrix, epikarst or fast flow pathways) and released with time.

iii. Caffeine shows the same patterns as CBZ in groundwater; concentrations increase with an increase of discharge implying that additional loads of caffeine are further introduced to the system through infiltration of raw wastewater under high flow conditions. However it is to be noted that caffeine concentrations fall below detection limits under intermediate flow periods outside event responses. 


\section{Acknowledgment}

The authors would like to thank Armin Margane and Jean Abi Rizk for assisting in the collection of the samples for the purpose of this study. Najib Najib and Ayman Ibrahim are deeply thanked for helping in the sampling logistics. Paul Souaid from the Dbayeh Water Authority is highly acknowledged for providing the laboratory facilities (Solid Phase Extraction (SPE) room and chemicals) for the extraction of the samples, as well as all the staff of the Dbayeh water treatment plant (Rajaa Mhanna, Roger Haddad, and Jihane Bedran).

\subsection{References}

Clara, M., Strenn, B., and Kreuzinger, N., 2009. Carbamazepine as a possible anthropogenic marker in the aquatic environment: investigation on the behavior of carbamazepine in wastewater treatment and during groundwater infiltration, Water Resources, 38: 947-954

Doummar, J., Nödler, K., Geyer, T., and Sauter, M., 2012b. Protection of the Jeita Spring: Analysis of organic micropollutants in the Jeita Spring catchment. Special report VII. Protection of the Jeita Spring. Applied Geosciences. Georg August University, Göttingen

Einsiedl, F., Radke, M., and Maloszewski, P., 2010. Occurrence and transport of pharmaceuticals in a karst groundwater system affected by domestic wastewater treatment plants. Journal of Contaminant Hydrology, 117: 26-36

Frey and Janz, 1985 H.H. Frey, D. Janz (Eds.), Antiepileptic Drugs, Springer Verlag, Berlin-Heidelberg (1985)

Gasser, G., Rona, M., Voloshenko, A., Shelkov, R., Tal, N., Pankratov, I., Elhanany, S., and Lev, O., 2010. Quantitative evaluation of tracers for quantification of wastewater contamination of potable water sources, 44: 3919-925

Ghauch, A., Baydoun H., and Dermesropian P., 2011. Degradation of aqueous carbamazepine in ultrasonic $/ \mathrm{Fe}^{0} / \mathrm{H}_{2} \mathrm{O}_{2}$ systems. Chemical Engineering Journal, 172: 18-27

Heberer, Th., 2002. Occurrence, fate, and removal of pharmaceutical residues in the aquatic environment: a review of recent research data. Toxicol. Lett., 131: 5-17

Heberer, T., 2002b. Tracking persistent pharmaceutical residues from municipal sewage to drinking water. Journal of Hydrology, 266: 175-189

Hillebrand, O., Nödler, K., Licha, T., Sauter, M., and Geyer, T., 2012. Caffeine as an indicator for the quantification of untreated wastewater in karst systems. Water Research, 46, no. 2: 395-402

Leclercq, M., Mathieu, O., Gomez, E., Casellas, C., Fenet, H. and Hillarie-Buys, D., 2009. Presence and fate of carbamazepine, oxcarbazepine, and seven of their metabolites at wastewater treatment plants, Arch. Environ. Contam. Toxicol., 56: 408-415

Nödler, K., Licha, T., Bester, K., and Sauter, M., 2010. Development of a multi-residue analytical method, based on liquid chromatography-tandem mass spectrometry, for the simultaneous determination of 46 microcontaminants in aqueous samples. J. Chromatography, A 1217: 6511-6521

Pronk M., Goldscheider, N., and Zopfi J., 2007. Particle-size distribution as indicator for fecal bacteria contamination of drinking water from karst springs. Environmental Science Technology, 41: 8400-8405

Scheytt, T., Mersmann, P., Lindstaedt, R., and Heberer, T., 2005. Determination of sorption coefficients of pharmaceutically active substances carbamazepine, diclofenac, and ibuprofen, in sandy sediments. Chemosphere, 60: 245-253 
Scheytt, T.J., Mersmann, P., and Heberer, T., 2006. Mobility of pharmaceuticals carbamazepine, diclofenac, ibuprofen, and propyphenazone in miscible- displacement experiments. J. Contaminant Hydrology, 83: 5369

Ternes, T.A., 1998. Occurrence of drugs in German sewage treatment plants and rivers. Water Resources, 32 : 3245-3260

Ternes, T. A., and R. Hirsch. 2000. Occurrence and Behavior of X-ray Contrast Media in Sewage Facilities and the Aquatic Environment. Environmental Science \& Technology, 34: 2741-2748

Tixier, C., Singer, H.P., Oellers, S., and Müller, R.R., 2003. Occurrence and fate of carbamazepine, clofibric acid, diclofenac, ibuproen, keteprofen, and naproxen in surface waters, Environmental Science \& Technology, 37: 1061-1068

Van Nuijs, A.L.N., Pecceu, B., Theunis, L., Dubois, N., Charlier, C., and Jorens, PG., 2009. Can cocaine usebe evaluated through analysis of wastewater? A nation-wide approach conducted in Belgium. Addiction 2009c, 104: 734-41

Zuccato, E., Chiabrando, C., Castiglioni, S., Calamari, D., Bagnati, R., and Schiarea, S., 2005. Cocaine in surface waters: a new evidence-based tool to monitor community drug abuse. Environmental Health 4:14 


\section{CARBAMAZEPINE BREAKTHROUGH AS INDICATOR FOR SPECIFIC VULNERABILITY OF KARST SPRINGS: APPLICATION ON THE JEITA SPRING, LEBANON}

Doummar, Joanna ${ }^{1}$, Geyer, Tobias $^{1}$, Michael Baierl ${ }^{1}$, Nödler, Karsten ${ }^{1}$, Licha, $_{\text {Tobias }}{ }^{1}$, Sauter, Martin ${ }^{1}$

(5) Geowissenschaften Zentrum, University of Göttingen, Goldschmidtstr. 3, D-37077 Göttingen, Germany;

*Corresponding author: e-mail: jdoumma@gwdg.de; Phone: (49) 551 397913; Fax: (49) 551399379.

Doummar, J., Geyer, T., Baierl, M., Nödler, K., Licha, T., and Sauter, M., 2012. Carbamazepine breakthrough as indicator for specific vulnerability of karst prings: application on the Jeita spring, Lebanon. In preparation for submission to a peer-reviewed journal 


\section{Keywords}

carbamazepine; precipitation event; karst; fast flow component.

\section{Abstract}

The pharmaceutical drug carbamazepine is considered an effective wastewater marker. The behavior of this drug was analyzed at a mature karst spring following a precipitation event. The results show that carbamazepine may enter the system through a fast flow pathway, leading to an increase of the concentrations of this drug in spring water shortly after a strong rainfall event. The analysis of the breakthrough curve of carbamazepine along with the electrical conductivity signal and major ions chemograph allowed the development of a conceptual model for event-based flow and transport in the investigated karst system. Furthermore the amount of newly recharged water and the mass of carbamazepine arriving to the karst system during the event could be estimated using a simple mixing approach. The distance between the karst spring and the potential carbamazepine source was estimated by the combination of results from artificial tracer tests and the carbamazepine breakthrough curve. The assessment of spring responses to precipitation event help assess the effect of waste water contamination at a spring and gives therefore insights to the specific vulnerability of a karst spring.

\subsection{INTRODUCTION}

Karst aquifers are complex flow systems which vulnerability is very difficult to assess. Recharge to a karst aquifer can occur as diffuse or concentrated via dolines and/or dry valleys. Moreover, a karst aquifer is formed by an unsaturated zone comprising soil, epikarst and unsaturated rock matrix, and a saturated zone formed of a highly permeable conduit system draining low permeability matrix storage (Doummar et al., 2012). In order to assess the vulnerability of a karst aquifer, it is important to understand the characteristics of a spring response, especially that karst spring show prominent variations in discharge and quality following precipitation events (Pronk et al., 2007). In the case of groundwater contamination by wastewater effluent, infiltrated polluted water can be either transported by fast flow pathways and have short effect term major risk on groundwater or infiltrate into fractures and matrix and therefore have a long term effect on the aquifer (Einsiedl et al., 2010). In order to identify the risk of wastewater infiltrating into an aquifer, researches have focused to date on the identification of suitable wastewater indicators. Pharmaceuticals and major ions were investigated as indicators in groundwater as they were detected in raw wastewater, treated wastewater, surface water and groundwater (Scheytt et al., 2006, Gasser et al., 2010). Many prescribed pharmaceuticals are not always completely eliminated by the human body. They are either excreted completely unchanged or in the form of metabolites (Heberer, 2002). In the case where pharmaceuticals are not eliminated in sewage treatment plants (STP), they can be found in surface waters, and might also infiltrate into groundwater (Heberer, 2002, Scheytt et al., 2006). Therefore, these compounds can be used as wastewater indicators. A good wastewater indicator fulfills the following criteria: 1) origin is exclusively from waste water, 2) abundance of the compound in wastewater above detection limits, 3) background concentration of the indicator in the investigated system should be relatively low, 4) low degradation rate 5) negligible retardation (Gasser et al., 2010, Einsiedl et al., 2010). Because of their low stability, micropollutants such as caffeine or ibuprofen fail to 
be suitable indicator for discharged treated or old stored waste water (Clara et al., 2004) but might be useful for identification of untreated wastewater with a short residence time in an aquifer (Hillebrandt et al. 2012). Nitrates and ammonia can also be ruled out as waste water indicators (Gasser et al., 2010, Scheytt et al., 2006, Clara et al., 2004) because of their presence in agricultural practices.

Carbamazepine (CBZ) is a frequently used as an anticonvulsant and mood-stabilizing drug (Scheytt, 2005). It was frequently detected in surface water as well as in effluents of sewage treatment plants, as less than $10 \%$ of carbamazepine are usually eliminated during sewage treatment and not attenuated during bank infiltration (Heberer, 2002). The pharmaceutical drug was found within concentrations of $30 \mathrm{ng} / \mathrm{l}$ in drinking waters (Germany; Ternes et al., 2001), and up to $1075 \mathrm{ng} / \mathrm{l}$ in surface water samples in Berlin (Germany; Heberer, 2002). The consumption of CBZin Austria amounted to $6334 \mathrm{~kg}$ per year in 1997 (Clara et al., 2004). In 1997, average loads of $114 \mathrm{~g} /$ day of CBZ were determined in the final effluent of an SPT in Frankfurt Germany, as CBZ show extremely low average removal rates (<7\%; Ternes, 1998). The body metabolizes about $98-99 \%$ of the CBZ into metabolites (metabolite carbamazepine-10,11-epoxide) (Clara et al., 2004, Leclercq et al., 2009, Ternes, 1998, Frey and Janz 1985). According to other sources, only $3 \%$ of the CBZ is metabolized by the body (Ghauch et al., 2010). CBZ is still considered to be fairly persistent in groundwater (Tixier et al, 2003), and is consequently regarded as an effective wastewater indicator because it is unlikely degradable or adsorbed, therefore can be present over detection limits in groundwater (Clara et al., 2004). In Lebanon, CBZ is known commercially by Tegretol (Ghauch et al., 2011) and is used as an antiepileptic, for treatment of schizophrenia, bipolar problems, and alcohol withdrawal. It is prescribed at doses varying between 800 and 1200 mg per day for the treatment of epilepsy and bipolar problems and between 400 and $800 \mathrm{mg}$ for the treatment of neuralgia (Clara et al., 2005).

The objective of the present work is to investigate rapid transport in a karst system, by analyzing the restitution of an indicator of stored wastewater triggered by a precipitation event. For this purpose, a spring is sampled for major ions and micropollutants following a precipitation event. Artificial tracer tests were employed to estimate groundwater flow velocities in the cave system. Based on the arrival time of the tracer, the distance to the contamination source can also be estimated.

\subsection{FIELD SITE}

The Jeita Spring is an important karst spring located north to Beirut in Jounieh area. It constitutes the main water source for the Beirut area and its northern suburbs for domestic use (about 1.5 million inhabitants). The discharge of the Jeita spring ranges from $1 \mathrm{~m}^{3} / \mathrm{s}$ during low flow periods to about $20 \mathrm{~m}^{3} / \mathrm{s}$ during high flow periods. Governed by open channel flow, the Jeita Spring drains a catchment of about $150 \mathrm{~km}^{2}$ extending east in the Lebanese Mountains (Figure 6-1). The catchment of the Jeita spring ranges from altitudes of about 90 to $2000 \mathrm{~m}$ above sea level. It is not well defined to date as very little is known about the flow connection between various locations on the catchment and the Jeita Spring. The total yearly precipitation is estimated from three different stations deployed over the Jeita catchment to about $1200 \mathrm{~mm}$ on average (2009-2011, Beirut International Airport). 
The Jeita cave is developed in limestone of Jurassic age over a total length (excluding subsidiaries) of $5300 \mathrm{~m}$. The Jurassic formation is mainly formed of limestone; however dolostones are intertonguing in the lower parts of the formation because of diagenetic dolomitization (Nader et al., 2007).

Very few effective wastewater treatment plants (WWTP) are present on the Jeita catchment area; therefore wastewater is either directly discharged into the river system or overflowing in valleys. Some practices suggest that wastewater might be in places illegally diverted into non equipped boreholes or sinkholes. It is therefore expected that raw wastewater is discharged onto the catchment with no prior treatment.

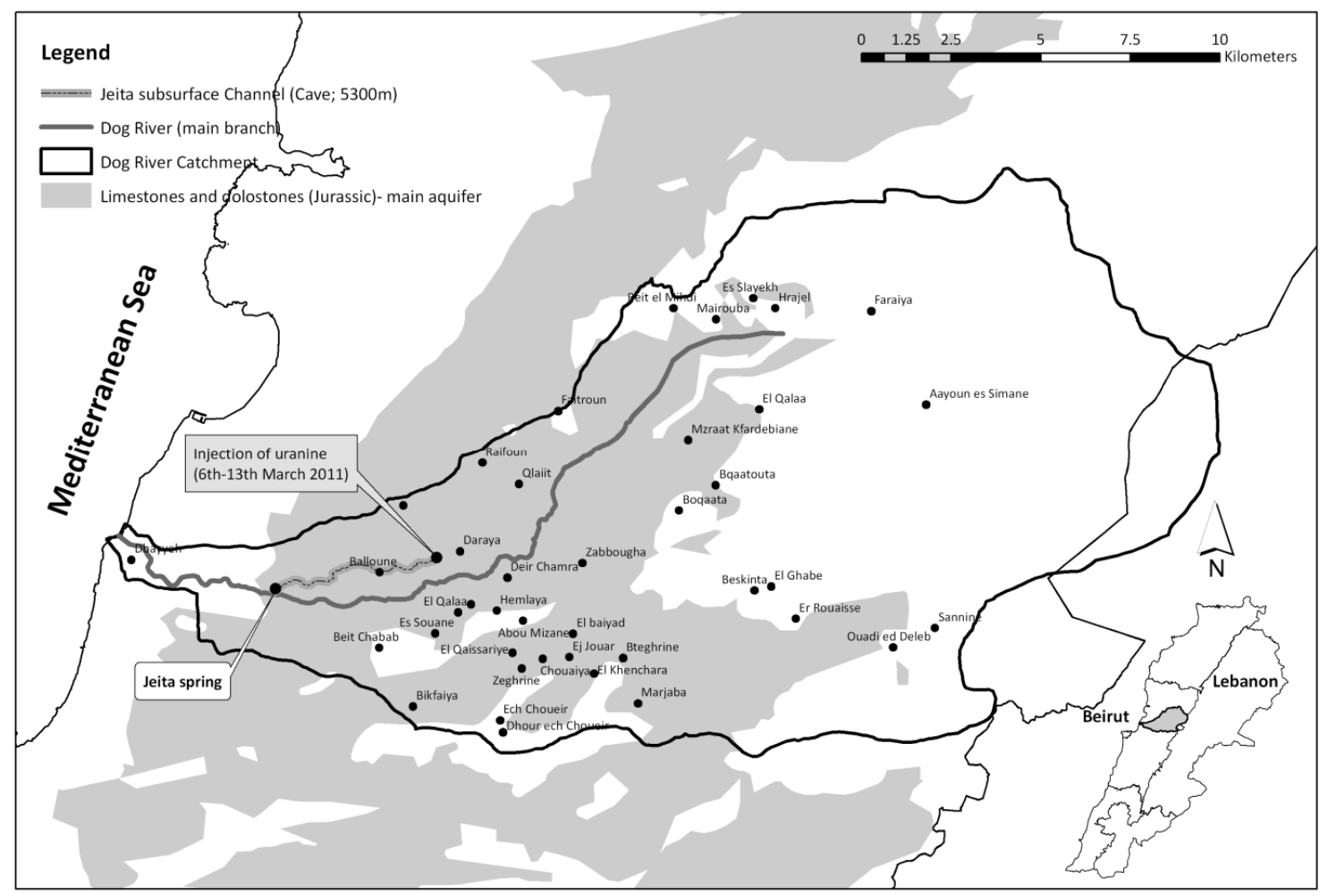

Figure 6-1 Overview map of the field site showing the location of the Jeita Spring within the Dog River surface water catchment

\subsection{Materials AND MEthods}

\subsubsection{Sampling and sample preparation}

A total of 28 samples were taken at varying time intervals (3-6 hours) following the beginning of a precipitation event at the Jeita spring between the $7^{\text {th }}$ and $23^{\text {rd }}$ of March 2011. Two rain samples were collected on the $8^{\text {th }}$ and $9^{\text {th }}$ of March 2011 for major ion analysis at an altitude of $800 \mathrm{~m}$ above sea level (asl). Bottles of $0.5 \mathrm{I}$ and 20 $\mathrm{ml}$ capacity were used the micro contaminant and major ions sampling, respectively. The samples were stored not longer than 24 hours at a temperature of $4^{\circ} \mathrm{C}$ until solid phase extraction (SPE) was performed. A multiresidue analytical method based on solid phase extraction (SPE) was performed on the samples for micro pollutant analysis within a period not exceeding 24 hours following sampling. $10 \mu$ of internal surrogate standard were added to the samples for analytical quality control (Nödler et al., 2010). After extraction, the dried SPE cartridges were stored at $-19^{\circ} \mathrm{C}$ until analysis. 
Electrical conductivity, turbidity and water levels were monitored every 20 minutes in-situ with a multi parameter probe installed at the spring. Based on a rating curve, discharge rates were estimated from the water level data measured at the spring.

\subsubsection{Artificial tracer tests}

Three tracer tests were undertaken in the subsurface channel during the event between March 6 th and 13 th 2011 to estimate mean and maximum velocities under prevailing conditions. Uranine was injected at the beginning of the sub-surface channel and retrieved at the spring outlet automatically using a field fluorometer (Schnegg, 2002). The breakthrough curves (BTC) were analyzed using the CXTfit software using the two Region Non Equilibrium Model (2RNEM; Toride et al., 1999, Geyer et al. 2007) to determine mean and maximum flow velocities within the channel regarded as a fast flow pathway.

\subsubsection{Chemical analysis}

The 28 samples (extracted cartridges) were further analyzed in the laboratory using high performance liquid chromatographic separation with tandem mass spectrometric detection (HPLC/MS-MS) was described by Nödler et al., (2010). The main analyzed micropollutants include wastewater indicators such as stimulants, analgesics, antibiotics, and anticonvulsants and sedatives. In this work CBZ is of major interest for the interpretation; the presence of other compounds in the spring (caffeine and its metabolites) will be used qualitatively to support the results. The method quantification limit and relative standard deviation CBZ were $2.2 \mathrm{ng} / \mathrm{l}$ and $3.1 \%$, respectively.

The samples for ion measurement were determined by means of ion chromatography (IC). A Dionex LC 20 with suppressor and conductometric detection, a Dionex CS12A column and a $20 \mathrm{mM}$ methanesulfonic acid eluent at a flow rate of $0.45 \mathrm{~mL} \mathrm{~min}^{-1}$ were used for the cations analysis. Additionally, prior to the analysis, $125 \mu \mathrm{l}$ methanesulfonic acid $99 \%$ were added to each of the samples and stirred in a shaker for 2 hours. On the other hand, the analysis of anions was performed on a Dionex IC 25 with suppressor and conductometric detection, a Dionex AS11 HC column, and a $30 \mathrm{mM} \mathrm{KOH}$ eluent.

\subsection{Results}

\subsubsection{Spring monitoring}

The result of the event monitoring is a chemograph showing the variation of the concentrations of cations $\left(\mathrm{Ca}^{2+}, \mathrm{Na}^{+}, \mathrm{K}^{+}, \mathrm{Mg}^{2+}\right)$ and anions $\left(\mathrm{NO}_{3}{ }^{-}, \mathrm{SO}_{4}{ }^{2-}, \mathrm{Cl}^{-}\right)$and the concentration of micropollutants. While $\mathrm{CBZ}$ is the only contaminant showing a breakthrough at the spring (Figure 6-2), other compounds like caffeine and its metabolites are intermittently present in relatively low concentrations/loads in comparison with CBZ. The chemograph is also associated with electrical conductivity. Increase of electrical conductivity is majorly triggered by an increase of $\mathrm{Ca}^{2+}$ concentration. Contrarily, $\mathrm{Mg}^{2+}$ is negatively correlated with electrical conductivity, i.e. event water dilutes $\mathrm{Mg}^{2+}$ concentration in spring water (Figure 6-2). CBZ negatively correlates with $\mathrm{Ca}^{2+}$ concentrationsand electrical conductivity (EC; Figure 6-3) and positively correlates with $\mathrm{NO}_{3}$. 
Analysis of CBZ signals during high and low flow periods show that concentrations of CBZ in the Jeita spring varies between $10 \mathrm{ng} / \mathrm{l}$ under high flow periods (march $2011 \approx 8 \mathrm{~m}^{3} / \mathrm{s}$ ) and $30 \mathrm{ng} / \mathrm{l}$ under low flow periods (September 2010, $2011 \mathrm{Q} \approx 1.5 \mathrm{~m}^{3} / \mathrm{s}$ ). Therefore loads of CBZ in groundwater under low flow conditions varies between 3.3-3.5 g/day. The constant background value can be explained by to a continuous source of CBZ existing on the catchment and leaching to the saturated zone even under low flow periods. Water stored in the matrix drained by the spring during recession period may also contain a background level of CBZ resulting from a complete mixing of fast and diffuse components of the aquifer system prior to recession.

The chemograph and the spring discharge curve can be both divided into four parts according to varying discharges and ions concentrations. The time intervals are given since the start of sampling.

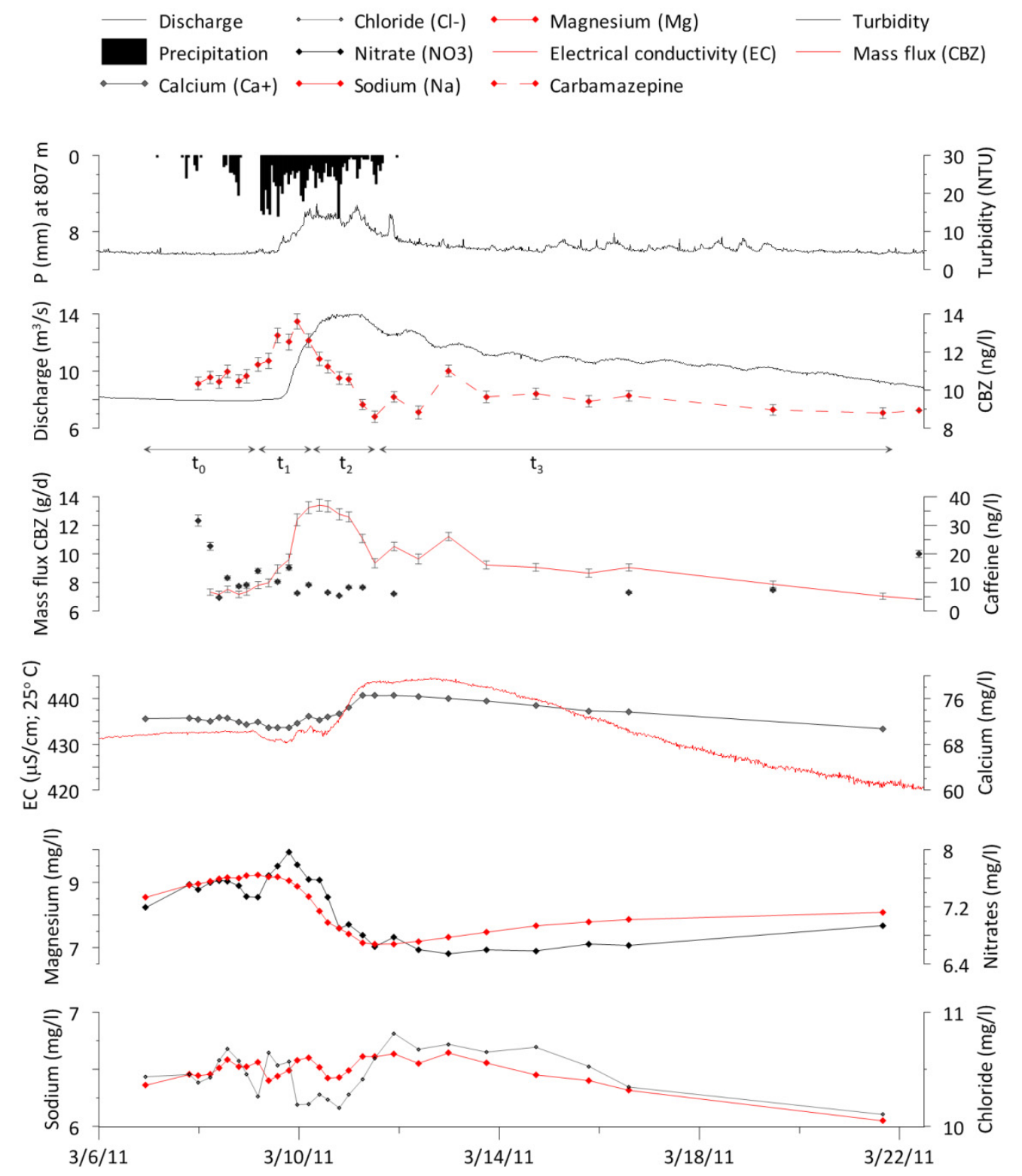

Figure 6-2 Chemograph showing the variation of physico-chemical parameters and CBZ concentrations as a response of the precipitation event. $t_{0}$ to $t_{3}$ refer to the division of the spring response into 4 different periods mainly according to the variation of EC 

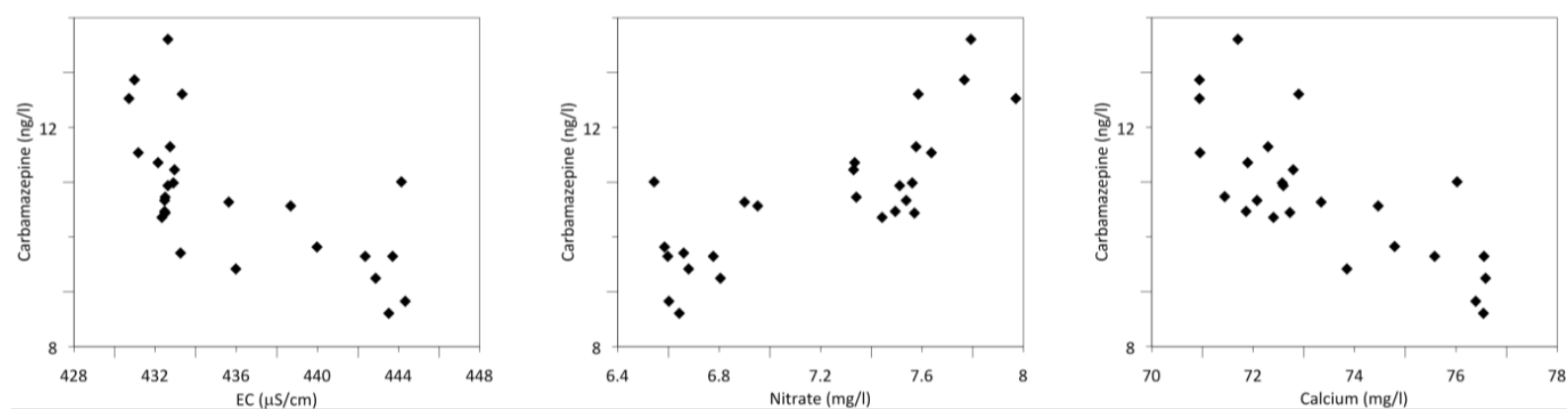

Figure 6-3 Negative correlation between carbamazepine, calcium and electrical conductivity, and positive correlation with nitrates

1. $t_{0}$ : Initial conditions under high flow conditions are characterized by a constant base flow discharge (8 $\mathrm{m}^{3} / \mathrm{s}$ ), electrical conductivity and turbidity. The background concentration of CBZ is $10.3 \mathrm{ng} / \mathrm{l}$, which implies loads of $7.1 \mathrm{~g}$ of CBZ per day under high flow periods.

2. $t_{1}$ : Section lasting for 25 hours depicting a decrease of EC and calcium, followed by an increase of discharge. A total volume of $660,000 \mathrm{~m}^{3}$ is discharged. A slight increase of $\mathrm{NO}_{3}{ }^{-}, \mathrm{SO}_{4}{ }^{2-}, \mathrm{Cl}^{-}$is also observed. CBZ starts to increase drastically to reach $13.6 \mathrm{ng} / \mathrm{l}$.

3. $t_{2}$ : Section lasting for 35 hours showing an increase of calcium concentration from $70.9 \mathrm{mg} / \mathrm{l}$ to reach $76.6 \mathrm{mg} / \mathrm{l}$ and a parallel decrease in magnesium concentration marked by a continuing increase of discharge. Electrical conductivity and turbidity also increase. A decrease of CBZ concentration occurs simultaneously to reach $8.6 \mathrm{ng} / \mathrm{l}$ which falls below the background value.

4. $t_{3}$ : The last part of the hydrograph portrays a series of snowmelt events, where a cyclic change of discharge is observed. Additionally, CBZ concentrations decrease below background levels ( $8.6 \mathrm{ng} / \mathrm{l})$. At the end of this section, the massive flux of CBZ falls to about $7 \mathrm{~g}$ per day, which is the same load observed during background conditions $\left(\mathrm{t}_{0}\right)$

\subsubsection{Tracer tests}

The tracer breakthroughs curves (TBC) were analyzed using the 2RNEM, to assess maximum and mean velocities under prevailing conditions. Mean and maximum velocities for each discharge value could therefore be estimated (Figure 6-4) in the subsurface channel and correlated linearly with the spring discharge $(Q)$. The average and maximum flow velocities range between 0.34 and $0.50 \mathrm{~m} / \mathrm{s}$ in the subsurface channel for discharge ranging respectively between 8 to $12 \mathrm{~m}^{3} / \mathrm{s}$. Maximum velocities estimated for the start of the event are about $0.4 \mathrm{~m} / \mathrm{s}(\approx 1410 \mathrm{~m} / \mathrm{h})$ in the subsurface channel, considered as a fast flow pathway. 


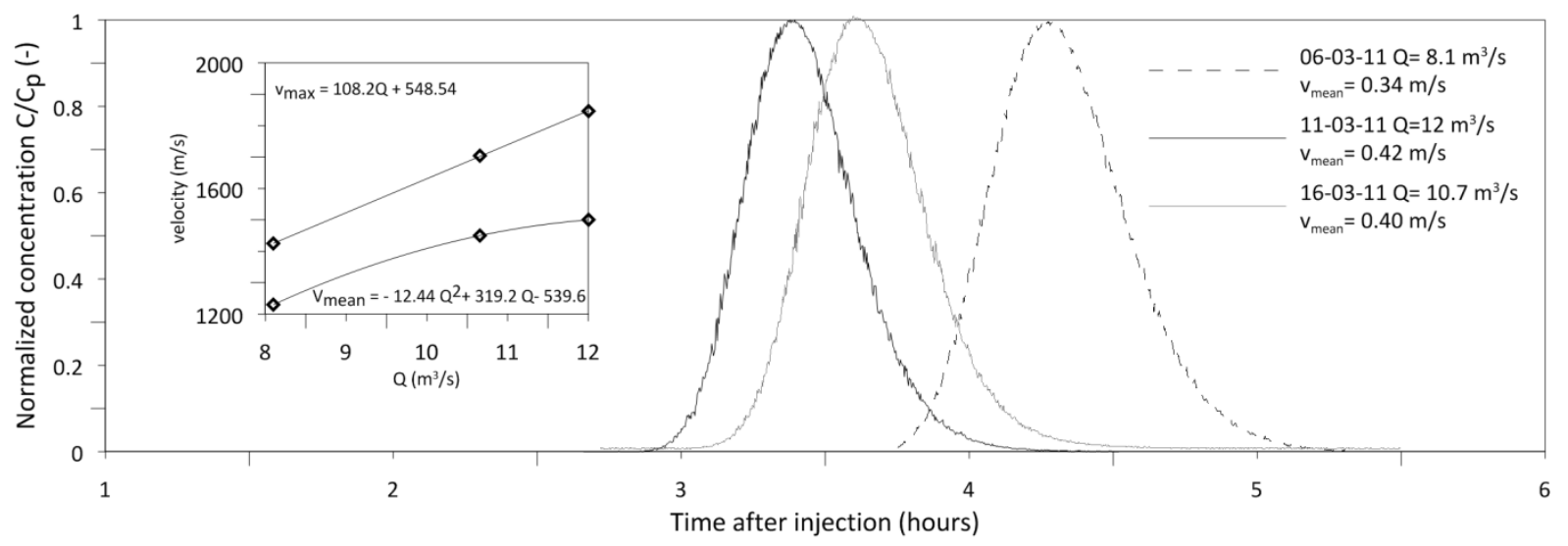

Figure 6-4 Results of the tracer tests performed in March 2011 in the subsurface channel showing mean velocities.

\subsection{DISCUSSION}

\subsubsection{Event march 2011}

Following an event, a mixing of water generated from various sources occurs at the spring. Water existing in epikarst storage, conduit storage, or fast recharged waters can arrive at various time intervals at the spring. The interpretation of the chemograph and the discharge curve obtained in response to the rain event occurring in March 2011 yield a conceptual model of flow and transport pre event during and post event (Figure 6-5).

1. $t_{0}$ : Background conditions of the spring under high flow periods;

2. $t_{1}$ : Arrival of event water at the spring: The event waters that infiltrated into the fast flow pathways arrive to the spring as fast discharge component. This is portrayed in the chemograph by a slight decrease in electrical conductivity. The latter is triggered mainly by the decrease in calcium concentrations, as rapid infiltrated waters cannot reach equilibrium with respect to calcite (Grasso and Jeannin, 2002). Additionally concentrations of nitrate and chloride increase during this time interval. It was reported that chloride levels are generally high in sewage when compared to tap water levels (Gasser et al., 2010). Sodium concentrations are negatively correlated with chloride in $\mathrm{t} 1$, which implies that chloride concentrations are not due to street salt poured by instances over the upper catchment.

3. $t_{2}$ :Flushing of old water by "piston flow effect" from epiphreatic zone/soil where water was stored from previous events exclusively in the area of concentrated recharge as epikarst is connected to conduits and acts as storage in a karst system (Einsiedl et al., 2010) and provide water as quick flow component in this case. The stored water in the epikarst mainly composed of limestone has a higher calcium concentration because of higher $\mathrm{CO}_{2}$ concentrations in the soil layer and the epikarst zone (Williams 1983). 
4. $t_{3}$ : Snowmelt events portrayed by the daily variation of discharge and electrical conductivity as a result of diurnal snow melt and nocturnal freezing. The increase of chloride and sodium concentration is the result of salt applied on the street in the upper catchment. In this period, CBZ increases at the spring periodically as a result of snow melt events.

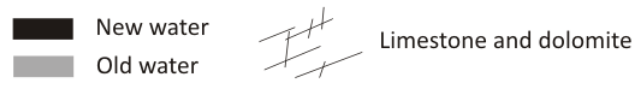

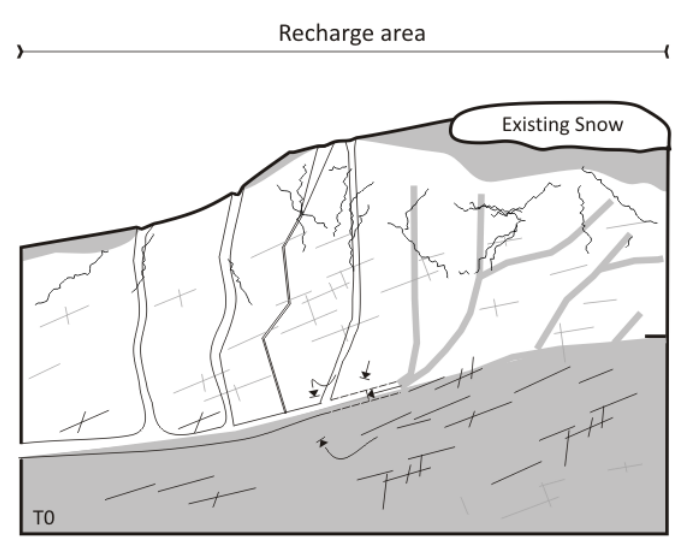

Baseflow conditions: background [CBZ]

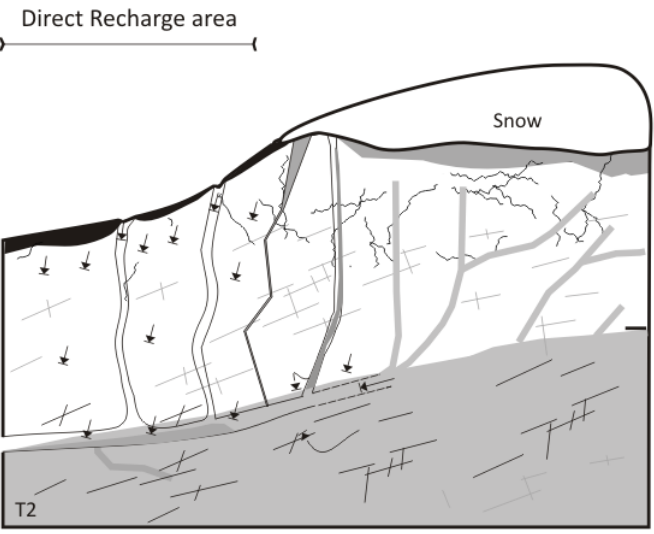

Flushing of old waters from epiphreatic zones: dilution effect; decrease of [CBZ]

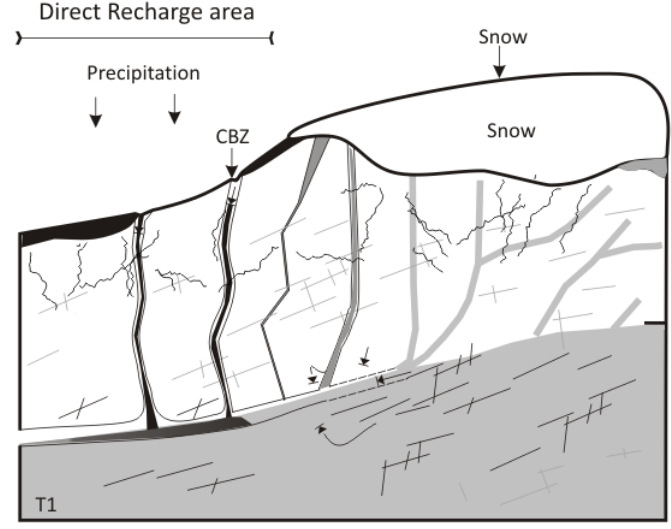

Arrival of new waters: increase of [CBZ]; CBZ breakthrough curve

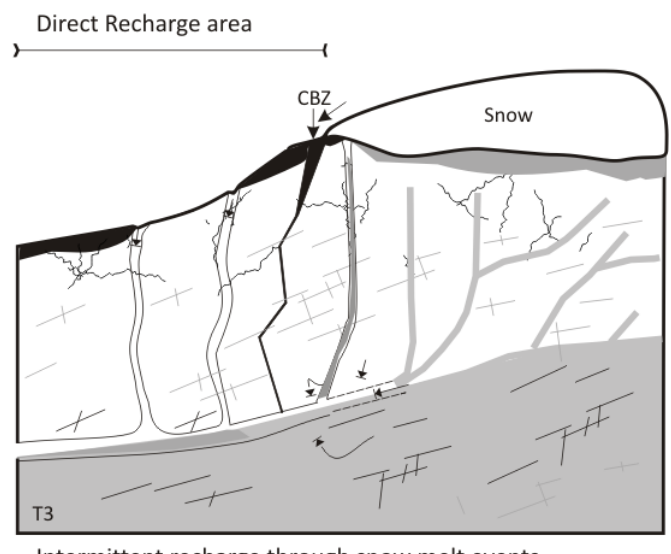

Intermittent recharge through snow melt events

Figure 6-5 Conceptual models of the aquifer behavior before and following the precipitation event

\subsubsection{Loads of CBZ}

The volume of discharged water during $t_{2}$ is about $750,000 \mathrm{~m}^{3}$ calculated from the integration of the discharge rate during this time (18 hours). This volume consists of a new water component and an old one. The concentration of calcium can be used to assess the mixing in the spring water $\left(V_{m}\right)$ at a concentration $\left(C_{m}\right)$ at the end of $t_{1}$ between the new infiltrated waters $\left(V_{p}\right)$ directly from precipitation $\left(C_{p}\right)$ and the old pre-event spring water $\left(V_{b}\right)$ at a background concentration of calcium $\left(C_{b}\right)$. 
$C_{m} V_{m}=C_{p} V_{p}+C_{b} V_{b}$

with

$V_{m}=V_{p}+V_{b}$

The amount of newly recharged water $V_{p}$ is estimated at $11,000 \mathrm{~m}^{3}$, which is about $1.5 \%$ of the total discharged water in $\mathrm{t}_{1}$

$C_{C B Z m} V_{m}=C_{C B Z p} V_{p}+C_{C B Z b} V_{b}+M_{C B Z w}$

where volume of discharged waste water is considered negligible with respect to the total rain infiltrated waters, and $C_{C B Z p}$ and $C_{C B Z b}$ are the concentration of $C B Z$ in the precipitation water and in the background waters. The concentration of $\mathrm{CBZ}$ in precipitation $C_{C B Z p}$ is zero. The equation can be rearranged as follows:

$M_{C B Z w}=C_{C B Z m} V_{m}+C_{C B Z b}\left(V_{m}-V_{p}\right)$

The mass of $C B Z\left(M_{C B Z w}\right)$ present in the waste water that infiltrated during this event is estimated based on Equation (1-4) to be about 2.6 grams in total.

\subsubsection{Origin of $\mathrm{CBZ}$}

Raw waste water is discharged without preliminary treatment as no waste water treatment plants are operational on the Jeita catchment. CBZ was the only wastewater indicator, which displayed an interpretable breakthrough curve (BTC) as a response to the precipitation event. The presence of very low concentration of other wastewater indicator e.g., caffeine (in comparison to CBZ), imply that those compounds have been already degraded in the point source wastewater. Therefore CBZ originates from old waste water stored on the catchment (sinkhole or pithole) that was flushed during the rain event as a pulse input. Therefore, caffeine in this case can be only used as a fresh wastewater indicator due to its relatively small residence time and good biodegradability (Clara et al., 2004; Hillebrandt et al. 2012). The quantity of CBZ entering the system following the rain event is about $2.6 \mathrm{~g}$, which is the non metabolized fraction of CBZ present in the old waste water.

The investigated discharge event occurred after many successive events in the end of February 2011. Therefore, it is assumed that a considerable amount of water was stored in the soil and the epikarst during background conditions (t0). Furthermore, during this event, rainfall occurred on the lower part of the catchment whereas on the upper part of the catchment, precipitation was only in form of snow. Therefore, it is assumed that the direct recharge area is located exclusively in the lower catchment area. The arrival of new waters (decrease of EC) is accompanied by an increase of the concentrations of CBZ. As CBZ is a good waste water marker (Gasser et al., 2010, Scheytt et al., 2006, Clara et al., 2004), it is assumed to have generated from CBZ loaded old domestic waste water or hospital waste water infiltrating in this case in pit holes or directly into via sinkholes. In this study, CBZ entered the Jeita karst system by a rapid infiltration triggered by the rain event ( $t 1)$. Upon flushing of old waters from the aquifer $\left(t_{2}\right)$, the CBZ concentration decreased because of dilution, mainly due to the fact that old stored waters in soil and epikarst have the same concentration of CBZ of the low pre-event background level in groundwater. Furthermore, the load of CBZ during flushing of old waters remains constant and decreases gradually. Additionally CBZ is found to be persistent in the subsoil and aquifer for a period of approximately 2 years, due to its very low degradability rate (Leclercq et al., 2009, 
Gasser et al., 2010), which implies that the water present in the soil and epikarst, infiltrated during previous events diffusively are not additional source of CBZ relatively to the background value.

The time difference between the increase of discharge and increase of CBZ can be regarded as the minimum time $t$ needed for CBZ to arrive at the spring and is about 6.5 hours.

The later is considered as a fast flow pathway draining in addition to the matrix storage, other fast flow pathways such as sinkholes. It is assumed that the velocity $v$ in the fast flow pathways is identical to the measured velocity in the subsurface channel. The maximum velocity and mean velocity corresponding to the first arrival of CBZ at the spring are about 1410 and $1213 \mathrm{~m} / \mathrm{h}$. The minimum distance $d$ to the CBZ input is $d=$ $v \times t \approx 7880-9165 \mathrm{~m}$.

The estimated distance exceeds the mapped length of the subsurface channel $(5300 \mathrm{~m})$, i.e., the source of CBZ is located some kilometers away from the end of the mapped subsurface channel and it can be suspected that the conduit system plays a major role for flow and transport in a wide range of the catchment.

\subsection{Conclusions}

Based on the combined analysis of the spring hydrograph, chemograph and breakthrough of the organic micropollutant carbamazepine, it was possible to develop a conceptual model for flow and transport in the Jeita spring karst system following a precipitation event (rain at low altitudes and snow at higher altitudes). Carbamazepine is present in spring waters at a background value (>3.5 g/d) implying that it is persistent in the aquifer. Based on a simple mixing model, about $2.6 \mathrm{~g}$ of carbamazepine were introduced to the system during this event, through fast flow pathways with a rapid flow component (which is only $1.5 \%$ of the total discharge observed in this event). In a later stage, old waters stored in the epikarst inflow to the system, and yield to the dilution of carbamazepine, where concentration decreases and mass fluxes of the later remain constant in the spring waters. An intermittent snow melt event reduces concentrations of carbamazepine to background levels. In this rain event, increasing discharge was due to old stored water and was responsible for a delayed dilution of the organic compound. It clearly shows the importance of the input function (precipitation) in the spring responses. The absence of caffeine in spring waters during carbamazepine breakthrough implies that the wastewater introduced to the system is old, where caffeine was likely affected by biodegradation. Mean and maximum flow velocities in fast flow pathways could be estimated from artificial tracer experiments performed during this event. Based on maximum transit time between increase of the hydraulic and the chemical signal, the distance to point source contamination could be estimated to be about 7100-9000 m from the spring, which is a relatively small distance from the end of the subsurface channel (phreatic cave).

\section{Acknowledgement}

This research is part of a PhD study funded by the Deutscher Akademischer Austausch Dienst (DAAD, Referat 441). The authors would like to thank BGR (Bundesanstalt für Geowissenschaften und Rohstoffe) for providing support for conducting tracer tests within the channel, as well as for the accommodation during field sampling. 


\subsection{References}

Clara, M., Strenn, B., and Kreuzinger, N., 2004. Carbamazepine as a possible anthropogenic marker in the aquatic environment: investigation on the behavior of Carbamazepine in wastewater treatment and during groundwater infiltration, Water Resources, 38: 947-954

Doummar, J., Sauter, M., and Geyer, T., 2012. Simulation of flow processes in a large scale karst system with an integrated catchment model (Mike She) - Identification of relevant parameters influencing spring discharge. Journal of Hydrology, 426-427: 112-123

Einsiedl, F., Radke, M., and Maloszewski, P., 2010. Occurrence and transport of pharmaceuticals in a karst groundwater system affected by domestic wastewater treatment plants. Journal of Contaminant Hydrology, 117:26-36

Gasser, G., Rona, M., Voloshenko, A., Shelkov, R., Tal, N., Pankratov, I., Elhanany, S., and Lev, O., 2010. Quantitative evaluation of tracers for quantification of wastewater contamination of potable water sources. Environmental Science Technology, 44: 3919-3925

Geyer, T., Birk, S., Licha, T., Liedl, R., and Sauter, M., 2007. Multi-tracer test approach to characterize reactive transport in karst aquifers. Ground Water 45, no. 1: 36-45

Ghauch, A., Baydoun H., and Dermesropian, P., 2011. Degradation of aqueous carbamazepine in ultrasonic $/ \mathrm{Fe}^{0} / \mathrm{H}_{2} \mathrm{O}_{2}$ systems. Chemical Engineering Journal, 172: 18-27

Grasso, A., and Jeannin, P.Y. 2002. A global experimental system approach of karst springs hydrographs and chemographs. Ground Water, 40, no. 6: 608-617

Heberer, T., 2002. Occurrence, fate, and removal of pharmaceutical residues in the aquatic environment: a review of recent research data. Toxicol. Lett. 131: 5-17

Heberer, T., 2002b. Tracking persistent pharmaceutical residues from municipal sewage to drinking water. Journal of Hydrology, 266: 175-189

Hillebrand, O., Nödler, K., Licha, T., Sauter, M., and Geyer, T., 2012. Caffeine as an indicator for the quantification of untreated wastewater in karst systems. Water Research, 46, no. 2: 395-402

Kahle, M., Buerge, I., Muller, M., and Poiger, T., 2009. Hydrophilicanthropogenic markers for quantification of wastewater contamination in ground- and surface waters. Environ. Toxicol. Chem., 28, 2528-2536

Leclercq, M., Mathieu, O., Gomez, E., Casellas, C., Fenet, H. Hillarie-Buys, D., 2009. Presence and fate of carbamazepine, oxcarbazepine, and seven of their metabolites at wastewater treatment plants, Arch. Environ. Contam. Toxicol., 56: 408-415

Nader, F.H., Swennen R., and Ellam, R.M., 2007. Field geometry, petrography and geochemistry of a dolomitization front (Late Jurassic, central Lebanon). Sedimentology, 54: 1093-1119

Nödler, K., Licha, T., Bester, K., and Sauter, M., 2010. Development of a multi-residue analytical method, based on liquid chromatography-tandem mass spectrometry, for the simultaneous determination of 46 microcontaminants in aqueous samples. J. Chromatography, A 1217: 6511-6521

Perrin, J., and Luetscher, M., 2008. Interference of the structure of karst conduits using quantitative tracer tests and geological information: example of the Swiss Jura. Hydrogeology Journal, 16: 951-967

Pronk, M., Goldscheider, N., and Zopfi, J., 2007. Particle-size distribution as indicator for fecal bacteria contamination of drinking water from karst springs. Environmental Science Technology, 41: 8400-8405 
Scheytt, T., Mersmann, P., Lindstaedt, R., and Heberer, T., 2005. Determination of sorption coefficients of pharmaceutically active substances carbamazepine, diclofenac, and ibuprofen, in sandy sediments. Chemosphere, 60: 245-253

Scheytt, T. J., Mersmann, P., and Heberer, T., 2006. Mobility of pharmaceuticals carbamazepine, diclofenac, ibuprofen, and propyphenazone in miscible- displacement experiments. J. Contaminant Hydrology, 83: 5369

Schnegg, P. A., 2002. An inexpensive field fluorometer for hydrogeological tracer tests with three tracers and turbidity measurement. Groundwater and Human Development, ed. E. Bocanegra, D. Martinez, and H. Massone, 1484-1488. Mar Del Plata, Argentina

Ternes, T. A., 1998. Occurrence of drugs in German sewage treatment plants and rivers. Water Resources, 32: 3245-3260

Tixier, C., Singer, H. P., Oellers, S., and Müller, R.R., 2003. Occurrence and fate of carbamazepine, clofibric acid, diclofenac, ibuprofen, keteprofen, and naproxen in surface waters, Environmental Science Technology, 37: 1061-1068

Toride, N., F.J.Leij, and M.T van Genuchten., 1999. The CXTFIT code (version 2.1) for estimating transport parameters from laboratory or field tracer experiments. U.S. Salinity Laboratory Agricultural Research Service, U.S. Department of Agriculture Riverside, California. Research Report 137

Williams, P.W., 1983. The role of the subcutaneous zone in karst hydrology. Journal of Hydrology, 61: 45-67 


\section{CONCLUSIONS AND OUTLOOK}

\subsection{General CONCLUSIONS}

Sustainable management and protection of karst systems against pollution is primordial, given that they constitute important water resources for supply in many regions of the world (Ford and Williams, 2007). Protecting karst aquifers implies assessing their vulnerability against potential pollution in a preventive approach, where treatment at the source is often too difficult to achieve. Various methods or models have been developed to date to assess the vulnerability of such systems; however, they failed to account for the spatial and temporal variation of processes and responses occurring within karst systems. Vulnerability can be only adequately assessed in a well characterized catchment area.

A well investigated karst catchment area was simulated with a physically based numerical model (MIKE She; DHI, 2007) accounting for all the processes taking place in a hydrological cycle (Chapter 3; atmosphere, unsaturated zone, and saturated zone) including the rapid flow component. A sensitivity analysis was performed on all the parameters involved in the flow processes. It has shown that many parameters play a role in reshaping the hydraulic system response transmitted through the compartments of a karst system, namely, hydraulic conductivity $\left(K_{s}\right)$ and moisture content of the soil $\left(\theta_{s}\right)$, saturated moisture content of the unsaturated rock matrix $\left(\theta_{\mathrm{uz}}\right)$, and the hydraulic conductivity of the highly permeable zone within the saturated zone $\left(\mathrm{K}_{\mathrm{c}}\right)$. Hydraulic signals and their variation are quantified and traced back through the different domains of a karst system. Therefore, the process based numerical model is a tool that provides insight to intrinsic vulnerability and allows depicting zones or areas that are highly vulnerable. It also enables to predict the hydraulic response at a spring according to varying input signals (precipitation etc.). Transport of conservative tracer could also be simulated using this process-based spatially distributed model, to have more insight into intrinsic vulnerability; however, a further characterization of transport parameters is important to achieve this purpose.

Artificial tracer tests can be employed to characterize transport in karst aquifers where transit times, dispersivities and tracer attenuation are highly involved in the definition of vulnerability (Chapter 4). Furthermore, an active aquifer portrays different geometries and behavior under variable discharge conditions (Smart, 1988). The analysis of breakthrough curves (TBCs) obtained from tracer experiments performed in many locations on a catchment area allows to assess the variation of geometry and transport parameters under different flow conditions (temporal; high and low flow conditions) and in various compartments (spatial; e.g., saturated matrix, conduit, fast flow pathway, unsaturated rock matrix etc.). The trend observed in these parameters is highly influenced by processes prevailing in the system (e.g., dilution). The one dimensional Two Region Non Equilibrium Model (2RNEM; CXTFIT, Toride et al., 1999) is usually adopted for the analysis of tracer experiments in karst systems where Advection Dispersion Models (ADM) fail to reproduce the tailing observed in the TBCs. It provides information about the variability of mobile regions in the different compartments of a system which is a high indicator of the duration of a tracer restitution and attenuation at a target. Further statistical relationships established between flow velocities and other transport parameters enable predicting the transport behavior under various flow conditions. The specific aspect of vulnerability deals with the 
assessment of the transport and fate of an indicator contaminant. Chapter 5 shows that 1) the mass fluxes of the organic micropollutant carbamazepine are invariable in the system under low flow conditions; 2 ) its mass flux increases under high flow periods; 3) it is highly persistent in the aquifer and in the phreatic conduit system, and can serve as an indicator for wastewater (Clara et al., 2004). In chapter 6, the analysis of the breakthrough of this indicator (carbamazepine) along with the recorded hydrograph and chemograph following a precipitation event yield information about the specific chemical and hydraulic response of this karst system. This includes quantifying the mass of contaminant arriving at the spring, identifying the pathways through which it infiltrated to the system, assessing the duration of the breakthrough and the dilution effects, and tracing back the source to contaminant. It also shows that specific vulnerability is highly dependent on the selected indicator contaminant and on the temporal and spatial distribution of the infiltrating water following precipitation events.

\subsection{Perspectives and outlook}

Based on a well investigated catchment, an integrated large scale numerical flow model reveals to be of the most suitable intrinsic vulnerability method. In this model, the bypass component could be further investigated to better define the fast flow component. Additionally, the effect of climatic input variation (climatic scenarios) or short term (spatial distribution snow) on the model is worth assessing for prediction purposes. The applicability of this approach is still to be tested and validated in other karst catchments. One potential application site would be the Jeita spring catchment in Lebanon, which is characterized by different climatic conditions and different degrees of karstification. Characterization methods of karst aquifers for vulnerability purposes could be further identified to allow a better understanding of the system.

Spring responses that are very easy to monitor at a spring (turbidity, electrical conductivity) will be further analyzed as quantitative indicator parameters under different flow conditions. The flow model can be further validated when supplemented with the transport component, e.g., the numerical simulation of electrical conductivity signals (event based) or artificial tracer tests.

\subsection{REFERENCES}

Clara, M., Strenn, B., and Kreuzinger, N., 2004. Carbamazepine as a possible anthropogenic marker in the aquatic environment: investigation on the behavior of Carbamazepine in wastewater treatment and during groundwater infiltration, Water Resources. 38: 947-954

DHI (Denmark hydrology Institute), 2007. Mike She User Manual and Reference Guide, Ed. Dec 2007. Denmark. (V1 \& 2).

Ford, D.C., and Williams, P.W., 2007. Karst Geomorphology and Hydrology. London, UK: Chapman \& Hall.

Smart, C.C., 1988. Artificial tracer techniques for the determination of the structure of conduit aquifers. Ground Water, 26: 445-453

Toride, N., Leij, F.J., and van Genuchten, M.T., 1999. The CXTFIT code (version 2.1) for estimating transport parameters from laboratory or field tracer experiments. U.S. Salinity Laboratory Agricultural Research Service, U.S. Department of Agriculture Riverside, California. Research Report 137. 


\section{APPENDIX A}

Table A-1 Transport parameters estimated from the artificial tracer tests undertaken in the subsurface channel and on surface features 


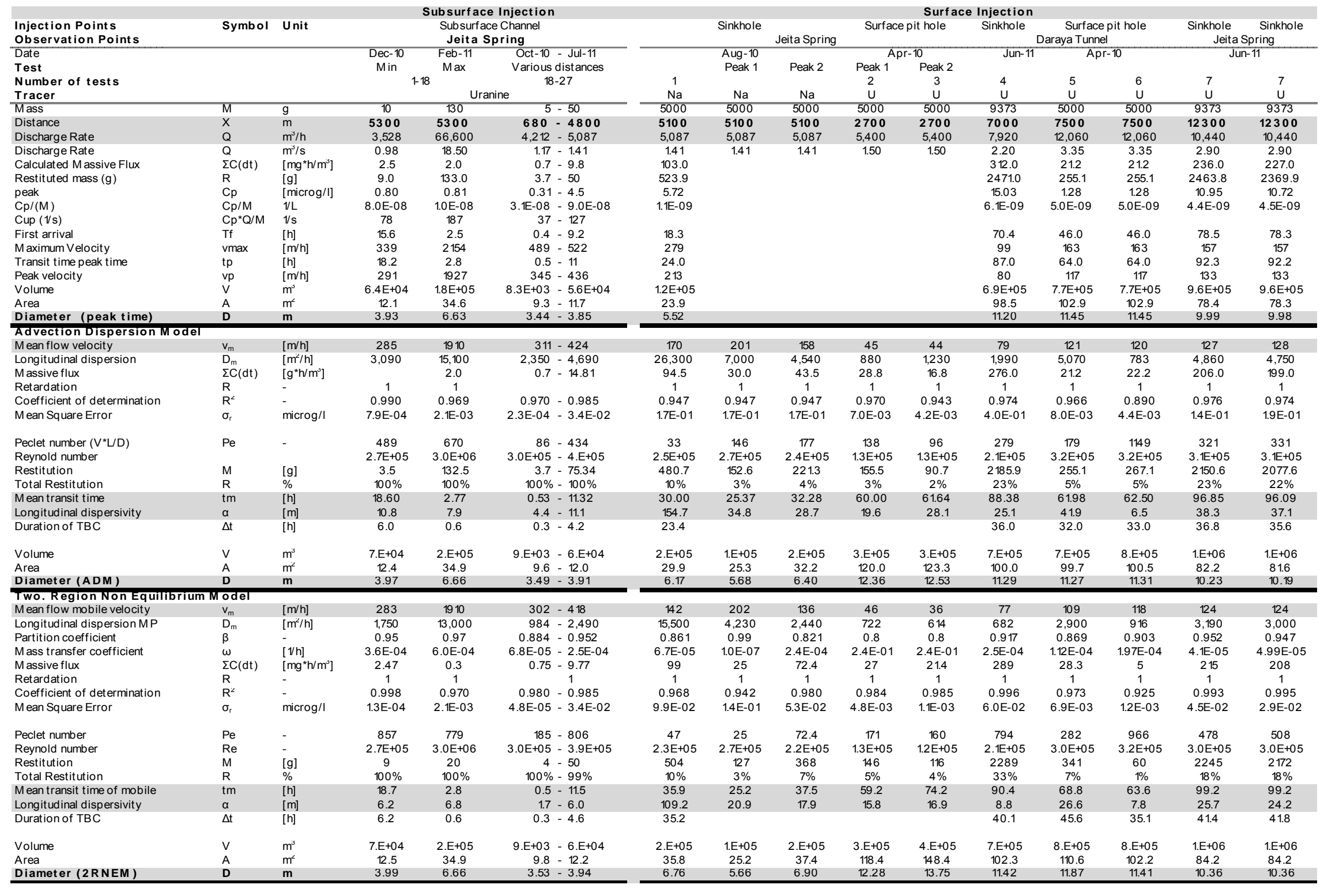


Refereed journal publications

Doummar, J., Geyer, T., Baierl, M., Nödler, K., Licha, T., and Sauter, M., 2012. Carbamazepine breakthrough as indicator for specific vulnerability of karst prings: application on the Jeita spring, Lebanon. In preparation for submission to a peer-reviewed journal

Doummar, J., Margane, A., Sauter, M., and Geyer, T., 2012. Assessment of effective transport parameters in a karst system under dynamic flow conditions by artificial tracer experiments. In preparation for submission to a peer-reviewed journal

Doummar, J., Sauter,M., Geyer,T. 2012 Simulation of flow processes in a large scale karst system with an integrated catchment model (Mike She) - Identification of relevant parameters influencing spring discharge, Journal of Hydrology, 426-427: 112-123

Abstracts submitted to international conferences

Doummar J., Baeirl M., Nödler K., Licha T., Sauter, M., and Geyer T., Carbamazepine as indicator for potential short-term contamination of karst springs. EGU 2012 (European Geological Union), Vienna- Austria, 22-27 Apr. 2012

Doummar J., Margane A., Geyer T., and Sauter M., Assessment of transport parameters in a karst system under various flow periods through extensive analysis of artificial tracer tests. EGU 2012 (European Geological Union), Vienna- Austria, 22-27 Apr. 2012 (Poster)

Doummar J., Margane A., Sauter M., Geyer T., 2011. Assessment of transport parameters in a karst system under various flow periods through extensive analysis of artificial tracer tests. BGR 2012 (Bundesanstalt für Geowissenschaften und Rohstoffe), Hannover- Germany, March. 2012 (Poster)

Doummar J., Geyer T., and Sauter M., Numerical simulation of the entire hydrological cycle of the karst system Gallusquelle Spring (Swabian Alps) with Mike She. AGU 2011 (American Geological Union), San FransiscoUSA, 5-8 Dec. 2011 (Poster)

Doummar J., Geyer T., and Sauter M., Numerical simulation of the entire hydrological cycle of the karst system Gallusquelle Spring (Swabian Alps) with Mike She. EGU 2011 (European Geological Union), Vienna- Austria, 3-8 Apr. 2011

Geyer T., Doummar J., Schmidt S., Reimann T, and Sauter M., Location of the rapid recharge areas in karst catchments by the combined analysis of spring responses and artificial tracer tests. EGU 2011, ViennaAustria, 3-8 Apr. 2011

Doummar J., Geyer T., and Sauter M., Numerical Simulation of the entire hydrological cycle Gallusquelle Spring (Swabian Alps) with Mike She. GeoDarmstadt 2010, Darmstadt- Germany, 10-13 Oct. 2010

Doummar J., Geyer T., and Sauter M., Identification of quantitative parameters for vulnerability assessment in karst aquifers: application on the Jeita spring. The Fifth Environmental Symposium of German-Arab Scientific forum, Lebanese American University (LAU), Byblos-Lebanon, 20-22 Sept. 2010

Doummar J., and Margane A., Tracer tests as a mean for the delineation of groundwater protection zones in the Nahr el Kalb catchment. The Fifth Environmental Symposium of German-Arab Scientific forum, LAU, Byblos-Lebanon, 20-22 Sept. 2010 
Reports

Doummar, J., Nödler, K., Geyer, T., and Sauter, M., 2012b. Protection of the Jeita Spring: Analysis of organic Micropollutants (2010-2011) in the Jeita spring catchment. Special report VII. Protection of the Jeita Spring. Applied Geosciences. Georg August University, Göttingen

Doummar, J., Geyer, T., and Sauter, M., 2012a. Protection of the Jeita Spring: Vulnerability mapping using the COP and EPIK Methods. Special report VI. Protection of the Jeita Spring. Applied Geosciences. Georg August University, Göttingen

Doummar, J., Margane, A., Geyer, T., and Sauter, M., 2011c. Protection of the Jeita Spring: Tracer tests analysis. Special report V. Protection of the Jeita Spring. Applied Geosciences. Georg August University, Göttingen

Doummar, J., Margane, A., Geyer, T., and Sauter, M., 2011b. Protection of the Jeita Spring: Tracer tests analysis. Special report IV. Protection of the Jeita Spring. Applied Geosciences. Georg August University, Göttingen

Doummar, J., Margane, A., Geyer, T., and Sauter, M., 2011a. Protection of the Jeita Spring: Tracer tests analysis. Special report III. Protection of the Jeita Spring. Applied Geosciences. Georg August University, Göttingen

Doummar, J., Margane, A., Geyer, T., and Sauter, M., 2010b. Protection of the Jeita Spring: Tracer tests analysis. Special report II. Protection of the Jeita Spring. Applied Geosciences. Georg August University, Göttingen

Doummar, J., Margane, A., Geyer, T., and Sauter, M., 2010a. Protection of the Jeita Spring: Tracer tests analysis. Special report I. Protection of the Jeita Spring. Applied Geosciences. Georg August University, Göttingen 


\section{CURRICULUM VITAE}

\section{PERSONAL DATA:}

Name:

\section{Joanna Jean Doummar}

Citizenship:

Marital Status:

Place and Date of Birth:

Lebanese

Single

Address:

Beirut, February 101981

Georg-August Universität, Department of Applied Geology

Goldschmidtstrasse 3, 37077, Göttingen, Germany

Contact Info:

Tel: 0049551397913

Mobile: 004915151851881

Email: jdoumma@gwdg.de

\section{EDUCATION:}

Oct.2009

PhD in Applied Geology (Hydrogeology)

Georg-August Universität, Department of Applied Geology (Angewandte Geologie), Göttingen- Germany

Oct. 2006- Jan. 2008

\section{Masters of Sciences (Hydrogeology) - Postgraduate Studies in}

\section{Hydrogeology}

University of Neuchâtel- Centre hydrogéologique de Neuchâtel (CHYN) - Switzerland

Thesis Title: Tracer tests and bacteriological analysis to assess the impact of a Swiss

Alpine hut (SAC) on the Muotathal Karst aquifer (Schwyz; Switzerland)

Oct. 2002- June 2005

\section{Masters of Sciences (Sedimentology)}

American University of Beirut- Lebanon

Thesis Title: Diagenesis and petrography of the albian rock sequence; (Tannourine -

Ehden Area; Northern Lebanon)

Oct. 1999- June 2002

Bachelor of Sciences (major Geology)

American University of Beirut- Lebanon

Oct. 1983- June 1999

\section{French Baccalaureate (major Physics-Chemistry)}

Lycée franco-libanais, Verdun Beirut- Lebanon

\section{PROFESSIONAL EXPERIENCE:}

Oct.2009-July 2012

Researcher- Georg August University- Göttingen (Germany)

Cooperation Project: Protection of the Jeita Spring

Project owner: Bundesanstalt für Geowissenschaften und Rohstoffe (BGR). Germany

Oct. 2010- June 2012

Researcher- Georg August University- Göttingen (Germany)

Supervision of Masters Students (Project work and literature review, master thesis teaching etc...)

June 2002- Feb.2009

Earth Link and Advanced Resources Development ELARD s.a.r.I.

Project Hydrogeologist- Project Environmental Geologist

Proposal writing, Project Management, Trainings and Technical Expertise in Water related projects.

LANGUAGE PROFICIENCY: (5: Excellent, 1: Fair):

Arabic (mother tongue), French (5), English (5), Spanish (5), Italian (5), German (4) 


\section{LEBENSLAUF}

\section{PERSÖNLICHE DATEN:}

Name:

Staatangehörichkeit:

Familienstand:

Geburtsort und Datum:

Address:

Contact Info:

\section{Joanna Jean Doummar}

libanesin

ledig

Beirut, am 10. Februar 1981

Georg-August Universität, Abteilung der Angewandte Geologie

Goldschmidtstraße 3, 37077, Göttingen, Deutschland

Büro: 0049551397913

Handy: 004915151851881

Email: jdoumma@gwdg.de

\section{AUSBILDUNG:}

Oct.2009-

Oct. 2006- Jan. 2008

Oct. 2002- Juni 2005

Oct. 1999- Juni 2002

Oct. 1983- Juni 1999
Promotionsstudium (Hydrogeologie)

Georg-August Universität, Angewandte Geologie, Göttingen- Deutschland

\section{Masters of Sciences (Hydrogeologie) - Postgraduate Studies}

University of Neuchâtel- Centre hydrogéologique de Neuchâtel (CHYN) - Schweiz Thema der Arbeit: Tracer tests and bacteriological analysis to assess the impact of a Swiss Alpine hut (SAC) on the Muotathal Karst aquifer (Schwyz; Switzerland)

\section{Masters of Sciences (Sedimentologie)}

American University of Beirut- Libanon

Thema der Arbeit: Diagenesis and petrography of the Albian rock sequence;

(Tannourine - Ehden Area; Northern Lebanon)

\section{Bachelor of Sciences (Geologie)}

American University of Beirut- Libanon

French Baccalaureate (Physics-Chemistry)

Lycée franco-libanais, Verdun Beirut- Libanon

\section{ERFAHRUNG:}

Oct.2009-Juli 2012

Wissenschaftliche Mitarbeiterin- Georg August Universität- Göttingen

(Deutschland)

Kooperationsprojekt: Protection of the Jeita Spring

Projektgeber: Bundesanstalt für Geowissenschaften und Rohstoffe (BGR).

Deutschland

Oct. 2010- Juni 2012

Wissenschaftliche Mitarbeiterin - Georg August Universität- Göttingen (Deutschland)

Betreuung von Master Studenten (Projektarbeit, Masterarbeit, Seminar)

Juni 2002- Feb.2009

Earth Link and Advanced Resources Development ELARD s.a.r.I.

Project Hydrogeologist- Project Environmental Geologist

Untersuchung zur Projekte im Hydrogeologie Bereich, Antragsschreiben,

Projektmanagement etc.

SPRACHKENNTNISSE: (5: sehr gut, 1: ausreichend):

Arabisch (muttersprache), Fransözisch (5), Englisch (5), Spanisch (5), Italienisch (5), Deustch (4) 